II. Z weiter Beratungsgegenstand

\title{
Die Gestaltung des Polizei- und Ordnungsrechts insbesondere in der britischen Besatzungszone
}

1. Bericht von Professor Dr. H a n s J. W o $1 \mathrm{f} f$, Münster (Westf.)

Ein halbes Jahrhundert lang: hat das Polizeirecht den soliden Kern des deutschen Verwaltungsrechts und erst recht der deutschen Verwaltungsrechtslehre gebildet. Die organisatorischen Grundlagen waren seit der Mitte des 19. Jahrhunderts im wesentlichen gelegt. Seine materiellen und formellen Grundsätze hat vornehmlich das preußische Oberverwaltungsgericht, dessen 75. Geburtstag wir am 20. November 1950 gedenken, in einer an den meisterhaft formulierten $\S 10$ II 17 ALR anknüpfenden bewunderungswürdigen Rechtsprechung entwickelt. 1931 war das allgemeine Polizeirecht zur preußischen Kodifikation des Allgemeinen Teils reif geworden.

Was eine feste Grundlage und Ansatzfläche für weitere verwaltungsrechtliche Kodifikationen hätte werden können, wurde kaum zwei Jahre später seiner eigenen rechtsstaatlichen Grundlagen - im wahrsten Sinne des Wortes: - beraubt. Degradiert zur Vogelscheuche, wehrte es allenfalls frechen Spatzen und wies nur noch den Feldhüter in seine Schranken. Schwert, Flinte und andere Zwangs- und Mordwerkzeuge aber riß eine anonyme Hydra an sich und diskreditierte mit dem Namen des Staates zum dritten Male den der „Polizei“, dem Achtung und Ansehen zu verschaffen sich Männer wie Carl Severing erfolgreich bemüht hatten.

Es ist daher nicht zu verwundern, daß die totale Umkehr, die dem Zusammenbruch der Hybris folgte, durch eine tiefgreifende Neugestaltung des Polizeiwesens eine Wiederholung ihres Mißbrauchs gründlich vereiteln wollte. Verständlich ist es auch, $\mathrm{da} B$ die Besatzungsmächte dieser Neuordnung ihre eigene Polizei-Ordnung zugrunde legten, ohne deren Finfügung in das deutsche organisatorische Gefüge und materielle Rechtssystem besondere Aufmerksamkeit zu widmen. Nur die französische Militärregierung bedachte, da $B$ der vornazistische Rechtszustand 
rechtsstaatlichen Anforderungen hinreichend entsprach, um durch seine Restituierung ,demokratischen“ Anforderungen zu genügen. In der britischen Besatzungszone insbesondere hat die Neuordnung des Polizeirechts eine Fülle von Fragen aufgeworfen, die die Landesgesetzgeber im Interesse einer guten, zweckmäßigen und billigen Verwaltung so bald wie möglich werden beantworten müssen. Zur Lösung der damit aufgegebenen Probleme beizutragen wird das Hauptanliegen meines Referates sein.

Das Thema - die Ge $s$ t a $1 \mathrm{t}$ u n g des Polizei- und Ordnungsrechts - erfordert jedoch zunächst noch einen Rückblick in die Vergangenheit und einen Utberblick über die gegenwärtige Rechtslage, um von diesem Standpunkt aus einen Ausblick auf eine wünschenswerte Neugestaltung zu gewinnen. Dabei werde ich mich freilich in knappster Form auf die für die bevorstehenden Gestaltungsaufgaben m. E. wichtigsten Momente beschränken müssen und auch beschränken können, da ich in diesem Kreise die Kenntnis der geschichtlichen Entwicklung des Polizeibegriffs und des Polizeirechts voraussetzen, wegen der im wesentlichen importierten Einrichtungen des englischen Rechts auf den Beitrag Hans Sch neider S in der Festschrift für Julius v on $\mathrm{G}$ i e $\mathrm{k}^{1}$ ) und im übrigen, insbesondere bzgl. des geltenden Rechts und der vorliegenden Entwürfe auf das "Polizeirecht" von $\mathrm{P}$ i o $\mathrm{ch}$ verweisen kann").

\section{I. $\mathbf{R u ̈ ~ c k b l i c k . ~}$}

Im Rückblick auf die geschichtliche Entwicklung des Polizeirechts erscheint mir besonders folgendes bemerkenswert:

a) Der Polizei-Begriff hat mehrere Momente, sein Gegenstand mehrere Dimensionen, die nur noch quantitativ (intensiv) variabel sind, z. T. allerdings selbst pro toto genommen werden, nämlich ${ }^{3}$ )

1. f u nkti on a l: Gewährleistung einer sozialen, politischen und Rechts-Ordnung innerhalb des Staates durch Verwaltungsorgane erforderlichenfalls unter Machteinsatz auf Grund nicht genau bestimmter Tatbestände;

1) Berlin 1950 S. 234-265, sowie derselbe in "Polizei-Praxis" 1949 S. 321 ff., $355 \mathrm{ff}$.

2) Hans-Hugo Pioch: Das Polizeirecht einschlie日lich der Polizeiorganisation (GrundriB des Verwaltungsrechts, hgg. v. L. Ambrosius Bd. 25, Tübingen 1950). Dort sind auch die im folgenden erwähnten Rechtsquellen, nicht aber die Entwürfe abgedrudst.

ग) Vgl. meinen z. T. ein wenig abweichenden Vortrag über Aulgaben und Organisation der Polizei- und Ordnungsverwaltung in systematischer und rechtspolitischer Hinsidht: Polizeirecht im neuen Deutschland (Polizei-Institut Hiltrup, Westf., 1949). 
2. funktione 11:

Vermeidung von Mißständen, insbesondere Bekämpfung akuter oder (und) latenter, konkreter oder (und) abstrakter Gefahren oder (und) Herstellung gewisser sozialer Zustände;

3. qualit a tiv: negativ oder (und) positiv, repressiv oder (und) praeventiv;

4. d i s p o s i t i v : speziell oder subsidiär oder universal; Subsidiarität besteht hinsichtlich

a) der Rechtsgrundlage (Generalermächtigung),

b) der Zuständigkeit anderer Behörden,

c) der Funktionsbefugnis nur bei dringender Eilbedürftigkeit (erster Zugriff);

5. m od a l: konkrete oder (und) abstrakte Anordnungen;

6. ef $f$ ek ti v : Ersatzvornahme, Zwangsgeld, unmittelbarer Zwang gegen Sachen oder (und) Personen, vorläufige oder (und) endgültige Bestrafung;

7. $s \mathrm{a} \mathrm{chlich} \mathrm{(Kompetenzen):} \mathrm{Rechtssicherheitspolizei} \mathrm{(z.} \mathrm{B.}$ Straßenverkehrspolizei, Kriminalpolizei), politische Sicherheitspolizei (z. B. Staatsschutzpolizei, Fremden-, Paß-, Vereins-, Versammlungspolizei),

Verwaltungs-(Ordnungs-)polizei (z. B. Gesundheits-, Gewerbe-, Baupolizei),

Wohlfahrtspolizei, Glückseligkeitspolizei;

8. örtlich: Orts- (Land- oder Stadt-), Kreis-, Landespolizei;

9. ins tituti on e 11 : ordentliche oder Sonder-Polizeibehörden (z. B. Wasserschutz-, Bahn-, Bergpolizei),

Allgemeine oder besondere Polizeibehörden (z. B. Polizeipräsidenten),

Orts-, Kreis- und Landespolizeibehörden, staatliche oder kommunale Polizeibehörden,

Polizei - Verwaltungs-, -Exekutiv- und -Wirtschaftsbehörden,

handelnde und Aufsichtsbehörden,

Sammlungs- und Informationsstellen;

10. forme 11: die Zuständigkeit der Polizeibehörden (z. B. auch Tier- und Landschaftspflege, Ausstellung von Quittungskarten der Invalidenversicherung).

b) Es hat zwar i $m$ m e $r$ der Sache nach und seit dem Beginn der Neuzeit auch dem Namen nach eine Polizei gegeben und 
muß sie auch geben, um die soziale Geltung der verfassungsmäßigen Ordnung i.w.S. nicht dem Zufall, insbesondere der Folgsamkeit der Regierten zu überlassen. In funktionaler Abhängigkeit vom Staatszweck galten jedoch jeweils Polizeibegriffe, die verschiedene Intensitäts- bzw. Quantitätsgrade jener Dimensionen miteinander verbanden. Dabei zeigt sich in charakteristischer Verbindung mit der Entstehung von Sonderbehörden eine allgemeine Tendenz der Einengung der polizeilichen Zuständigkeiten und damit des Polizeibegriffs.

c) Wie schon die Reaktionszeit und jede diktatorische Periode brachte jedoch erst recht die nationalsozialistische eine A u s deh n u $\mathrm{g}$ der inhaltlichen und modalen organisatorischen und politischen Zuständigkeiten der Polizei durch Ausrichtung auf ein angebliches Volkswohl. Die Ausschaltung der Mitwirkung volkspräsentativer Organe und besonders die zunächst teilweise, dann vollständige Ausschaltung gerichtlicher Kontrolle enthob die Polizei praktisch aller rechtlichen Schranken. Es ist sehr lehrreich, da $B$ dies de jure durch einen der kürzesten Paragraphen, nämlich $\S 7$ des prG ü.d. Geheime Staatspolizei vom 10. 2. 1936, bewerkstelligt werden konnte. - Es gibt übrigens keinen Schutz gegen dergleichen, w e $\mathrm{n}$ die Voraussetzungen der Diktatur im übrigen gegeben sind.

\section{II. Úber b li ck.}

a) Die „Anweisung des Obersten Befehlshabers an die Vorsteher der deutschen Polizeibehörden im Kontrollgebiet der Militärregierung Deutschland" 1945, verlangte Den a zifizierung, Demilitarisierung und Dezentralisier u n g der Polizei.

Eine (nicht veröffentlichte) Instruktion der britischen Militär-Regierung (brMR) vom 25. 9.1945 führte die britische Beschränkung der Polizei ein auf reine Exekutive (uniformierte Schutz- und Kriminalpolizei) ,zur Verhinderung und Aufklärung von Straftaten sowie zur unbedingten Aufrechterhaltung von Gesetz und Ordnung" unter Ausschluß der „gesetzgebenden" und der „,richterlichen Gewalt“ (d.h. des Verordnungs- und Strafverfügungsrechts), anfangs sogar ohne die Zuständigkeit zum Erlaß schriftlicher Verfügungen und zur Anwendung mittelbaren Zwanges (Erl. OP Westf. v. 25. 2. 1946). Die übrigen ehemaligen polizeilichen Kompetenzen blieben ungeregelt.

Gegliedert ist die Polizei i.e. S. seit 1. 10.1946 in je selbständige Stadtkreis - (SK-) und Regierungsbezirks(RB-) Polizei en, so daB zwar überall eine gewisse Stärke erreicht, die örtliche Polizei aber allermeist von der Hauptstadt des Regierungsbezirks her ausgeübt wird. 
Durch brMRVO 57 wurde zwar die Polizeigewalt den Ländern überlassen; doch standen und stehen diese unter anhaltendem starken Einfluß der Militär-Regierung bzw. der Regional Commissioners, die auch die Polizeiorgan is a tionsgesetzgebung der Länder weitestgehend vorschrieben. Diese (nwthergangsG v. 20.12.46 i. d. Fssg. v. 6. 3.1947-GVBl 165 -, shG v. 4.1.1947 - Amtsbl. 11 -, nds. UbergangsG v. 23. 4.1947 - GVBl. 58 - hambG v. 7.11.1947 - GVBl. 73) löste die Polizeibehörden (außer in Hamburg) von den Verwaltungsbehörden und sah für jede einen Polizeiausschuß für die Haushalts- und Wirtschaftsverwaltung und für die politische Kontrolle sowie einen Polizeichef für die Exekutive vor. Die diesbezüglichen Grundsätze wurden in brMRVO 135 unter Stärkung des Polizeichefs ausgesprochen. Die materielle Zuständigkeit wurde dort in Art. 1 ähnlich wie in § 14 prPVG generell, aber sehr unexakt umschrieben; gemeint ist wohl mehr eine Beschränkung des Aufgabenkreises als eine Ermächtigung.

b) Die geltenden Polizeigesetze der Länder (niedersächsisches mehrfach verlängertes Ubergangsgesetz v. 23. 4. 1947, hamburgisches G. v. 7.11.1947, schleswig-holsteinisches G. v. 23. 3. 1949 - GVBl. 61 - mit Änderung v. 23. 1. 1950 - GVBl. 23 - nordrhein-westfälisches G. v. 9. 5. 1949 - GVBl. $\left.143-)^{3}\right)$ variieren mehr oder weniger jene Grundsätze und beschränken sich fast ganz auf eine organisatorische Neuregelung der allgemeinen Polizei im institutionellen Sinne. -

Die Wasserschutz-, Eisenbahn-, Berg- u. a. Sonderpolizeien stehen außerhalb dieser Organisation. Sie bleiben auch im folgenden außer Betracht.

1. SK-Polizeibehörden bestehen nur in Großstädten über 100000 Einwohnern, in Niedersachsen nur in Braunschweig und Hannover. In Schleswig-Holstein gibt es je eine Polizeigruppe Nord, Süd, Kiel und Lübeck.

2. In Hamburg ist die Polizeibehörde staatlich. Sie untersteht einem Senator. Der Polizeiausschuß hat nur beratende Zuständigkeiten.

In Schleswig-Holstein ist die Polizei Einrichtung des Landes.

In Niedersachsen und Nordrhein-Westfalen bilden die SKund RB-Polizeien (genauer Polizeibehörden) rechtsfähige öffent-

'a) Die nach Abschluß des MS ergangenen einschlägigen Gesetze, nämlich die Aufhebung der brMRVO 135 durch AHKVO 220 (ABl. 1950 S. 702), das ndsG ü. d. öffentl. Sicherheit u. Ordnung v. 21.3. 1951 (GVB1. 79), die Neufassung des shPolG v. 31. 3. 1951 (GVBl. 91), die Neufassung des nwPolG v. 19.6. 1951 (GVBl. 73), das shG über ein Verwaltungsabkommen zwischen der Bundesregierung und den Landesregierungen uber die Errichtung von Bereitschaftspolizeien der Länder v. 18. 5. 1951 (GVBI. 105) mit jenem Verwaltungsabkommen v. 27. 10. 1950 als Anlage, und das nwG ú. d. Bereitschaftspolizei v. 3. 8. 1951 (GVBl. 105), konnten in dem insoweit 2 . $T$. überholten Text nicht mehr berüdssichtigt werden. 
liche Anstalten mit eigenen Rechten und Pflichten, eigenem, von den Gemeinden und dem Lande gespeistem Haushalt und eigener Dienstherrlichkeit, hängen also organisatorisch ,in der Luft".

Sie sind für ihren Kompetenzbereich die Orts- und Kreispolizeibehörden des älteren Rechtes, so daß diese also heute ihren Sitz in der Hauptstadt des Regierungsbezirks haben. Folge: Sie sind „zu weit vom Schuß" und müssen eilbedürftige Entscheidungen auf örtliche Stellen delegieren.

3. Der PolizeiausschuB ist (außer in Hamburg) ein Unterorgan der Polizeibehörde und selbst Behörde i.S. d. §25 Abs. 2 brMRVO Nr. 165 über Verwaltungsgerichtsbarkeit. Er vertritt die Polizeibehörde beamtenvermögensrechtlich, zivilrechtlich und zivilgerichtlich. Schadenersatz- und Entschädigungsklagen sind daher gegen ihn zu richten.

Seine sieben bis neun Mitglieder werden von den Stadträten bzw. Kreistagen der zum Polizeibezirk gehörenden Städte und Kreise aus deren Mitte (in Hamburg: aus der Bevölkerung) für deren Wahlperiode gewählt. Sie sind an Weisungen - auch des Rates der Stadt bzw. des Kreistages - nicht gebunden, haben jedoch in Nordrhein-Westfalen die Ansichten der entsendenden Kreise zu vertreten. Sie wählen einen Vorsitzenden aus ihrer Mitte und nach Bedarf Unterausschüsse. Beschlüsse werden mit einfacher Mehrheit gefaßt. Die laufenden Geschäfte führt ein vom Polizeiausschuß eingestellter Geschäftsführer mit seinem Verwaltungspersonal ohne Stimmrecht im Ausschuß. In Nordrhein-Westfalen bedarf es der Bestätigung durch den IM. Für die Außenvertretung sind $\mathrm{m}$. E. die gemeinderechtlichen Vorschriften entsprechend anzuwenden ${ }^{4}$ ).

In Niedersachsen und Nordrhein-Westfalen führt der Polizeiausschuß die allgemeine Aufsicht über die Polizeieinheit, stellt den Haushalts- und Stellenplan auf, der jedoch vom Innenminister zu genehmigen ist, und verantwortet die Buch- und Kassenführung, auf die m. E. ebenfalls die kommunalrechtlichen Vorschriften Anwendung finden. Er ernennt, entläßt und versetzt den Polizeichef ggf. in den Ruhestand. In NordrheinWestfalen steht ihm auch die Ernennung, Beförderung und Entlassung der Polizeibeamten vom Obermeister an aufwärts auf Vorschlag des Chefs der Polizei zu. Uberall beschließt er über die Personalfragen der Wirtschaftsverwaltungsbeamten, Angestellten und Lohnempfänger. In Schleswig-Holstein ist seine Stellung wesentlich schwächer. In Hamburg hat er sogar nur beratende Funktionen.

\footnotetext{
9) Vgl, dazu Elleringmann: Die allgemeine AuBenvertretung der Gemeinden im Lande Nordrhein-Westfalen = Verwaltung und Wirtschaft H. 1 (Festschrift der Westfälischen Verwaltungsakademien, Münster, Berlin, Bad Godesberg, 1950) S. 77-118.
} 
In Nordrhein-Westfalen kann die Landesregierung einen PolizeiausschuB, der seine Pflichten nicht erfüllt, durch einen Kommissar ersetzen.

4. Der $\mathrm{Ch}$ e f d e r Polize $\mathrm{i}$ ist der Leiter der Polizeieinheit, die - das ist der Vorteil der Zusammenfassung zu SK- und RB-Polizeieinheiten - verhältnismäßig stark und schlagkräftig ist.

Auch der Chef der Polizei ist „Behörde“ i.S.d. §25 Abs. 2 brMRVO 165, so daß „die Polizeibehörde“ also aus drei „Behörden" besteht. Maßnahmen der Polizeibeamten sind Verwaltungsakte des Chefs der Polizei.

In Hamburg wird er vom Senat ernannt, sonst vom Polizeiausschuß gewählt. In Niedersachsen bedarf die Wahl der Genehmigung des Innenministers, in Nordrhein-Westfalen und in Schleswig-Holstein sind diesem die auf die Ausschreibung der Stelle eingegangenen Bewerbungen vorzulegen; er kann Bewerber ausscheiden. In Nordrhein-Westfalen bedarf der Gewählte außerdem noch der Bestätigung des Innenministers. Entlassen wird er in Schleswig-Holstein auf Antrag des Polizeiausschusses durch den Innenminister, in Nordrhein-Westfalen durch den PolizeiausschuB mit Zustimmung des Innenministers. Das bezieht sich aber nur auf die Amtsstellung, da das Dienstverhältnis der Polizeibeamten nach sechs Dienstjahren lebenslänglich ist. In Nordrhein-Westfalen und m. E. auch in Niedersachsen und in Schleswig-Holstein (Arg. aus $§ 44$ Ziff. 5 DBG) können die Polizeichefs in den Wartestand versetzt werden.

Der Chef der Polizei ist allein verantwortlich für den Einsatz der Polizeikräfte seines Bereiches, aber nicht für deren Leistungsgrad. Im Bedarfsfalle kann er polizeiliche Hilfe eines benachbarten Polizeichefs anfordern. Nur in Hamburg ist er an Weisungen des Polizeisenators gebunden. Er führt die Dienstaufsicht und hat die Disziplinargewalt über die Polizeibeamten, so daß er in Nordrhein-Westfalen den PolizeiausschuB vor ein fait accompli stellen kann. Dort werden die unteren, sonst alle Polizeibeamten von ihm ernannt, befördert und entlassen. Zurruhesetzung von Polizeibeamten steht in Hamburg dem Senat, in Nordrhein-Westfalen dem Polizeiausschuß, in Niedersachsen und in Schleswig-Holstein dem Polizeichef mit Zustimmung des Polizeiausschusses zu.

An den Beratungen des Polizeiausschusses nimmt er ohne Stimmrecht teil.

Entsteht ein Notstand durch das Verhalten eines Polizeichefs, so kann in Nordrhein-Westfalen der Innenminister diesen vorläufig vom Amte entheben und einen anderen oberen Polizeibeamten mit der Wahrnehmung der Geschäfte beauftragen. 
5. Polizeia ufsichts behörde ist nur noch der Innenminister. Er wirkt mit bei der Ernennung des Polizeichefs, in Nordrhein-Westfalen auch des Geschäftsführers, in SchleswigHolstein aller Polizeibeamten vom Inspektor an aufwärts und kann in Schleswig-Holstein und Nordrhein-Westfalen die Polizeibeamten auf ihren Antrag oder auf Antrag des Chefs der Polizei bzw. des Polizeiausschusses aus in ihrer Person liegenden Gründen versetzen. Er stellt - im Einvernehmen mit dem Finanzminister - den Haushaltsplan der Polizeibehörden fest (!) und kann allgemeine Dienstvorschriften, Laufbahnrichtlinien, Anstellungs- und Beförderungsbestimmungen u. ä. erlassen. Er kann ferner seinem Willen nach englischem Vorbild durch Gewährung oder Versagung besonderer Zuschüsse Nachdruck verleihen.

In Notfällen kann er Polizeieinheiten zur gegenseitigen Hilfeleistung zusammenfassen, in Nordrhein-Westfalen aber erst nach Ermächtigung durch den Hauptausschuß des Landtages oder in Eilfällen der Landesregierung.

In Nordrhein-Westfalen sind die Regierungspräsidenten mit gewissen Polizeiaufsichtsfunktionen (z. B. allgemeiner Aufsicht über die Polizeiausschüsse, Verhängung der Polizeiaufsicht, Bestätigung von Hilfspolizeibeamten $-\S 13$ prPVG) beauftragt.

Den Innenministern stehen Polizeiinspektoren und in Nordrhein-Westfalen ein vom Landtag gewählter Polizeirat beratend zur Seite.

6. Die neuen Polizeibehörden sind - was besonders beamtenrechtlich wichtig ist - Rechts n a ch fol ger der ehemaligen Reichspolizei. Nur in Nordrhein-Westfalen ist diese Rechtsnachfolge gesetzlich ( $\$ 1$ Abs. 2 PolG) ausdrücklich ausgeschlossen worden. $\S 22$ des Beamtenrechtsänderungsgesetzes vom 30.6.1933 findet hier keine Anwendung ${ }^{5}$ ). Auch in NordrheinWestfalen sind die neuen Polizeianstalten jedoch Rechtsnachfolger der früheren kommunalen Polizei.

7. Das Deutsche Polizeibeamtengesetz ist in Nordrhein-Westfalen durch § 7 III. SparVO v. 19. 3. 1949 aufgehoben; seine Geltung im übrigen ist zweifelhaft, m. E. mindestens in Hamburg und Schleswig-Holstein zu bejahen. Die Beamten der Polizei in Hamburg sind ohne Veränderung ihrer Anstellungsverhältnisse durch VO v. 10. Februar 1948 (GVBl. S. 5) als Beamte der Hansestadt Hamburg übernommen worden.

8. Die Poliz eik os te n werden je zur Hälfte von der Stadt bzw. den Kreisen und vom Lande getragen. Sie, insbesondere auch die kommunalen Anteile namentlich der kleinen Gemeinden, sind sehr erheblich höher als nach dem früheren preußi-

s) So aud nwOVG v. 15.6.1950 - IV A 257. 
schen Recht. Außerdem leistet die derzeitige Polizei weniger, weil die gesamte Ordnungsverwaltung nicht mehr dazu gehört $\left.{ }^{\circ}\right)$.

c) Dieses Landespolizeirecht wird ergänzt durch einige b u n desrechtliche Rechtssätze wie insbesondere

1. den Art.91 GG, nach dem ein Land im Falle eines $S t$ a a $t s$ notst andes die Polizeikräfte aus anderen anfordern und im Gefahrfalle die Bundesregierung mit Billigung der Besatzungsbehörden die Polizeikräfte der Länder ihren Weisungen unterstellen kann.

2. Nach Art. 72 Ziff.10 GG hat der Bund ferner die ausschließliche Gesetzgebung über die $Z$ us ammenarbeit des Bundes und der Länder in der Kriminalpolizei und in Angelegenheiten des Verfassungsschutzes, die Einrichtung eines Bundeskriminalpolizeiamtes sowie die internationale Verbrechensbekämpfung. Derartige Einrichtungen des Bundes, von denen auch in Art. 87 GG die Rede ist, dürfen jedoch nach dem Willen der Besatzungsmächte noch nicht selbst über einen exekutiven Apparat verfügen. Das Bundesgesetz über die Zusammenarbeit des Bundes mit den Ländern in Angelegenheiten des Verfassungsschutzes vom 27. 9. 1950 (BGBl. 682) betont daher ausdrücklich in $\S 3$ Abs. 2: „Polizeiliche Befugnisse oder Kontrollbefugnisse stehen dem Bundesamt für Verfassungsschutz nicht zu. Das Amt darf einer polizeilichen Dienststelle nicht angegliedert werden."

9) Deshalb und wegen der Xnderung des Polizeikostenrechts während des Krieges durch das Gesetz vom 29. April 1940 ist ein Vergleich schwierig. Immerhin mögen folgende Zahlen angegeben werden:

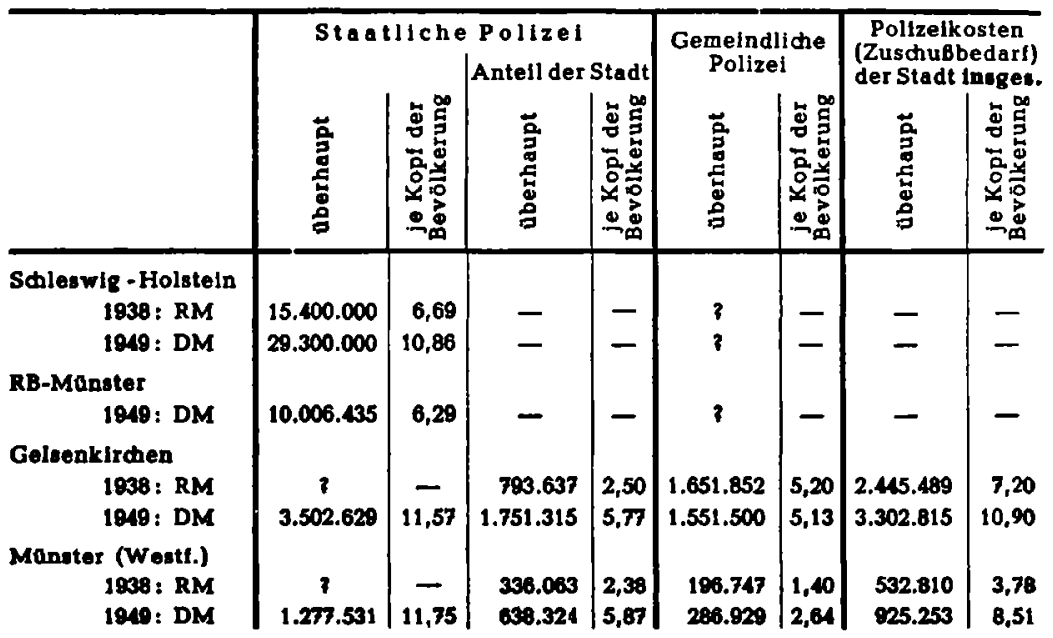


3. Gleichwohl können' Bundespolizeibehörden auch mit Ex e $k u t$ iv befugnissen eingerichtet werden, und zwar nicht nur die Bahnpolizei, sondern auch Bundesgrenzschutzbehörden, die in Art. 87 Abs. 1 Satz 2 GG erwähnt und von den Besdtzungsmächten im sogen. Polizeibrief vom 14. April 1949 zu 1 a ausdrücklich zugestanden sind. Auch für das zu errichtende Bundeskriminalpolizeiamt sind gewisse Exekutivbefugnisse vorgesehen ${ }^{7}$ ).

Die Bundespolizeibehörden haben nächst dem Bundesrecht das Landrecht des jeweiligen Eingriffsortes anzuwenden.

4. Der Wille der Besatzungsmächte zur Nicht-Militarisierung und Dezentralisierung der deutschen Polizei kommt übrigens noch in einer Anweisung der Alliierten Hohen $\mathrm{K}$ o $\mathrm{m} \mathrm{m}$ is si on an die Landeskommissare vom 21. September $1949^{8}$ ) zum Ausdruck. Dort wird auch u. a. erneut festgestellt, da $\beta$ der Erlaß von Verordnungen und daß solche Funktionen, die "von Rechts wegen den Justizbehörden zustehen" nicht „Aufgaben der Polizei" sein dürfen und daß diese, d.h. die Polizeibehörden, keine Aufgaben übernehmen dürfen, die nicht in direktem Zusammenhang stehen mit der Sorge für die Aufrechterhaltung der öffentlichen Ordnung und Sicherheit, der Verhütung von Verbrechen und der rechtlichen Verfolgung von Verbrechen oder mit der Information der alliierten Behörden über Vorgänge, die deren Sicherheit beeinträchtigen.

Z.Z. schweben bekanntlich Verhandlungen mit dem Ziel, diese starre, sachlich schwer gerechtfertigte Haltung der $\mathrm{Be}$ satzungsmächte aufzulockern ${ }^{9}$ ).

d) Die Fortgeltung des preuBischen Polizeiverwaltungsgesetzes v om 1. Juni 1931 (prPVG) für die Polizeibehörden i.e. S. ${ }^{10}$ ).

1. Trotz der organisatorischen Neuordnung und kompetenziellen Beschränkung ist auch die Polizei im neueren, engeren Sinne überall „Angelegenheit des Staates" geblieben. In Hamburg und Schleswig-Holstein ist das unzweifelhaft. Auch in Niedersachsen und Nordrhein-Westfalen ist $\S 1$ prPVG niemals

7) Das Gesetz ist inzwischen am 8. März 1951 (BGBl. S. 165) ergangen.

•) „Die Polizei" 1949 S. 382 f. und Pioch: Polizeirecht, Anlage 8 (S. 208 ff.) nebst Ergänzungsschreiben ebenda Anlage 46 (S. 28B).

†) Durch eine dem Bundesminister des Innern am 14. November 1950 mitgeteilte Instruktion der Alliierten Hohen Kommission an die Landeskommissare ist inzwischen eine gewisse gesetzliche Zentralisation der Polizei auf Landesebene zugelassen; den -independently governed municipalities" soll jedoch ihr Recht zur Unterhaltung einer unabhängigen Ortspolizei gesichert bleiben.

10) Fast alles Folgende ist umstritten: Das Schrifttum ist übersichtlich geordnet von Galette: Zur gesetzlichen Neuregelung des Rechts der öffentlichen Sicherheit und Ordnung $=$ Dóv $1950 \mathrm{~S} .575$ f. Anm. 4-7. Auf diesen vortrefflichen Aufsatz (DöV 1950 S. 574-580 und 612-617), der mir erst nach meinem Vortrag bekannt geworden ist. set zur Ergänzung auch des rechtspolitischen Teils (unten III) nachdrücklich hingewiesen. 
aufgehoben oder die Polizeiverwaltung zur Selbstverwaltungsangelegenheit erklärt worden. Die Gemeinden sind an ihr vielmehr nur mittelbar durch die Wahl der Mitglieder des Polizeiausschusses und die anteilige Tragung der Kosten beteiligt. Auch auf diese hat aber kein Gemeindeorgan einen rechtlichen Einfluß. Ein solcher Einfluß steht vielmehr, wennschon eng begrenzt, nur dem Innenminister oder der Landesregierung zu. Der Staat übt allerdings in Nordrhein-Westfalen seine Polizeigewalt durch rechtlich selbständige Anstalten aus, die sich in der Wahrnehmung dieser Auftragsangelegenheit erschöpfen.

2. §§ 2-7, 9-12 prPVG gelten nach dem Gesagten für die Polizei i. e. S. nich t mehr. Wegen $\S 8$ s. o. II b a. E. und hambVO über die Wasserschutzpolizei v. 31. August 1948 (GVBl. S. 94).

3. $\$ 13$ prPVG ist in Niedersachsen, in Nordrhein-Westfalen und in Schleswig-Holstein in Geltung geblieben. Die Bestätigung von Hilfspolizeibeamten steht danach dem Minister des Innern zu. Sie ist in Nordrhein-Westfalen durch RdErl. IM v. 14. Oktober 1949 (MinBl. S. 996) bzgl. Talsperrenwächtern, Feld- und Frosthütern den Regierungspräsidenten zur Wahrnehmung übertragen worden. In Hamburg: VOn v. 5. September 1947 (GVBl. S. 53) und v. 14.12.1948 (GVBl. S. 153) auf Grund des Gesetzes vom 26. Januar 1921.

4. $\S \S 14-17$ prPVG (betr. A u f g a b e n) sind in Geltung geblieben und von Schleswig-Holstein wörtlich in sein PolG übernommen worden.

In Nondrhein-Westfalen hält man $\S 14$ Abs. 2 prPVG, d.h. die Ubertragung polizeifremder Angelegenheiten, nicht mehr für anwendbar. Doch ist das Sache des Gesetzgebers, der diesbezüglich auf eine besondere Genehmigung des Hohen Kommissars angewiesen ist. Die alten polizeifremden Zuständigkeiten sind allerdings den Polizeibehörden durch die Militärregierung genommen.

Nach Art. 35 GG sind die Polizei- wie alle Behörden anderen Behörden zur A m t s h i lf e verpflichtet. In $\S 152 \mathrm{GVG}, \S \S 158$, 159, 161, 163 Abs. 2 und 189 StPO, \$§ 758, $759 \mathrm{ZPO}, \S 76$ der Eisenbahnbau- und Betriebsondnung, in $\$ \S 25,188,189,424$ und $427 \mathrm{RAO}$, in den Geschlechtskranken-Gesetzen und sonst ist ihre Amtshilfepflicht ausdrücklich und z. T. näher bestimmt worden. Sie gilt - entgegen der in Nordrhein-Westfalen und z. T. in Hamburg herrschenden Auffassung - aber auch sonst - allerdings mit der Finschränkung, da $B$ Amtshilfe insoweit nicht verbindlich verlangt werden kann, als die ersuchende $\mathrm{Be}-$ hörde selbst zur Durchführung der Maßnahme rechtlich verpflichtet und dazu auch imstande ist (z. B. die Ordnungsverwaltung oder der Bundestagspräsident - Art. 40 Abs. 2 GG). In 
diesem Falle kann sich die Polizeibehörde darauf beschränken, für den Schutz des Vollziehungsbeamten zu sorgen.

Wird die Polizeibehörde auf Ersuchen tätig, dann verantwortet sie nur die allgemeine Zuständigkeit der ersuchenden Behörde zur Anordnung der ersuchten Maßnahme und ihre eigene Tätigkeit bei deren Ausführung.

Wie die Polizeibeamten Hilfsbeamte der Staatsanwaltschaft sind, so sind sie auch Hilfsbeamte der Ordnungsbehörden, insofern sie die notwendigen Maßnahmen zur Gefahrenabwehr zu treffen, also sowohl im Eilfalle aus eigener Entschließung das zur Abwehr einer unmittelbar bevorstehenden Gefahr an Ort und Stelle Notwendige zu tun, als auch die Ordnungsbehörden darüber und in allen Fällen beobachteter materiell-polizeilicher Gefährdungen zu unterrichten, als endlich diesen mit den ihnen eigenen Mitteln beizustehen haben.

In Schleswig-Holstein (RdErl. v. 8.3.1949 bei X 3) werden nur die Polizeibeamten zur Anwendung unmittelbaren $Z$ wanges für zuständig gehalten. In der Tat wird man andere Behörden dazu i.d.R. als tatsächlich "nicht imstande" ansehen können.

So ist die Polizei ,der starke Arm der Verwaltung“ auch in diesem Sinne geblieben.

5. $\S 18-21$ (betr. polizeipflichtige Personen) und $\S \S 22-23$ (betr. ör t li ch e Z u ständigkeit) prPVG gelten fort und werden durch die neuen Bestimmungen über die polizeiliche Nachbarhilfe und Zusammenfassungen in Notfällen ergänzt. Niedersachsen hat mit Hamburg, Schleswig-Holstein und Bremen Vereinbarungen über die Erweiterung der örtlichen Zuständigkeiten ihrer Polizeien getroffen (ndsG v.7.7. 1950 - GVB1. S. 35-36).

6. Polizeiverordnu ngen ( $\$ 24-39$ prPVG) können die Polizeibehörden i. e.S. - also auch die Polizeiausschüsse nicht erlassen. Dieses Recht ist auf den Rat der Gemeinden bzw. den Kreistag übergegangen und steht außerdem - wie früher den Regierungspräsidenten und den Ministern zu.

7. $\S \S 40-44$ prPVG (betr. polizeiliche Verfügung e n) gelten auch für die Polizeibehörden neuen Rechts. Insbesondere können sie auf ihrem Kompetenzgebiet (z. B. dem Straßenverkehrsrecht) auch schriftliche Verfügungen erlassen und sind sie auf Grund des $\S 14$ sowohl berechtigt als auch verpflichtet, angetroffenen akuten Gefahren jeder Art durch mündliche Verfügungen zu begegnen (vgl. oben bei 4 a. E.).

Der Re ch t s m it te l z u g der $\$ \S 45-54$ prPVG (Beschwerde und Anschlußklage binnen 2 Wochen) gilt für die Verfügungen der Polizeibehörden i. e. S. nicht mehr. Zwar läBt $\$ 49$ brMRVO 165 ältere Vorschriften unberührt, doch würde es sich mit der von der brMR befohlenen und von den Polizeigesetzen durch- 
geführten Trennung der Polizei- von den anderen Verwaltungsbehörden nicht vertragen, wenn die Rechtsnachfolger der Landräte und wenn die Regierungspräsidenten im Beschwerdewege in das Ermessen der Polizeibehörden eingreifen könnten. Polizeiliche Verfügungen sind daher mit dem Einspruch des $\S 44$ brMRVO 165 und anschließender Klage nach $\S \S 22,48$ brMRVO 165 - je binnen 1 Monat - anfechtbar.

8. Die Polizeibehörden i.e.S. können unmit telbaren $\mathrm{Zw}$ ang und auch $-\mathrm{z}$. B. auf straßenverkehrspolizeilichem Gebiet - Ers a t z v or n a h me nach $\$ 55$ ff prPVG androhen und anwenden $\left.{ }^{11}\right)$. Die Androhung und Verhängung von $Z$ wangsgeld und Zwangshaft ist ihnen jedoch durch die Militärregierung versagt worden und auch durch neuere deutsche Gesetze noch nicht wieder zugestanden. Sie können also Unterlassungen nur durch einen wiederholten unmittelbaren $Z$ wang durchsetzen.

9. Polizeiliche Strafverfügungen können nicht mehr erlassen werden. Sie galten der Militärregierung und gelten den Hohen Kommissaren als "gerichtliche" Funktionen, obwohl sie nur einen vorläufigen Charakter haben und der Delinquent stets gerichtliche Entscheidung beantragen konnte. Jenen $\mathbf{m}$. E. unbegründeten Bedenken der Militärregierung haben nicht nur 1946 die Oberlandesgerichtspräsidenten dadurch Rechnung getragen, daß sie die Nachprüfung polizeilicher Strafverfügungen ( $\$$ 413-448 StPO) durch die Ermöglichung gerichtlicher Strafverfügungen ohne mündliche Verhandlung wegen Ubertretungen auf Anzeige der Polizeibehörde ersetzten; diese höchst unzweckmäBige Neuerung ist auch in die Strafprozeßnovelle von 1950 ( $\$ 413$ ) übernommen und sogar über den Bereich der polizeilichen auf alle bisherigen Strafverfügungen von Verwaltungsbehörden ausgedehnt worden. Das hat zur Folge, daß nicht mehr diejenige Behörde, die die Ubertretung festgestellt hat, sie unmittelbar in der ihr angemessenen Weise ahndet, sondern daß ein oder mehrere Richter täglich hunderte vorbereiteter Strafverfügungen unterschreiben müssen und erfahrungsgemä $B$ höhere Strafen als die Verwaltungsbehörden festsetzen. Damit ist nicht mal einem Prinzip, geschweige denn den Beteiligten, sondern allenfalls den Formulardruckereien und dem juristischen Nachwuchs durch die erforderliche Vermehrung der Richterstellen gedient ${ }^{12}$ ).

Die zeitweilig von den Besatzungsmächten verbotene, sehr zweckmäßige gebührenpflichtige Verwarnung ist neuerdings wieder möglich.

11) Die Bedenken von Kohlhass (DRZ 1950, 440), die Polizisten kōnnten wegen Art. 2 Abs. 2 Satz 3 GG von der Wafre nicht Gebrauch machen, bestehen im Geltungsgebiet des 55 prPVG und in Hamburg nicht.

v) Vgl. auch Kern: MDR 1950, 585 . 
10. $\$ \S 70-73$ prPVG betr. Entschädigungen gelten fort.

11. In s g es a $\mathrm{m} t$ läßt sich sagen, daß die polizeiliche Tätigkeit in den Ländern der britischen Zone trotz der $z$. T. weitergehenden Befugnisse tatsächlich - auch dies nach dem Vorbild des englischen Rechts - beschränkt ist auf die Regelung des Straßenverkehrs, die Anwendung unmittelbaren Zwangs zur Behebung akuter Gefahren einschließlich der Tumultpolizei und - hier liegt heutzutage das Schwergewicht - auf die Strafverfolgung, und zwar nicht nur der Kriminalpolizei, sondern auch der uniformierten "Schutzpolizei", die nicht mehr selbst Recht setzt und durch mittelbaren Zwang oder polizeiliche Strafverfügung durchsetzt, sondern sich darauf beschränkt, Ubertretungen den Gerichten zur Bestrafung anzuzeigen. Damit ist die früher so umfassende "Polizei" in der britischen Zone selbst zu einer Sonderbehörde, ihr Recht fast zu einem Sonderrecht geworden. Jene Allgemeine Polizei aber ist unter Verlust ihres Namens an die sogen. Ordnungsverwaltung übergegangen: Zur Rechten sieht man wie zur Linken die Polizei gespalten sinken. Die linke Hälfte führt das Schwert, kann aber nur noch unbeholfen schreiben; die rechte Hälfte führt die Feder, kann aber nur noch indirekt zwingen. Dies wird ebenso wie die geschilderte neue Organisation der Polizeibehörden weithin als nicht zweckmäßig und unbefriedigend angesehen (s. a. unten bei $f$ ).

e) Was ist nun aus den von den Polizeibehörden i. e. S. nicht übernommenen Kompetenzen der ehemaligen Orts- und Kreisbehörden geworden? Der Praxis erschien das zunächst sehr zweifelhaft. Es ist aber mit einem Satz zu sagen: kraft des juristischen und organisatorischen Trägheitsprinzips sind sie in dem bisherigen Umfang und in der bisherigen Weise denjenigen Organen verblieben, die sie bisher innehatten oder die an Stelle dieser Organe getreten sind ${ }^{13}$ ). Sie haben also ihren polizeilichen Charakter nur dem Namen nach, nicht aber materiell eingebüßt. Heute heißen sie „Ordnungsangelegenheiten" und werden von "Ordnungsbehörden" wahrgenommen. (Diese Benennung ist nicht eben glücklich, da sie sich mit dem bisherigen Begriff der polizeilichen Ordnung ${ }^{14}$ ) nicht deckt und die "öffentliche Ordnung " in dem überkommenen Sinne nicht nur von den Ordnungs-, sondern auch von den Polizeibehörden zu schützen ist. Die gelegentlich vorgeschlagene und verwendete Bezeichnung „Aufsichtsangelegen-

\footnotetext{
19) Ebenso awOVG v. 25. 1. 1950 - III A 110/49. - Vgl. zum Folgenden H. J. Wolff: Die Rechtsgrundlagen der sog. Ordnungsverwaltung im nordwestdeutschen Geltungsgebiet des prPVG = MDR 1950 S. 5 ff., mit Schrifttumsangaben und AöR 75 S. $470 \mathrm{fH}$.

11) Vgl. Bill Drews: PreuBisches Polizeirecht I (5. Berlin 1936) 14-26.
} 
heiten" ist nicht empfehlenswert, da das Wort "Aufsicht" staats- und verwaltungsrechtlich bereits einen anderen Sinn hat. Es wäre auch zumindest unschön, von der Aufsicht über die Aufsichtsführung zu sprechen. Das Gewerbeaufsichtsamt ist ferner etwas anderes als das Gewerbeordnungsamt).

Für diese sogen. Ordnungsverwaltung gilt das prPVG mit wenigen Ausnahmen fort.

1. Sie ist Angelegenheit des States, wird aber ausgeübt von einem Gemeindeorgan. Sie ist aber nicht, wie meist gelehrt wird, Auftragsangelegenheit der Gemeinde. Das prPVG hat vielmehr die Polizeiverwaltung einem bestimmten Gemeindeorgan im Wege der sogen. Organleihe übertragen, nämlich dem Bürgermeister bzw. Amtmann, in Landkreisen dem Landrat als Orts- bzw. Kreispolizeibehörden. Bürgermeister und Landräte gibt es in der britischen Zone zwar noch dem Namen nach; nach der dort geltenden Neufassung der Deutschen Gemeindeordnung sind sie aber nicht Rechtsnachfolger der Bürgermeister und Landräte älteren Rechts. Das sind vielmehr gem. $\S 32$ brDGO die Gemeinde- bzw. Amtsräte bzw. Kreistage. Auf diese also sind die einst den Orts- bzw. Kreispolizeibehörden zugeschriebenen Zuständigkeiten übergegangen. Sie können sie, soweit es sich um regelmäßige Verwáltungsgeschäfte handelt, durch einen Hauptausschuß (§53 Abs. 4 brDGO) ausüben lassen ${ }^{15}$ ). Die laufenden Geschăfte werden durch den zuständigen Gemeindebeamten wahrgenommen. $\mathrm{Ob}$ das stets der Hauptgemeindebeamte ist oder sein kann, mag ununtersucht bleiben. M. E. ist er es nicht, soweit ein besonderer Gemeindebeamter (Gemeinderat, Stadtrat, Beigeordneter) zuständig ist. Für die Verwaltung der Landkreise gilt entsprechendes. Ordnungsangelegenheiten, insbesondere der Erlaß von Verfügungen, werden in der Regel "laufende Geschäfte" sein, weil und soweit es sich nur um Gesetzesanwendung - wennschon innerhalb eines Ermessensspielraums - handelt. Dadurch wird die Unzweckmäßigkeit der juristischen Konsequenz - ein großes und sogar ein kleines Kollegialorgan ist wenig geeignet, polizeiliche Aufgaben zu erfüllen - weitgehend ausgeglichen.

Die Ordnungsverwaltung ist in einigen Städten organisatorisch $\mathrm{z} u \mathrm{~s}$ a $\mathrm{mm}$ e $\mathrm{g}$ e $\mathrm{f}$ a $\beta \mathrm{t}$, in anderen den jeweils sachlich verwandten Dezernaten (z. B. die gewerbepolizeilichen Angelegenheiten den Wirtschaftsämtern) zugewiesen. M. E. ist - wo möglich - eine Zusammenfassung vorzuziehen ${ }^{16}$ ), weil die Handhabung der PVG, insbesondere der Generalermächtigung, gewisse Rechtskenntnisse erfordert, weil andernfalls eine Ver-

14) Vgl. nwoVG v. 1. 6. 1950 - III A 118/50 (DVBl. 1951 S. 149 ff)

19) Ebenso Höhn: Stusev 1950, $11 \mathrm{f}$. 
mischung von Selbstverwaltung und staatlicher Verwaltung, pflegerischer und hoheitlicher Verwaltung nahegelegt wird und weil Fachstellen geneigt zu sein pflegen, in einer Störung ihrer eigenen Belange gleich eine Störung der öffentlichen Ordnung zu erblicken.

Die nicht von den Polizeibehörden i.e. S. übernommenen Aufgaben der ehemaligen Polizeipräsidenten sind ebenfalls an die örtlich zuständige Ordnungsbehörde (zurück-)gefallen.

Uber viele ehemalige polizeiliche Erlaubnisse oder Dispense entscheiden die auf Grund brMRVO 141 Art. VIII Ziff. 1 gebildeten Beschlußausschüsse.

Von Besonderheiten in den einzelnen Ländern, insbesondere auch im ehemaligen Braunschweig, Lippe und Oldenburg sei hier abgesehen. Das aufgestellte Prinzip gilt überall.

2. Ordnungs a u f sichtsbehörden sind nach wie vor ( $\S 9$ ff. prPVG) die Regierungspräsidenten und der Minister des Innern, sowie als Fachaufsichtsbehörden auch die anderen Minister. An Stelle des Landrats ist auch hier der insoweit von Weisungen des Regierungspräsidenten abhängige Kreistag getreten.

3. Weil und soweit die Polizeibehörden i.e.S. nicht mit „polizeifremden“ Aufgaben betraut werden dürfen, müssen den Ordnungsbehörden eigene Vollzugsbe amte zur Verfügung stehen, die insbesondere auch die Bau-, Lebensmittelusw. Kontrollen durchzuführen haben. Hier liegt einer der Gründe für die Kostspieligkeit der derzeitigen Polizeiorganisation i.w. S.

$\mathrm{Da}$ die Vollzugsbeamten der Ordnungsbehörden nicht unmittelbare Staatsbeamte sind, bedürfen sie gem. §13 prPVG der Bestätigung durch die unmittelbar vorgesetzte Ordnungsaufsichtsbehörde (den Kreistag bzw. den Regierungspräsidenten).

4. Aus dem Grundsatz der Fortgeltung des prPVG für die Ordnungsbehörden folgt $u$. a., daß auch ihnen die Ge n e r a 1 e r m ä chti g u n g des $\S 14$ Abs. 1 prPVG zur Verfügung steht (was im shPolG \& 1 Abs. 3 sogar allen Verwaltungsbehörden eingeräumt ist, „soweit sie zur Aufrechterhaltung der öffentlichen Sicherheit oder Ordnung tätig werden"), daß die Ordnungsbehörden materiell-polizeiliche Verfügungen nach $\S \S 40 \mathrm{ff}$. prPVG erlassen und daß diese mit den $R$ e ch t s m it t e ln der $\S \S 45$ ff., d.h. mit Beschwerde und Anschlußklage binnen zwei Wochen angefochten werden können. Die Beschwerdefrist ist allerdings gem. $\S 49$ brMRVO 165 allgemein auf 1 Monat erhöht. Utber die Beschwerde entscheiden, wenn die Ordnungsverwaltung ihr nicht selbst abhilft, der Kreistag oder dessen Hauptausschuß bzw. der Regierungspräsident. Da es sich dabei nicht 
um eine Angelegenheit der laufenden Verwaltung handelt, möchte ich den Oberkreisdirektor mindestens im Innenverhältnis nicht für zuständig erachten.

In Hamburg ist durch G. v. 29. 10.1949 (GVOBl. 265) der Einspruch als einziges Rechtsmittel gegen Verwaltungsakte eingeführt.

Gegen erstinstanzliche, materiell-landespolizeiliche Verfügungen des Regierungspräsidenten ist gem. $\S 49$ prPVG i. Vb. m. $\S 44$ brMRVO 165 unmittelbare Klage gegeben.

An die Stelle der Revision ist selbstverständlich die Berufung an das OVG getreten.

5. Als $\mathrm{Z}$ w ang $\mathrm{m}$ it te $\mathrm{l}$ stehen den Ordnungsbehönden die des $\S 55$ prPVG zur Verfügung - nicht, wie zeitweilig angenommen wurde, die des $\S 132$ prLVG, weil dieser für das (materiell) polizeiliche Gebiet durch $\S 79 \mathrm{~m}$ prPVG außer Kraft gesetzt worden ist und ein anderer Rechtstitel als die Vorschriften des PVG oder der anderen „polizeiliche“ Zuständigkeiten begründenden Gesetze für die Maßnahmen der Ordnungsbehörden fehlt ${ }^{17}$ ).

Zwangshaft kann angesichts des Art. 104 Abs. 2 GG auch als Ersatzstrafe von Verwaltungsbehörden nicht mehr verhängt werden. Auch dem hat die Strafprozeßnovelle vom 12.9.1950 leider nicht. Rechnung getragen. Doch sind m. E. die Amtsgerichte bereits unmittelbar aus Art. 104 Abs. 2 Satz 2 GG zur Umwandlung eines nicht beitreibbaren Zwangsgelds in Haft zuständig ${ }^{17} \mathbf{z}$ ). In Hamburg sind es die Vormundschaftsgerichte (hambG v. 17. 8. 1949 - GVBl. 177).

6. Auch Polizeiver ord nungen können die Ordnungsbehörden, $d . h$. der Rat der Gemeinden bzw. der Kreistag, der Regierungspräsident und die Minister, erlassen. Dies kann selbstverständlich weder dem (Ober)stadt(Kreis)direktor noch auch den Hauptausschuß überlassen bleiben ( $\$ 52$ brDGO). Die umstrittene Frage, ob eine solche Verordnung, wie § 32 Buchstabe b prPVG vorschreibt, als „Polizeiverordnung" zu bezeichnen ist, ist $\mathrm{m}$. E. zu bejahen. Auch $\S 32$ Buchst. b prPVG ist nirgends aufgehoben und gilt für die Ordnungsverwaltung. Diese übt materiell Polizeireckt aus. Ubrigens stand das Polizeiverordnungsrecht auch früher schon Behörden zu, die nicht Polizeibehörden waren (z. B. den Oberpräsidenten). Materiellpolizeiliche Gebote statt in einer Polizeiverordnung in einer Ortssatzung zu erlassen, wäre jedenfalls unzulässig, da es sich nicht um „eigene Angelegenheiten“ und, wie gesagt, nicht einmal um Auftragsangelegenheiten der Gemeinden handelt.

\footnotetext{
17) Ebenso nwOVG v. 25. 5. 1950 - IV A 21950. bei $\mathrm{V}$

"a) Dazu Wolff: Das Verfahren bei Freiheitsentziehungen - DoV 1951 S. 313 ff.
} 
Nach Aufhebung des $\S 25$ Abs. 2 prPVG durch das prG v. 31.5. 1933 haben die Minister ihre Polizeiverordnungen nicht mehr dem Landtag zur Kenntnis zu bringen. - Obwohl das prAnpassungsG vom 15.12.1933 den § 26 prPVG nicht ausdrücklich übernommen hat, entfällt doch (entgegen Erl. nw IM v. 26.3. 1949 - I 108-79/49) die Zustimmung des Beschlußausschusses für den Regierungsbezirk zu den Polizeiverordnungen des Regierungspräsidenten, weil auf den Beschlußausschuß nur die Zuständigkeiten der ehemaligen Bezirksausschüsse „im Beschlußverfahren" übergangen sind (z. B. nwVO v. 23. 6. 1948 § 3 Abs. 1 i. Vb. m. Art. VIII Ziff. 1 brMRVO 141 u. m. $\S 2$ VO OP Westfalen v. 2. 8. $1946 \S 2$ Abs. 1).

f) Die damit umrissene Gestaltung des Polizei- und Ordnungsrechts in der britischen Zone ist, darüber sind sich fast alle einig, namentlich in organisatorischer Hinsicht - mit Ausnahme der Hamburger und z.T. der schleswig-holsteinischen Organisation - noch weit u n b efriedigender, als es der derzeitige Zustand unserer Verwaltung überhaupt ist. Was sich in Großbritannien in liberalistischen Zeiten historisch entwickelt hat und von der dortigen demokratischen Praxis sinnvoll erfüllt wird, fügt sich nicht in das in Nordwestdeutschland historisch gewordene Organisations- und Rechtssystem, das keine kasuistischen Störungstatbestände entwickelt und die staatliche Beugegewalt nicht bei den Gerichten und deren Hilfsorganen konzentriert hat. Es haften dem geltenden Polizeirecht m. E. aber noch weitere Mängel an. Insbesondere möchte ich auf folgende Mißstände hinweisen:

1. Das Schwergewicht des Polizeibegriffs ist von dessen funktionellem zu dessen instituti onellem Moment verschoben. Die „Polizei" wird also vielfach als Subjekt statt als Funktion angesprochen.

2. Damit zusammen geht eine - allerdings leider zeitgemäße - Selbstherrlichkeit des Technischen und - auch politische - Eigengewichtigkeit des Apparats, die gerade dann bedenklich sind, wenn es sich um die Technik des Machtapparates handelt. Exempla docent.

3. Der Polizei-Institution $f$ e $h 1 \mathrm{t}$ a l so die Ver b indung zur allgemeinen Staats- und kommunalen Selbstverwaltung. An deren Stelle ist mancherorts eine Entfremdung oder gar Gegnerschaft getreten.

4. Insbesondere hat der Regierungspräsident gar keinen Einfluß mehr auf die Polizei.

5. Der Einfluß des I $n$ e $n m$ in is te r $s$ ist beschränkt auf eine Mitbestimmung bei der Auswahl des Polizeichefs und seines ständigen Vertreters, auf den Haushalt und auf allgemeine Anordnungen. Er hat mithin insbesondere keinen Einfluß 
auf die Auswahl des sonstigen Personals - weshalb 8 von 11 Innenministern kürzlich bekennen mußten, sie seien gegen parteipolitische Infiltration der Polizeiverbände vollkommen machtlos. Das ist um so bedenklicher, als von der Militärregierung 1945/46 Personen in die Polizeieinheiten eingestellt wurden, die zwar angeblich antifaschistisch gesonnen waren, deren Verfassungstreue aber nicht unzweifelhaft ist. Zur Durchsetzung seines Willens stehen dem Innenminister, abgesehen vom Grenzfall der Kommissarbestellung, nur die Gewährung oder Versagung finanzieller Zuschüsse zur Verfügung - als ob der Stand einer Institution dadurch verbessert werden könnte, daß man ihr die Mittel schmälert.

6. Die $\mathrm{Kr}$ eise und $\mathrm{kreisfreien} \mathrm{Städte}$ entsenden zwar Vertrauensleute in den Polizeiausschuß, haben aber nicht den geringsten Einfluß auf deren Verhalten und Beschlüsse. Die kommunalen Verwaltungen haben auch keinen Einblick in und erst recht keinen Ehnfluß auf die Finanzgebarung, des Haushalts- und des Stellenplans der Polizeibehörde, was um so bittorer ist, als sie die Hälfte des Finanzbedarfs bezahlen müssen.

7. Aber auch der PolizeiausschuB hat nur einen geringen Einflu $B$ auf den Stand und die Leistungskraft der Polizeieinheit, obwohl er nach $\S 10$ brMRVO $135, \S 3$ ndsG und § $6 \mathrm{nwG}$ dafür ,verantwortlich" ist. Denn ihm sind durch die Festlegung der Planstärken und der Besoldung sowie durch die Anforderungen an die Schulung und an die technische Ausrüstung seitens des Innenministers, der auch selbst den Haushaltsplan feststellt, die Hände gebunden. Außerdem kann er in allen wesentlichen Hinsichten vom Polizeichef vor ein fait accompli gestellt werden.

8. Der Polizeichef wiederum ist praktisch abhängig einerseits von den im Polizeiaysschuß herrschenden politischen Strömungen und personellen Verhältnissen, andererseits vom Haushaltsplan und den allgemeinen Anordnungen des Ministers. Immerhin ist seine Stellung bei weitem die stärkste. $\mathrm{Er}$ ist von konkreten Weisungen völlig unabhängig, und er kann es sich leisten, z. B. Amtshilfeersuchen nicht zu entsprechen und Vorteile aus der höchst unklaren materiellen Zuständigkeit der Polizeibehörden zu ziehen.

9. Wer prüft z. B. Lichtspielvorführungen, die Innehaltung von Maßnahmen zur Viehseuchenbekämpfung, die Zuverlässigkeit eines Wandergewerbetreibenden, die Mängelbeseitigung an einem Kraftfahrzeug, die Eighung eines Jugendlichen zur Erlangung eines Führerscheins, wer veranlaßt die Aufstellung von Verkehrszeichen? All dies und noch viel mehr ist zumindest zweifelhaft gewesen. Man sagt, daß die unheilvolle Verbreitung 
der Tuberkulose wesentlich auf unterlassene Milchkontrollen zurückzuführen sei.

10. Angesichts der sehr erheblichen rechtlichen Beschränkung und zusätzlichen Selbstbeschränkung der Polizei sind deren Beamte nicht mehr a usgelastet. Auf der anderen Seite fehlt den Gemeinden und Gemeindeverbänden das Personal oder das Geld, um Vollzugsbeamte einzustellen, die sich der von den Polizeibeamten nicht mehr versehenen Verrichtungen annehmen.

11. Trotzdem und infolge jener organisatorischen Mißstände ist die Polizeiverwaltung - sogar im engeren Sinne verstanden - viel teurer als sie es sogar in Zeiten polizeilicher Hybris gewesen ist.

\section{Ausblick.}

a) Die zuständigen Ministerien haben diese Mängel längst erkannt und Ge se tzen $t$ w ü $r f e$ ausgearbeitet, die das Polizei- und Ordnungsrecht auf eine neue rechtliche Grundlage stellen sollen. Dabei versucht man $z$. T., das alte preußische Polizeirecht durch Verwertung der neuen, insbesondere der organisatorischen Formen über den Stand von vor 20 Jahren hinaus fortzuentwickeln.

1. Am 21. Juni 1949 hat der Senat der Hansestadt $\mathrm{H}$ amburg (unter Nr. 145) der Bürgerschaft die Entwürfe eines Polizeiverwaltungsgesetzes und eines Gesetzes über die Organisation der Polizei vorgelegt. Der letztere bringt nichts Neues, der erstere bezieht sich sowohl auf die "ordentliche Polizei" als auch auf "die Verwaltungsbehörden, sofern sie polizeiliche Aufgaben wahrnehmen". Er überwindet das derzeitige Nebeneinander des sogen. Verhältnisgesetzes vom 23. April 1879 i. d. Fassg. v. 8. 10. 1923 mit gewohnheitsrechtlicher Geltung des $\S 10$ II 17 ALR neben der Fortgeltung des prPVG in den ehemaligen preußischen Landesteilen im Sinne einer weitergehenden Ubernahme und teilweisen Ergänzung des prPVG.

2. In Schleswig-Holstein, das in der Neugestaltung des öffentlichen Rechts den anderen Ländern der britischen Zone voraus ist, ist es bereits zum Landtagsbeschluß eines das Polizeigesetz vorn 24. 3. 1949 ergänzenden Gesetzes über die öffentliche Sicherheit und Ordnung vom 30.5.1950 gekommen (Landtagsvorlage Nr. 318/3). Das Gesetz ist jedoch von den Hohen Kommissaren abgelehnt worden, weil es die Polizeigewalt nicht hinreichend dezentralisiert und den Verwaltungsbehörden zu weitgehende Zuständigkeiten einräumt. Auch dieser Gesetzesbeschluß lehnt sich an das prPVG an, beschränkt aber die Polizeiverwaltung einerseits auf unaufschiebbare Fälle, überläßt ihr jedoch andererseits fast den gesamten Vollzug. 


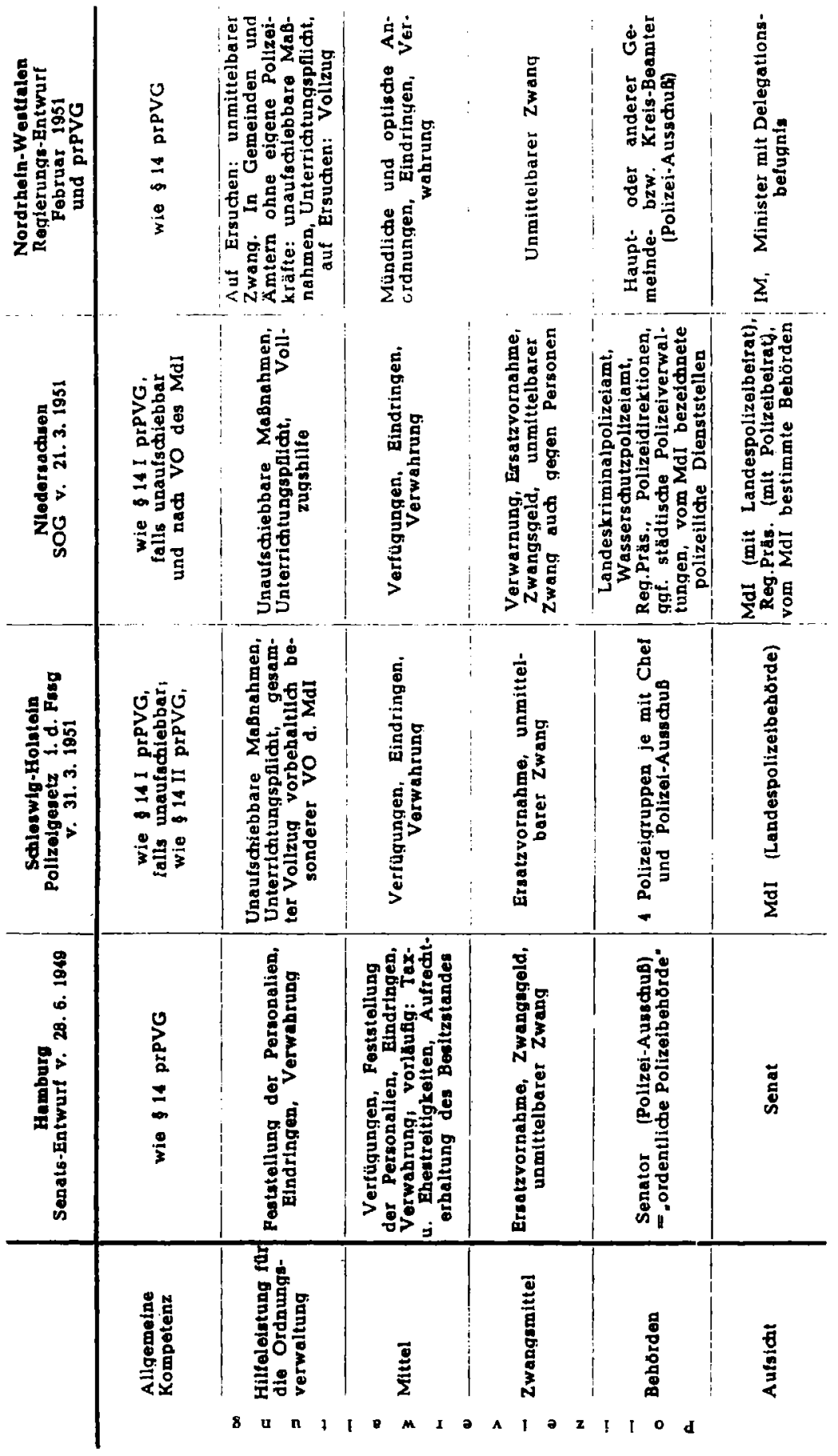


Die Gestaltung des Polizei- und Ordnungsrechts

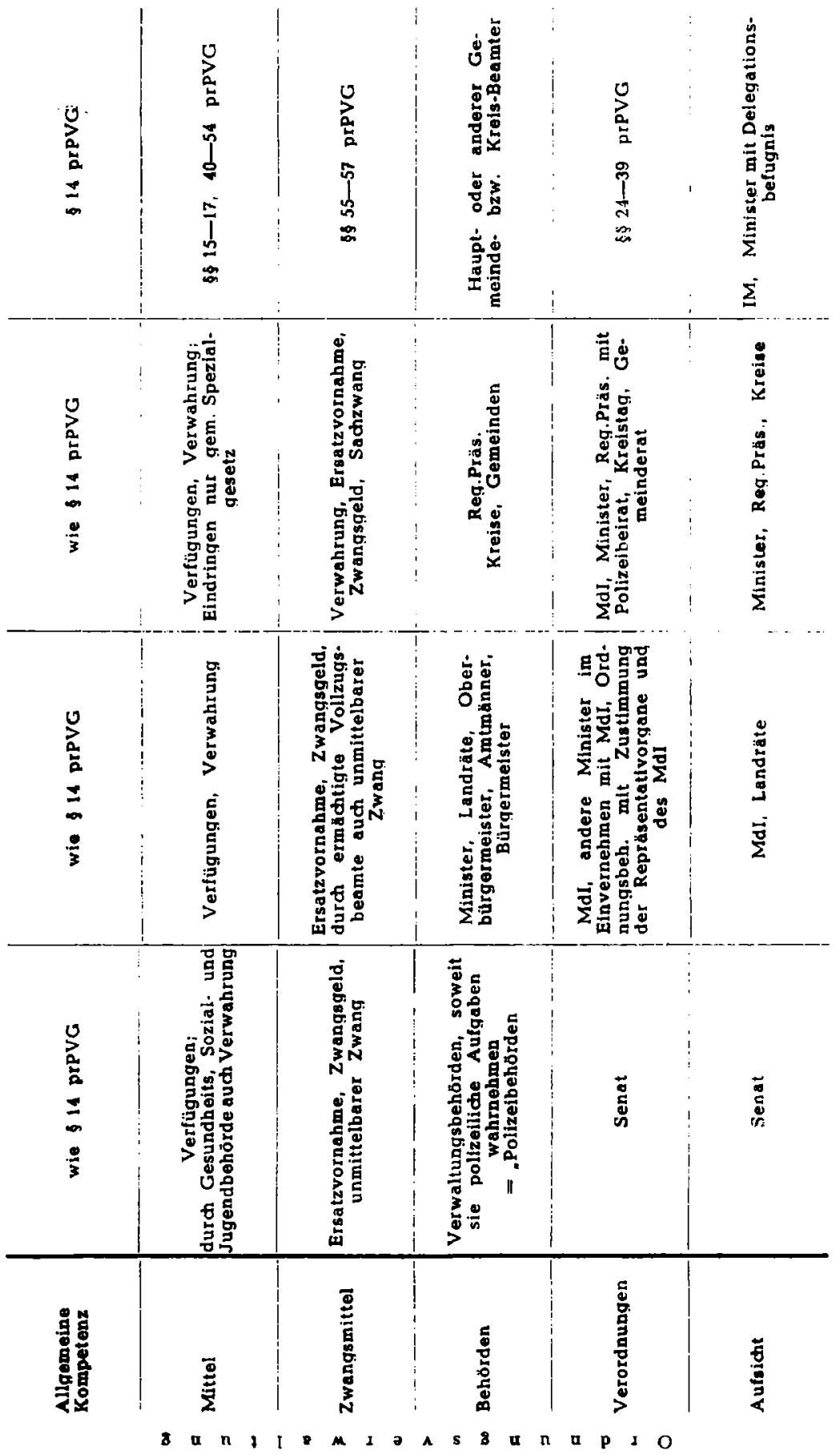


3. Auf der Grundlage des nämlichen Referentenentwurfs hat die niedersächsische Landesregierung im März 1950 dem Landtage den Entwurf eines Gesetzes über die Verwaltung der Ordnungsbehörden und der Polizei vorgelegt ${ }^{18}$ ).

4. Diese beiden, einander ähnlichen Problemlösungen haben z. T. recht lebhaften Widerspruch gefunden. In $\mathrm{N}$ or $\mathrm{drh}$ e i $\mathrm{n}$ We $\mathrm{t} f \mathrm{f}$ l e n etwa möchte man einerseits zu den Grundsätzen des prPVG zurückkehren, andererseits den Kompetenzbereich der Polizeibehörden i.e.S. tunlichst einschränken und den der Verwaltungs-, insbes. der Selbstverwaltungsbehörden erweitern. Besonderen Wert legt man hier, wenn ich recht orientiert bin, auf eine möglichst weitgreifende Entpolizellichung derzeitiger Zweige der Ordnungsverwaltung ${ }^{10}$ ).

5. Dies letztere erstrebt auch der Deutsche Städtetag, der außerdem mindestens die Ordnungsverwaltung als Selbstverwaltungsangelegenheit (allenfalls mit „verstärkter Staatsaufsicht") anerkannt wissen möchte.

Von den Polizeireferenten der Ministerien, den Polizeichefs und den Polizeiausschüssen sowie vom Institut zur Förderung öffentlicher Angelegenheiten und im Schrifttum sind die einschlägigen Fragen wiederholt erörtert worden. Eine herrschende Meinung hat sich noch nicht herausgebildet.

b) Bevor man die Fragen nach einer vergleichsweise besten Neugestaltung des Polizei- und Ordnungsrechts beantwortet, wird man gut tun, sich über einige Tatsachen, Grundsätze und Regeln Klarheit zu verschaffen:

1. Polizei im funktionalen Sinne ist praktisch n ot w e n d i g. Es darf nicht dem Zufall überlassen bleiben, ob die von der Verfassung und Regierung gewollte Ordnung beachtet wird oder nicht. JERUSALEM hat daher die Polizei als eine der drei Grundfunktionen des Staates bezeichnet ${ }^{20}$ ). Sie ist es insbesondere auch dann, wenn die Verfassung - wie das Bundesgrundgesetz - die Wirksamkeit der öffentlichen Organe auf die Herstellung und Bewahrung eines Rechtszustandes ausrichtet. Denn dieser ist ein (normatives) Ideal, das sich nicht kraft Naturnotwendigkeit durchsetzt, sondern auch gegen Uneinsichtigkeit und Böswilligkeit von Menschen durchgesetzt werden muß. Macht zu sein gehört bekanntlich zum Wesen, die Staatsgewalt zum Begriff des Staates. Dazu genügen aber nicht die Anordnungen und Drohungen der - selbst nur normativen - Gesetze, Verordnungen und Verfügungen. Ihnen muß vielmehr

\footnotetext{
10) Er ist am 21. 3. 1951 ergangen (GVBl. 79).

iv) Von einer genaueren Berichterstattung über diese Entwürfe sehe ich ab, da ich sie im DVBl. 1951 S. 300-303, 334-337 besprochen habe. Eine schematische Obersicht über die Entwürfe findet sich auf den vorhergehenden Seiten.

") F. W. Jerusalem: Der Staat (1935) 193 ff.; Ders.: Kritik der Rechtswissenschaft (1948) 348.
} 
eine potentielle $Z$ wangsgewalt entsprechen, die wieder ihrerseits erforderlichenfalls in aktueller physischer Machtentfaltung zum Ausdruck kommen muß. Diese liegt nicht nur bei der Polizei, und die Polizei erschöpft sich nicht in der physischen Machtentfaltung. Beide aber gehören wesentlich zueinander und zum Staate. Es wäre anarchistische Utopie, auf dies "staatsmachtliche Instrument" verzichten $\mathrm{zu}$ wollen ${ }^{21}$ ). Es bedeutete die Selbstaufgabe des Staates, dieses Instrument anderen Kräften wie etwa politischen Parteien zu überlassen. Ebenso unangebracht ist eine ohnmächtige Polizei oder der Versuch, ihre Kraft durch organisatorische Maßnahmen zu hemmen. Militärische Macht des Staates oder einer Besatzung können diesen Sachverhalt verdecken, nicht aber ändern.

Ist Polizeimacht notwendig, so ist auch das Risiko des Machtmißbrauchs unvermeidlich. Möglich ist jedoch, den machtmäßigen Eingriffen des Staates rechtliche Schranken zu ziehen und dafür zu sorgen, daß diejenigen Menschen, denen die legalen Machtmittel anvertraut sind, sie im verfassungsmäßigen Sinne handhaben, sowie die Machthaber und ihre Maßnahmen zu kontrollieren.

Daraus folgt einerseits die Regel tunlichster Konzentration der staatlichen Exekutivfunktionen, andererseits die Geltung der rechtsstaatlichen Forderungen der Gesetzmäßigkeit, des Gesetzesvorbehaltes und der Ablehnung unbestimmter positiver Zwangsgewalt sowie die Forderung demokratischer, gerichtlicher, disziplinarer und Gebarenskontrolle auch und gerade der Polizei in jedem Sinne.

2. Notwendig sind insbesondere Schutzleute, die das öffentliche Leben beobachten, öffentliche Gefährdungen des Lebens, der Gesundheit und der Sachgüter nach Möglichkeit verhindern und nach eingetretenen Schäden erforderlichenfalls autoritativ die Rechtsverfolgung sichern. Notwendig ist eine $\mathrm{Streitmacht}$, die jeden möglichen Widerstand gegen die verfassungsmäßige Ordnung $\mathrm{zu}$ brechen und den Fortbestand dieser Ordnung zu sichern imstande ist. Notwendig sind ferner Beamte, die begangene $S t r a f t a t e n z u r V e r f o l g u n g$ bringen, und notwendig sind solche, die Ordnungs$s t$ ör u n g e $n$ aller Art mit geeigneten Maßnahmen begegnen. Eine besondere Frage ist es, ob alle diese Funktionen von denselben oder in welcher Weise sie von verschiedenen Menschen wahrgenommen werden sollen. Im allgemeinen wird man sagen können, daß das, was e i n e $r$ machen kann, auch e i n e r machen soll, weil mit jeder weiteren Beteiligung Reibung, Zeit und Kosten im Quadrat anwachsen. Dabei ist örtlicher Zusammenhang und die Art und Weise der Geschäftserledigung nicht nur

:1) Dies zu Gut: DöV 1949, $466 \mathrm{f}$. 
billiger, sondern auch wichtiger als sachlicher Zusammenhang, da die Bearbeitung wechselvoller Aufgaben vor schematischer Einseitigkeit bewahrt und ein lebendigeres Interesse wachzuhalten vermag. Was alles gerade auf polizeilichem Gebiete geleistet werden kann, haben die preußischen und außerpreußischen Landjäger (Gendarmen) in ihrem täglichen Dienst bewiesen.

3. Die i. w. S. polizeilichen Funktionen stehen in sehr engem, manchmal kaum trennbarem $\mathrm{Z}$ u s a m $\mathrm{m}$ e $\mathrm{h}$ ang miteinander und mit anderen Staatsfunktionen. Schließlich dient fast die gesamte rechtsstaatliche Wirksamkeit der Aufrechterhaltung der für das Gemeinschaftsleben notwendigen guten Ordnung. Auch die Gesetzgebung, die Rechtsprechung und weite Teile der allgemeinen Verwaltung wenden Gefahren ab, wenn man diese Begriffe nicht in einem engeren "polizeirechtlichen" Sinne versteht.

Daher ist ein enges Zusammenarbeiten verschiedener Behörden auch auf denselben Lebens- (nicht Kompetenz-) gebieten angesichts des Umfanges und der arbeitsteiligen Differenzierung der modernen öffentlichen Verwaltung schlechterdings unvermeidlich. Dennoch ist eine trennende Unterscheidung notwendig, um klare Zuständigkeiten und damit eindeutige Verantwortungen der Behörden und Beamten zu schaffen ${ }^{22}$ ). Es darf aber auch keine Verantwortung (wie z. Z. die des Polizeiausschusses) über die eingeräumte rechtliche Zuständigkeit hinausgehen, wenn man gefährliche Reibungen, Anmaßung und Anonymität vermeiden will.

4. Im übrigen hat die Beantwortung jener Frage auszugehen nicht von den Wünschen vorhandener Behörden und anderer politischer Mächte, sondern von den zu bewältigenden Aufgaben. Sie hat also zu ermitteln, wer die gegebenen Funktionen am besten wahrnehmen kann. Dabei ist zu berücksichtigen, daß - ganz anders als noch vor 50 oder gar vor 100 Jahren - sämtliche Zweige der öffentlichen Verwaltung, auch die der Polizei im weiten wie sogar im engsten Sinne - z. B. der einfache Streifen- und Bereitschaftsdienst - je besonderen "t e c h $\mathrm{n}$ is ch e $\mathrm{n}^{\prime \prime}$ (einschl. rechts- und verwaltungskundlichen) $S$ a chvers t and erfordern. Darum kann längst nicht mehr jeder "gebildete Mensch" und nicht jeder Beamte alles gut erledigen. Laien sind daher nicht mehr imstande, befriedigend zu verwalten, soweit sie nicht selbst (zufällig) Sachkenner sind. Sie können nur anregen, zwischen

\footnotetext{
n) Hőchst unzwedłmäBig ist es aber z. B., wenn, wie in Nordrhein-Westfalen, über gewerberechtliche Ausnahmen und Beschwerden von einer anderen Behörde zu entscheiden ist, als von der gewerberechtlichen Aufsichtsinstanz (wie übrigens jede Beschneidung von Zuständigkeiten des Regierungspräsidenten).
} 
mehreren „technisch" möglichen Problemlösungen entscheiden, über die Grundzüge genereller Normen und Planungen sowie über die Anwendung klarer Rechtssätze auf übersehbare Sachverhalte befinden und Kontrollberichte prüfen. Viele "Laien" in der heutigen öffentlichen Verwaltung, insbesondere Volksvertreter, sind freilich mehr oder minder sachverständige Interessenvertreter und als solche da, aber auch nur da am Platze, wo es gilt, die vertretenen Interessen zur Geltung zu bringen, nicht aber Gefahren, i.e.S. abzuwehren und das geltende Recht ohne Rücksicht auf widerstreitende Interessen durchzusetzen. - Daß reine Exekutivfunktionen nicht kollegialisch versehen werden können, weiß jedermann.

c) Obzwar m. E. ein zwingender Grund zur Preisgabe der ziemlich einheitlichen und übersichtlichen Polizeiorganisation von 1931 weder bestand noch besteht, ist doch zu prüfen, ob und in welcher Weise den von den Besatzungsmächten eingeführten neuen Gesichtspunkten Rechnung zu tragen und dabei das ältere deutsche Recht glücklich fortzubilden ist. Das ist nur dann möglich, wenn es gelingt, den einheitlichen Kompetenzbereich der Polizei im alten Sinne a u $\mathrm{z} u \mathrm{gli}$ ledern. Einen Ansatzpunkt hierfür bietet die bereits erwähnte fachliche Verbesonderung der verschiedenen Sparten der Polizei, die ja übrigens auch schon in der ehemaligen Kompetenzverteilung zwischen den Polizeipräsidenten und den Bürgermeistern zum Tragen kam.

1. So könnte und sollte man $\mathrm{m}$. E. zunächst alle diejenigen früher polizeilichen, nun zur Ordnungsverwaltung gehörenden Gebiete a usscheiden, die im Laufe der Jahre in der formellen und materiellen Gesetzgebung eine fast schon erschöpfende Regelung gefunden haben. Man sollte also die Entwicklung fortsetzen, die durch die Entpolizeilichung des Fürsorgeund Schulwesens, des Feld- und Forstwesens ( $\$ 78$ prPVG), sowie von Teilen des Bau- ${ }^{23}$ ), des Gewerbe- ${ }^{24}$ ) und des Gesundheitswesens ${ }^{25}$ ) bereit seit langem im Gange ist. M. E. sirnd nun auch die letzteren und ist dazu das Melde-, Fund-, Veterinärund Jagdwesen reif, je so weitgehend kodifiziert zu werden, daß sie allgemeiner polizeilicher Ermächtigungen nicht mehr

m) Vgl. prFluchtlinienG v. 5.7.1875 \$\$1 (Gemeindevorstand), 12 und 15 (Ortsstatute), prWohnungsG v. 28. 3. 1918 Art. $6 \$ 1$ (Wohnungsaufsicht), nwG v. 7. 12.1948 52 (Bebauungsverordnungen).

4) RGewO 1 ff., $16 \mathrm{ff}, 41-42$ b, 55-60, 81 ff., 139b usw., sowie zablreiche Nebengesetze.

5) RGewO $\$ \$ 29-30$ b, RG betr. Bekämpfung gemeingefährlicher Krankheiten vom 30. 6. 1900, VO 2. Bekōmplung übertragbarer Krankheiten v. 1. 12. 1938, RG ४. d. Gecundheitswesen v. 3. 7. 1934, prAVO RG ü. Geschlechtskrankheiten 3, RArzteordnung, RApothekerO v. 18. 4. 1937, RBestallungsO $t$. Apotheker v. 8. 10. 1937, RHebammenG v. 21. 12. 1938, RFleischbeschauG v. 29.10, 1940 u. a. 
bedürfen und von anderen als den Ordnungs- oder gar Polizeibehörden i. e.S. wahrgenommen werden können ${ }^{20}$ ).

Tiefer gerechtfertigt wäre dies freilich nur dann, wenn es sich hierbei nicht oder nicht mehr um Gefahrenabwehr im engeren polizeilichen Sinne handelt. Dem ist in der Tat so. Der funktionelle Polizeibegriff hängt mit dem dispositiven auf das engste zusammen. Infoige der Subsidiarität der Polizei im alten Sinne war und ist eine Gefahr nur dann und insoweit eine ,polizeiliche“, als ihr nicht durch andere als „Polizeibehörden“ auf Grund besonderer gesetzlicher Ermächtigung und Verpflichtung zu begegnen ist. Solche gesetzlichen Zuständigkeiten besonderer Behörden fehlten vielfach, und zwar nicht zuletzt deshalb, weil die Polizeibehörden den festen Kern der staatlichen Behördenorganisation bildeten und imstande waren, mit Hilfe der polizeilichen Generalermächtigung die erforderlichen näheren rechtlichen Bestimmungen selbst zu treffen. Das ist inzwischen z. B. auf baupolizeilichem Gebiet so ausführlich geschehen, daß es für eine gesetzliche Kodifikation reif geworden ist ${ }^{27}$ ). Auf anderen Gebieten hat sogar der Gesetzgeber selbst allmählich die wichtigsten Ermächtigungen spezialisiert, so da $B$ der Anwendungsbereich des $\$ 14$ prPVG dort recht schmal geworden ist und nur noch wenig fehlt, um ihn fast ganz entbehrlich zu machen. Daß es die gewi $\beta$ nicht unberechtigte Scheu vor der Errichtung von Sonderbehörden und die bei weitem nicht so berechtigte Scheu vor der tberlassung an die Selbstverwaltungskörperschaften war, die ihren "polizeilichen“ Charakter bewahrten, ergibt sich auch daraus, daß etwa die Gewerbeordnung weithin die Polizei im materiellen und funktionellen Sinne hat fernhalten, also polizeifeste Rechtsstellungen hat schaffen wollen. Es ergibt sich ferner daraus, da $B$ der Gesichtspunkt der Gefahrenabwehr z. B. bei der Bedürfnisprüfung (vor Art. 12 Abs. 1 Satz 1 GG), im Bau-, Melde-, Jagd-, Veterinär- und z.T. auch im Gesundheitsrecht ziemlich weit hergeholt ist. Im sozialen Rechtsstaat rückt er vollends in den Hintergrund. Es kommt nun, wie mir scheint, auf den genannten Lebensgebieten und, um ein weiteres besonders deutliches Beispiel zu nennen, bei der Unterbringung Obdachloser in erster Linie auf eine gerechte soziale Gestaltung innerhalb der verfassungs- und gesetzesrechtlichen Ermächtigungen und erst in zweiter Linie auf deren Sicherung an - wie das z. B. für den Anschlußzwang an gewisse Gemeindeeinrichtungen in §18 DGO

a) Vgl. hierzu und zum Folgenden: H. U. Scupin: Die Angelegenheiten der öffentlichen Ordnung in .Recht, Staat und Wirtschaft" Bd. 2 (1950) S. 298-319, und Ders.: „Recht, Staat, Wirtschaft" Bd. 3 (1951).

"1) Eine vollstăndige, entpolizeilicheode Kodifkkation des gesamten Baurechts versucht der, allerdings in wichigen Hinsichten miBlungene, Entwurf zu einem Baugesetz für die Bundesrepublik Deutschland (z. B. $\$ 155,166,206$ fi.). 
bereits Gesetz geworden ist. Die ins Auge gefaßte spezialgesetzliche Regelung bedeutet also durchaus nicht, $\mathrm{da} \beta$ die dadurch erfaßten Verwaltungsbereiche befehls- und zwangslos bleiben, sondern nur daß die auf ihnen getroffenen gestaltenden Verwaltungsmaßnahmen auf Grund spezieller gesetzlicher Ermächtigung mit den ihnen jeweils gemäßen Befehlsinhalten und Zwangsmitteln gesichert werden sollen. Statt der Gefahrenabwehr sollte also die Sicherung der Daseinsvorsorge durch Zwangsmittel im Vordergrund stehen. Wie weit man dabei hinter dem Ideal konzise gefaßter Tatbestände im Interesse der Anpassungsfähigkeit an die höchst vielgestaltigen Lebenserscheinungen zurückbleiben muß, ist eine andere, nicht mehr grundsätzliche Frage. Grundsätzlich wichtig aber ist, daß auch neben oder besser hinter einer solch spezialgesetzlichen Regelung und den danach verwaltenden Behörden die materiellpolizeiliche Generalermächtigung der Ordnungs- und Polizeibehörden zur subsidiären Gefahrenabwehr verbleibt - wie es trotz \& 1 RGewO und Art. 19 Abs. 1 GG bei den polizeilichen Beschränkungen der Ausübung des Gewerbebetriebs und wie es trotz der entpolizeilichten Wohnraumbewirtschaftung und -Fürsorge bei der polizeilichen Unterbringung Obdachloser verblieben ist oder wie BGB und ZPO ein polizeiliches Einschreiten auf bürgerlich-rechtlichen Gebieten nicht völlig ausschließen.

Indes dies alles kann einstweilen nur ein Hinweis für die Gesetzgeber auf rechtssystematisch mögliche und - nicht nur meines Erachtens - zweckmäßige Neuregelung gewisser bislang materiell-polizeilicher Lebensgebiete sein. Vorerst gehören sie noch zum Polizei- oder vielmehr "Ordnungsrecht".

2. Eine der soeben für wünschenswert gehaltenen Abspaltungen gewisser Verwaltungsbereiche aus dem Gesamtbereich der Polizei im traditionellen Sinne hat in anderer Hinsicht inzwischen stattgefunden. Witzigerweise ist nämlich die Polize i selbst „entpolizeilicht", d. h. vom Kernbereich der staatlichen Verwaltungsorganisation abgesondert und besonderen, eben den Polizeibehörden im neueren, engeren Sinne übertragen worden. $\mathrm{Ob}$ diese wesentlichste Veränderung unseres überkommenen Polizeirechts auch fernerhin in irgendwelcher Weise beizubehalten ist, hängt davon $a b$, ob und wie eine sinnvolle Unterscheidung von Polizei- und Ordnungsverwaltung möglich ist. Dafür kann man grundsätzlich an jede der Dimensionen des Polizeibegriffs anknüpfen mit Ausnahme der formellen und der institutionellen, nach denen gerade gefragt ist. Auch die qualitative Dimension kann von vornherein ausscheiden, weil eine positive Sozialgestaltung mit ungenau bestimmter Zwangsgewalt im Rechtsstaat weder der Polizei noch der Ordnungsverwaltung gestattet werden darf. Danach verbleiben drei 
Unterscheidungsgruppen: Man kann ansetzen bei den polizeilichen bzw. Ordnungs-Maßnahmen rechtfertigenden Tatbeständen, indem man einen prinzipiellen Unterschied sucht zwischen den Gefahren, deren Bekämpfung allein den Polizeibehörden und denen, deren Bekämpfung allein den Ordnungsbehörden obliegt. Oder man kann sich darauf beschränken, die jeweiligen Kompetenzgebiete aufzuzählen. Oder man kann endlich nach den Rechtsfolgen, d.h. hier nach den Mitteln, unterscheiden, mit denen die Gefahren einerseits von den Polizei-, andererseits von den Ordnungsbehörden bekämpft werden.

Die prinzipielle Unterscheidung nach den rechtsfolgebedingenden Tatbeständen wäre hier wie sonst juristisch die beste. Es ist daher verlockend, sie schon in die funktionale Dimension hineinzulegen, indem man die Unterschiedenheit im Begriffspaar "Sicherheit und Ordnung" auswertet. Den Namen nach ist das sicherlich möglich: Die Polizei i. e. S. ist Sicherheitspolizei, die Ordnungsverwaltung materiell Ordnungspolizei. Aber abgesehen davon, daß diese Bezeichnungen wesentlich anders verstanjen werden müßten, als in der Vergangenheit, fragt es sich, was denn Sicherheit im Gegensatz zu Ordnung ist.

Es ist bekannt, daß es nicht angeht, die Sicherheitspolizei dadurch näher zu bestimmen, daß sie gegen den bösen Willen von Menschen gerichtet ist. Denn sie bekämpft auch Gefahren, die durch Naturereignisse veranlaßt werden; und die Ordnungsverwaltung sollte nicht dann unzuständig sein, wenn etwa ein Bauwerk durch Verschulden eines Menschen gefahrdrohend ist.

Erst recht kann man nicht auf den Unterschied von Rechtsund Sozialordnung abstellen, weil der Schutz beider den Polizei- und den Ordnungsbehörden anvertraut ist. Es erscheint mir überdies sehr zweifelhaft, ob man diesen Unterschied - jedenfalls in der von ANSCHUTZ ${ }^{28}$ ) vorgeschlagenen Weise - machen kann. Denn auch diejenigen Normen, „deren Befolgung nach den jeweils herrschenden ethischen und sozialen Anschauungen als Vorbedingung gedeihlicher Koeexistenz aller mit allen als Grundlage des Gemeinschaftslebens gelten", sind ungeschriebene Bestandteile der Rechts ordnung, wenn sie überhaupt Rechtsfolgen auszulösen imstande sein sollen.

Vielleicht aber läßt sich an den Unterschied zwischen absoluten und relativen Rechtsgütern derart anknüpfen, da $B$ man unter der von den Polizeibehörden zu gewährleistenden "Sicherheit" einen Selbstzweck, unter der von den Ordnungsbehörden zu gewährleistenden „Ordnung“, aber ein relatives Rechtsgut versteht, das nur um anderer, absoluter Güter, insbesondere der Würde, des Lebens, der Gesundheit und des

m) Gerhard Anschütz: Die Polizei (Vorträge der Gehe-Stiftung 11, 1910) S. 17. 
Eigentums willen aufrechtzuerhalten ist. Dann ließe sich der engere Begriff einer "absoluten Gefahr" bilden, die von den Polizeibehörden abzuwenden ist, während die Ordnungsbehörden relative Gefahren zu vermeiden, indem sie Störungen ihrer Ordnungsbewahrung abzuwenden haben. Da die absoluten Rechtsgüter der Verwaltung objektiv vorgegeben sind, bedarf es zu deren Sicherung keiner Rechtsgestaltung, während die Ordnungsverwaltung die von ihr zu sichernde Ordnung selbst zu konkretisieren hat. Diese Unterscheidung zielt indes nicht so sehr auf die von Polizei und Ordnungsverwaltung, als vielmehr auf die von materiell Polizeilichem und zu Entpolizeilichendem (oben III c 1). Die auf ihn implizit abstellenden Erwägungen des Deutschen Städtetages eilen der gegebenen und sogar der wünschbaren Rechtslage voraus, wenn sie die gesamte Ordnungsverwaitung unter diesem Gesichtspunkt sehen und demgemäß entpolizeilicht wissen wollen.

So bleibt in der ersten Gruppe nur noch die Anknüpfung an die Art der Gefahr nicht ihrer Quelle oder ihrer Richtung, sondern ihrer Aktualität nach. Dahin zielen denn auch der schleswig-holsteinische und der niedersächsische Entwurf, wenn sie die Polizeibehörden für die Regel auf die unaufschiebbare Bekämpfung von Gefahren beschränken, und der Städtetag, wenn er ihnen die Bekämpfung akuter Gefahren vorbehalten will. Auch dabei wäre aber der Gesichtspunkt der Subsidiarität zu berücksichtigen: Auf ihren Sachgebieten sind auch die Ordnungsbehörden (wie alle Behörden auf allen Gebieten) verpflichtet, auftretenden akuten Gefahren mit ihren Mitteln zu begegnen. Sehr scharf ist auch diese Abgrenzung also nicht.

Sie wird in modaler und effetiver Hinsicht ergänzt werden müssen. Die Beschränkung der Polizeibehörden auf die Bekämpfung akuter Gefahren hat zur Folge, ihr den ErlaB abstrakter Anordnungen vorzuenthalten, weil diese der Bekämpfung latenter Gefahren dienen. (Der Unterschied von speziellen und generellen Anordnungen ist in diesem Zusammenhang - wie sonst meist - unerheblich.) Was so in modaler Hinsicht die Ordnungsverwaltung vor der Polizeiverwaltung voraus hat, sollte diese vor jener in effektiver Hinsicht voraus haben, nämlich die Anwendung mittelbaren $Z$ wanges gegen Personen. Ihr den gesamten Vollzug (oder gar den Gesetzesvollzug im Gegensatz zur Gesetzesanwendung) anzuvertrauen, würde jedoch m. E. einstweilen noch zu weit gehen. Abgesehen davon, daß die Abgrenzung sehr schwierig ist und die Vollstreckung von Geldforderungen sicherlich ausscheiden müßte, sollten die Ordnungsverwaltungen ihre Anordnungen, wenigstens soweit das besonders technische Kenntnisse voraussetzt - wie bei der Bau-, Lebensmittel- und z. T. auch Gewerbe-Kontrolle - durch 
eigenes geschultes Personal durchführen und die Polizeibeamten davon verschont werden.

Die funktionalen und funktionellen, modalen und effektiven Besonderheiten der Polizei i. e. S. werden verbunden, wenn man ihr diejenigen Kompetenzen vorbehält, die sie allein technisch und situationsgemä $B$ recht zu handhaben versteht. Eben dahin zielt auch SCUPIN von der Ordnungsverwaltung her, wenn er deren "spezialisierte Gefahrenabwehr" der nichtspezialisierten Gefahrenabwehr durch die Polizei gegenüberstellt ${ }^{20}$ ). Dabei darf aber nicht übersehen werden, da $\mathrm{B}$ auch die polizeiliche Tätigkeit bestimmte spezialisierte Techniken erfordert. Es sind dies die Techniken der ständigen, insbesondere okularen Beobachtung des öffentlichen sozialen Lebens, soweit es sich auf und an der Straße abspielt, einschließlich der ohne besondere Fachkunde möglichen therwachung der Beachtung bestehender Gesetze und Verordnungen (z. B. bzgl. der Sperrstunde, der Ladenöffnungszeiten, des ambulanten Gewerbes, der Hausnummern, des Plakatierens, der Straßensammlungen, der Straßenreinigung und sonstigen Schuttbeseitigung), der vorläufigen Vermittlung bei Taxstreitigkeiten, Fhegüterzwist und Besitzstreitigkeiten, der Straßenverkehrsregelung, des ersten Zugriffs bei Gefahr im Verzuge, sowie als wichtigstes des unmittelbaren Zwanges gegen Personen (einschl. der Tumultbekämpfung, der vorläufigen Festnahme und Verwahrung) und des damit eng zusammenhängenden gewaltsamen Eindringens in eine Wohnung sowie der Strafverfolgung im übrigen. Das gilt auch von den Sonderpolizeibehörden der Wasserschutz-, Eisenbahn-, Steuer- und Zollpolizei, während die Strand- und Fischereipolizei überwiegend zur Ordnungsverwaltung gehören.

Die Verbindung mit den übrigen Verwaltungs-, insbesondere mit den Ordnungsbehörden besteht in der originären Pflicht der Polizeibeamten, beobachtete Rechts- und Ordnungswidrigkeiten den zur Sachbearbeitung zuständigen Behörden (wie längst schon der Staatsanwaltschaft) anzuzeigen, die Durchführung unmittelbarer Maßnahmen anderer Behörden durch den Schutz der sie ausführenden Beamten und Strafverfolgung sich Widersetzender zu gewährleisten und Außenermittlungen durchzuführen, zu denen die ersuchende Behörde nicht imstande ist. Diesen über die Amtshilfe hinausgehenden Beistand schuldet die Polizei a lle $n$ anderen Behörden als das Auge und der starke Arm der Regierung und der Verwaltung - dem Innenminister wie dem Verkehrsminister, der Gemeindeverwaltung wie der Staatsanwaltschaft. Zur letzteren und zur Ordnungsverwaltung

\footnotetext{
๑) H. U. Scupin: Recht, Staat, Wirtschaft III (Stuttgart 1951) nach dem Manuskript zitiert.
} 
sind ihre Beziehungen nur wegen der gemeinsamen Aufgaben der Verbrechens- bzw. der Gefahrenbekämpfung besonders eng.

Diesem Kern der polizeilichen Zuständigkeiten sollten $\mathrm{m}$. E. andere hinzugefügt werden, die in engem Zusammenhang mit ihnen stehen, um eine eindeutige Verantwortung sicherzustellen und Reibungen zu vermeiden. Außerdem würde ich es für vorteilhaft halten, wenn die Polizeibehönden, die praktisch so vielfältig von den Rechtsgestaltungen und Ersuchen anderer, insbesondere der Ordnungsbehörden, abhängen, auch ihrerseits eigene materielle Verwaltungszuständigkeiten haben, um die volle Verantwortung für ihren Kompetenzbereich tragen zu können. Dafür käme m. E. in Frage die Utbernahme der Zuständigkeiten der Straßenverkehrsämter und der sonstigen Wegeund Wegebaupolizei, das Waffen- und Sprengstoffwesen ${ }^{30}$ ) sowie sämtliche Zweige der politischen Polizei mit Vereins- und Versammlungspolizei, ferner Theater- und Lichtspielpolizei, weil diese nach der verfassungsrechtlichen und gesetzlichen Sicherung der diesbezüglichen Freiheiten in unlösbarem $\mathrm{Zu}$ sammenhang mit der Kriminalpolizei stehen und ein etwa anzuwendender $Z$ wang i.d. R. unmittelbar gegen Personen zu richten ist ${ }^{\mathbf{8 1}}$ ). Umgekehrt erfüllt $\mathbf{z}$. B. das Meldewesen pclizeilich (kriminalistisch) nur eine Hilfsfunktion, die auch bei einer Wahrnehmung durch die Ordnungsverwaltung unschwer gesichert werden kann, und hängt die Ausländeraufsicht mit dem Staatsangehörigkeitswesen so eng zusammen, da $B$ sie büromäßig mit diesem zu bearbeiten ist.

Die Frage nach einer sinnvollen Abhebbarkeit der Polizeiverwaltung i.e.S. ist daher $\mathrm{m}$. E. wegen der typischen Besonderheit der von ihr zu bekämpfenden Gefahren und erst recht wegen der Besonderheit der von ihr anzuwendenden Mittel gerechtfertigt. Außerdem lassen sich gewisse Kompetenzgebiete aufzählen, deren Bearbeitung ihnen zweckmäßig überlassen werden.

3. Was nach der Abspaltung der spezialisiert zu regelnden ehem. Verwaltungspolizei einerseits, der Polizei i. e. S. andererseits von den früheren materiellpolizeilichen Zuständigkeiten verbleibt, ist die sogen. Ordnungsverwaltung. Sie ist

\footnotetext{
m) Das Waffen- und Sprengstoffwesen gehört in der britischen Zone bereits jetzt zu den Kompetenzen der Polizeibehōrden.

1) Galette: DVBl. 1951 S. 614 I., wendet sich gegen die Obernabme derartiger Verwaltungsaufgaben durch die Polizeibehörden, weil diese dann einen neuen selbstīndigen Behŏrdenaufbau schaffen müBten und zusammenhăngende Aufgabengebiete auseinandergerissen werden wūrden. Diese Argumente sind sehr gewichtig. Sie treffen aber m. E. nicht zu. Ein selbständiger Behördenaufbau der Polizei ist, wenn man níht zur behōrdlichen Einheit von Polizei- und Ordnungsverwaltung zurüdkehrt, ohnehin notwendig. Die genannten Kompetenzen kōnnen und sollen ohre Vermehrung des Personals durch Polizeibeamte wahrgenommen werden. Schlieblich soll gerade Zusammengeböriges nicht auseinandergerissen werden.
} 
gekennzeichnet durch generelle Subsidiarität der negativen und präventiven Ordnungsbewahrung mit Hilfe einer Generalermächtigung zum Erlaß abstrakter und konkreter Anordnungen und deren Durchsetzung mit Ausnahme des unmittelbaren Zwanges gegen Personen.

$\mathrm{DaB}$ auch die Ordnungsverwaltung - wie die Polizei - eine Generalermächtigung nach Art des $\S 14$ prPVG benötigt, folgt $z$ wingend aus der Unvorhersehbarkeit aller möglichen Ordnungsstörungen. Es ist zwar richtig, daßdiepolizeiliche Generalermächtigung im Zuge der Entwicklung durch speziellere Regelungen typischer Lebensverhältnisse hinsichtlich ihres Anwendungsbereichs erheblich eingebüßt hat. Was einst durch konkrete polizeiliche Verfügungen angeordnet wurde, wurde im Laufe der Zeit durch abstrakte lokale und dann bezirkliche Polizeiverordnungen, schließlich vielfach durch formelle Gesetze und deren allgemeine Durchführungsverordnungen geregelt ${ }^{32}$ ). Es ist auch richtig und wäre $z$. $T$. wünschenswert, daß dieser Schrumpfprozeß fortgesetzt wird (vgl. III c 1). Ein Blick in aie Kommentare zu $\S 14$ prPVG zeigt aber, daß er für eine schwer übersehbare Zahl von $z$. T. wichtigen Fällen noch unerläßlich ist. Die Generalermächtigung hat sich daher auch in den Ländern durchgesetzt, wo sie nicht in einem geschriebenen Gesetz enthalten ist. $\mathrm{DaB}$ man in Großbritannien ohne sie auskomme, ist übertrieben (die Polizei hat "the King's peace" zu wahren, sect. 249 des Local Government Act 1933 ermächtigt die Country- und Borough-Councils, by-laws zu erlassen "for the good rule and government of the whole or part of the county or borough, as the case may be and for the prevention an suppression of nuisances therein ${ }^{33}$ ) und liegt im übrigen nur daran, daß dort fast alle Rechtsdurchsetzung richterlich ist und den Gerichten hinreichend elastische Tatbestände zur Verfügung stehen. Was die Formulierung des $\S 14$ prPVG anlangt, so gestehe ich, daß ich eine bessere nicht anzubieten habe. Und wenn das der Fall wäre, so fragt es sich doch sehr, ob nicht die in siebzig wechselvollen Jahren bewährten Begriffe dennoch den Vorzug verdienen, weil sie einen so elastischen wie didaktisch soliden Gehalt gewonnen haben. Jedenfalls gestatten sie jeder, sogar einer labilen sozialen und politischen Situation gerecht zu werden. Die Abschaffung der Generalermächtigung würde über kurz oder lang zu einem Aufblühen des berüchtigten „Staatsnotrechts" führen, zu dessen Beschränkung sie gerade

II) So ist etwa die einst so vortreffliche Anschützsche Fallsammlung fast unbrauchbar geworden, weil nun unmittelbar einem Spezialgesetz zu entnebmen ist, was einst aus $\$ 10$ II 17 ALR zu entwidkeln war.

4) Weiteres hierüber auBer bei Shneider (oben Anmerkung 1) in der noch unveroffentliche Habilitationsschrift von $H$. Ridder uber die neueste Entwidklung des englischen Verwaltungsrechts. 
erfunden wurde. Eine Beschränkung der Generalermächtigung auf konkrete Anordnungen würde der Verschiedenheit der örtlichen Ordnungsbedürfnisse und der bekannten Schwerfälligkeit der Landesgesetzgebung nicht Rechnung tragen.

Obschon die Ordnungsbehörden, wie gesagt, den Beistand der Polizeibehörden genießen oder doch genießen sollten, müssen auch sie - wenigstens in den Großstädten-über Voll z u g s b e a $m$ t e verfügen, nämlich solche, die technisch auf die besonderen Fachgebiete der Ordnungsverwaltung (z.B. Eich-, Lebensmittel-, sonstige Gewerbe- und Handels-, Bau- u. ä. Kontrollen) spezialisiert oder für Dienste einsetzbar sind, die den Polizeibeamten nicht ohne das Risiko des Autoritätsverlustes zugemutet werden können. Die Kontrollbeamten sollten zu Hilfsbeamten der Staatsanwaltschaft erklärt werden $(\S 152$ Abs. 2 GVG), um ihnen ein strafverfolgendes Einschreiten zu ermöglichen.

Besonders hingewiesen sei schließlich auf die ehemals „polizeilichen " Zuständigkeiten zur Mit w i r k u n g bei verschiedenartigen Verwaltungsmaßnahmen (z. B. im Fluchtlinien-, Wege-, Wasserrecht). Bei ihrer Begründung stand i.d. R. nicht so sehr das Interesse an einer Gefahrenabwehr im Vordergrund als der Wunsch, überörtliche Gesichtspunkte, objektive öffentliche Interessen, eine gewisse Rechtskontrolle sowie das Staatsinteresse und die Staatsautorität (durch den weisungsabhängigen Amtsvorsteher) gegenüber den Selbstverwaltungsorganen zur Geltung zu bringen. Sie gehören, zumal Gefahrenabwehr immerhin mitspricht, heute sicherlich zur Ordnungsverwaltung. Es fragt sich aber, ob sie ganz dorthin passen. Das wird vornehmlich davon abhängen, welchen Behörden die Ordnungsverwaltung anvertraut wird. Es ist jedenfalls unzweckmäBig, wenn nicht gar sinnlos, daß dasselbe Gemeinde- oder Kreisorgan ,die Zustimmung der Ortspolizeibehörde" zu einem von ihm selbst gefaßten Beschluß zu erklären hat.

d) 1. Damit ist die besonders schwierige, in Hamburg allerdings nicht auftauchende Frage angeschnitten, wie die O r g a $n$ is ation der Polizei- und der Ordnungsverwaltung zu gestalten ist. Das kann in vier verschiedenen Weisen geschehen: es können staatliche Behörden geschaffen oder benutzt werden, die Aufgaben können einem Gemeindeorgan im Wege der Organleihe übertragen werden, so daß dieses Organ - unabhängig von seiner gemeinderechtlichen Stellung und Verantwortung gewissermaßen als Commissarius loci des Staates die Polizei- bzw. Ordnungsverwaltung führt, oder sie können den Gemeinden bzw. den Kreisen als solchen übertragen werden, so daß deren Organe sie nach näherer Maßgabe der Gemeindeverfassung im staatlichen Auftrage wahrnehmen, 
oder sie können schließlich den Gemeinden bzw. Kreisen als Selbstverwaltungsangelegenheiten überlassen werden. Im letzteren Falle wäre noch zu unterscheiden, ob die Selbstverwaltungskörperschaften einer nur negativen Rechtsaufsicht oder einer verstärkten, auch positiven Staatsaufsicht unterstellt sind oder in den Angelegenheiten der Polizei- bzw. Ordnungsverwaltung unterstellt werden.

Welche dieser Organisationsnormen man wählt, hängt davon ab, ob es sich um örtliche oder um überörtliche Angelegenheiten und - zumal im letzteren Falle - ob der zentralen Staatsgewalt ein unbeschränktes Eingriffs- oder gar Weisungsrecht gesichert bleiben muB, ob die Steuerung durch allgemeine und abstrakte Dienstanordnungen und Geldzuweisungen oder ob gar eine Steuerung durch formelle Gesetze genügt. Angesichts der engen Verflochtenheit des sozialen und politischen Lebens in der Gegenwart, insbesondere auch der lebhaften Fluktuation der Bevölkerung gibt es nur noch wenige Angelegenheiten, die ausschließlich von örtlicher, gar nicht von überörtlicher Bedeutung sein können. Es kann daher diesbezüglich nur auf das Schwergewicht ankommen und darauf, die Verwaltung durch Delegierung echter Verantwortung tunlichst aufzulockern, um den öden Anweisungsschematismus, diese Seuche der modernen parteipolitischen Verwaltung, zu überwinden. Briefbeförderungen sind der Post zu überlassen! - Außerdem muß man berücksichtigen, daB ja doch auch die Kommunalverwaltung öffentliche, daB sie mittelbare Staatsverwaltung ist, und vollends in einem demokratischen Staate die Unterschiede zur unmittelbaren Staatsverwaltung nur bestehen in der unterschiedlichen Zusammensetzung der Organe, der politischen Ausgeglichenheit der Gemeinden und Gemeindeverbände, in denen die Minderheitsparteien nicht so sehr von der Regierung und Verwaltung ausgeschlossen sind wie in den Ländern und im Bunde, und vor allem hinsichtlich der verwaltenden Menschen und ihres Verwaltungsstils. Daneben spielt die getrennte Haushaltsführung angesichts der Staatsabhängigkeit der - hier muß man schon fast sagen: "sogenannten" - Selbstverwaltungskörperschaften leider nur noch eine geringe Rolle. Im übrigen ist der erhebliche Unterschied zu beachten, der besteht zwischen den Verwaltungsverhältnissen in kleinen Gemeinden und Ämtern, in Landkreisen und in kreisfreien Städten.

2. Tritt man auf Grund dieser und der früher angestellten allgemeinen Erwägungen zunächst an das Organisationsproblem der Polizei i.e.S. heran, so wird man diese wohl trotz der Art. 83 der bayerischen und Art. 85 der württemberghohenzollernschen Verfassung als eine Angelegenheit des Staates ansehen müssen, die der Selbstverwaltung nicht über- 
lassen werden kann, weil der Staat dieses wesentliche Machtmittel ohne Selbstpreisgabe ebensowenig aus der Hand geben kann wie etwa die Strafrechtspflege. Auch Art.91 GG spricht übrigens von den Polizeikräften der Länder, die es also grundgesetzlich geben muß.

Man wird jedoch unterscheiden müssen zwischen der Tumult(Bereitschafts-)polizei, der Autobahnpolizei, der Verfolgung überörtlicher Verbrechen (z. B. Schmuggelei) und reisender Verbrecher (Falschmünzerei, Hochstapelei u. a.) sowie besonders schwierigen Verbrechensaufklärungen einerseits und den übrigen Sparten und Aufgaben der Polizei andererseits. Denn nur jene sind eindeutig von überörtlicher Bedeutung, während die sonstige Straßenverkehrspolizei, der Streifendienst und auch der Großteil der Kriminalpolizei den Schwerpunkt ihrer Tätigkeit am Orte haben. Kleine Gemeinden und auch Ämter vermögen allerdings eine eigene Polizei weder zu tragen noch zu handhaben. Außerdem muß mindestens die Polizei aus dem unvermeidlichen örtlichen Klüngel herausgehalten werden. Ebensowenig darf auch nur die leiseste Möglichkeit bestehen, $\mathrm{da} ß$ eine große Gemeinde oder gar ein Oberbürgermeister alten Stils, auf eine Polizeimacht gestützt, die Staatspolitik zu beeinflussen vermag. Andererseits sind Regierungsbezirke zu groß, um eine lebendige tbersicht und Einsicht zu gestatten.

Daher empfehle ich eine zentralisierte Verwaltung der - mehreren - Bereitschaftspolizeigruppen und zentralen Polizeieinrichtungen (Schulen, Kriminaluntersuchungs- und Fahndungsstellen mit Exekutivbefugnissen); im übrigen aber eine Dekonzentration auf die Kreisstufe also auf dem Lande nach Art der früheren Landjägerei, die sich meiner Erfahrung nach sehr bewährt hat, in den kreisfreien Städten nach Art der früheren Polizeipräsidien. Die so gebildeten Polizeieinheiten müßten selbstverständlich in amtlicher wie in dienstlicher Hinsicht einem für sie verantwortlichen Polizeichef unterstehen; die Polizeibeamten müßten mit dessen Einverständnis von und zu den Bereitschaftspolizeigruppen versetzbar sein. Außer den untersten Rangstufen sollten alle Polizeibeamten, auch die Inhaber von Polizeichef-Stellen, unmittelbare Staatsbeamte auf Lebenszeit sein. Die Kreispolizeigruppen sollten zentraler fachlicher Inspektion und außer der Gesetzgebung auch fachlichen Direktiven und sogar Weisungen des Innen- und des sonst beteiligten Fachministers unterliegen. Für Ausnahmezustände kann auf die im Grundgesetz.vorgesehene Weisungsbefugnis der Bundesregierung nicht verzichtet werden.

Eine m.E. notwendige Verbindung mit der Allgemeinen Staatsverwaltung läßt sich durch die allgemeine Aufsicht mit Weisungsbefugnis des Regierungspräsidenten, die noch not- 
wendigereVerbindung mit den Kommunalverwaltungen dadurch erreichen, daß die Polizeibehörde ihnen - wie ja schon den Staatsanwaltschaften und den Verkehrsbehörden - Beistand zu leisten hat, daß die Entscheidungen über die wirtschaftlichen Belange der Polizeiverwaltung unter Beteiligung eines dafür gebildeten Ausschusses des Kreistages bzw. des Rates der Stadt getroffen werden, daß der Kreis bzw. die Stadt zu den Kosten der Polizeiverwaltung insoweit beiträgt, als sie über das in unmittelbarem staatlichen Interesse unerläßliche $\mathrm{MaB}$ hinausgehen, daß der Kreis bzw. die Stadt den Leiter und das Personal der polizeilichen Rechts- und Wirtschaftsverwaltung stellt, und - vor allem - daß der Polizeichef, sein ständiger Vertreter und vielleicht sonstige höhere Polizeibeamte im Einvernehmen mit dem erwähnten Polizeiausschuß bestellt werden. Dadurch wird zugleich eine parteipolitische Uniformität aller Polizeimachthaber vereitelt. Dem Polizeiausschuß besondere anstaltliche Rechte oder selbständige Behördenstellung zu verleihen, halte ich für nicht angebracht; genug, daB er die demokratische Kontrolle ausübt und die Interessen der Polizei im Kreistag bzw. im Rate der Stadt vertritt.

Im übrigen müßte, wie in $\S \S 22,23$ prPVG, dafür Sorge getragen werden, da $B$ die Behendigkeit und Schlagkraft der Polizeibehörden und -beamten durch die Kreis-, ja sogar durch die Ländergrenzen nicht behindert wird und daß es jederzeit möglich ist, Sachverständige an beliebigen Orten einzusetzen.

$\mathrm{DaB}$ eine solche staatliche Polizei übermächtig werde, ist angesichts der Kleinheit und parteipolitischen Differenziertheit der deutschen Länder sowie der verfassungsmäßigen Sicherungen gewi $\beta$ nicht zu befürchten.

Für die polizeilichen Zuständigkeiten des Bundes reichen m. E. Art. 87 Abs. 1 Satz 2 und Art. 91 Abs. 1 und 2 GG aus.

Auch die sonstigen Bedenken, die gegen eine solche $\mathrm{Ab}-$ trennung der Polizei i.e.S. von der Ordnungsverwaltung erhoben werden, vermag ich nicht zu teilen. Wo staatliche Polizeiverwaltungen bestanden, waren ja $a \mathrm{uch} f \mathrm{rüh}$ e $\mathrm{ruf}$ den meisten Gebieten der nunmehrigen Ordnungsverwaltung andere, nämlich Kommunalbehörden, tätig, ohne daB das zu wesentlichen Schwierigkeiten geführt hätte. Andererseits bietet die Abtrennung der Polizei i. e.S. von der Ordnungsverwaltung die Möglichkeit, jene unbeschadet ihrer sachlichen $\mathrm{Ab}$ hängigkeit von Gerichts-, Kommunal- u. a. Behörden in eine m.E. wünschenswerte pers on elle Abhängigkeit von der Landesregierung zu bringen.

Eine so organisierte Polizei würde eine notwendige Staatsfunktion in eigener Verantwortung erfüllen, indem sie als Landespolizei nach Maßgabe der Staatsführung, insbesondere 
des Innenministers, für die Aufrechterhaltung der allgemeinen politischen Sicherheit und Ordnung sorgt, als staatliche Kreispolizei bestimmte, mit ihren sonstigen Aufgaben in engstem Zusammenhang stehende Verwaltungskompetenzen wahrnimmt, als Hilfsorgan der Staatsanwaltschaft dieser bei der Aufklärung und Verfolgung von Straftaten teils auf Ersuchen, teils mit vorläufigen Maßnahmen und Berichterstattungen in eigener Entschließung unersetzbar behilflich ist und endlich als Hilfsorgan der Verwaltungsbehörden, insbesondere der Ordnungsbehörden, wiederum teils auf Ersuchen, teils mit vorläufigen Maßnahmen und Berichterstattung in eigener Entschließung reine Exekutivfunktionen, insbesondere auf Grund einer Generalermächtigung, unbestimmten unmittelbaren $Z$ wang, und zwar gegen Personen in ausschließlicher Zuständigkeit, ausübt ${ }^{34}$ ).

3. Auch die Ordnungsverwaltung ist m. E. als Angelegenheit des Landes anzusehen. Gewi $\beta$ ist das unmittelbare staatliche Interesse auf diesen Gebieten weniger beteiligt als auf denen der Polizei i.e. S. und das örtliche meist sogar überwiegend. Trotzdem handelt es sich bei der Gefahrenabwehr um vitale Interessen des Staates, die dieser nicht völlig dem Ermessen kommunaler Organe überlassen kann. Auch kann die Staatsregierung nicht darauf verzichten, ihren Willen auch auf anderen Gebieten als denen der Polizei-, Finanz- und Arbeitsverwaltung bis in die untersten Instanzen zur Geltung zu bringen, zumal es sich dabei um Bundesauftragsangelegenheiten handeln kann. Es mag vom Standnunkt der Gemeinden aus genügen, wenn das nur auf den Gebieten der Gefahrenabwehr der Fall ist. Würden die Gemeinden oder doch die Kreise und kreisfreien Städte morgen die Uberlassung der Ordnungsverwaltung zur Selbstverwaltung erreichen, würden wahrscheinlich übermorgen neue staatliche Sonderverwaltungsbehörden errichtet werden. Statt dessen sollten sie $\mathrm{m}$. E. ihren Einfluß dahin geltend machen, daß ihnen alle a nde ren als die Ordnungszuständigkeiten zur Selbstverwaltung überlassen werden.

Damit habe ich schon gesagt, daß die Ordnungsverwaltung m. E. der Kommunalverwaltung an- oder einzugliedern ist. $\mathrm{Ob}$ das am besten in der strafferen Form der Organleihe oder in der der Auftragsangelegenheit erfolgt, hängt von dem Charakter der jeweiligen Angelegenheit ab. Organleihe eines kommunalen Einmannorgans halte ich im Zweifelsfalle wegen der klareren Anweisungszuständigkeit für zweckmäßiger und jedenfalls dann für erforderlich, wenn zur Ordnungszuständig-

s) Weitgehend übereinstimmend eine unveroffentlichte Denkschrift des Chef der RB-Polizei, Arnsberg, Polizeidirektor Hahnzog, v. 26. Nov. 1950. 
keit gewisse Kontrollbefugnisse gegenüber der Kommunalverwaltung gehören, wie z.B. auf den Gebieten des Fluchtlinien- und Wegerechts - es sei denn, diese Zuständigkeiten würden den Polizeibehörden i.e.S. übertragen, wofür allerdings gerade auf jenen straßenverkehrsnahen Gebieten. vieles spricht. Andererseits eignen sich zur Wahrnehmung als Auftragsangelegenheiten die, aber auch $\mathrm{n}$ u r diejenigen Materien, in denen den kollegialen Gemeindeorganen ein Ermessensspielraum belassen werden kann. Dazu gehört stets die Zuständigkeit zum Erlaß von Verordnungen.

Bei der ordnungsrechtlichen Zuständigkeit kommunaler B e $s \mathrm{chl}$ u B a us s ch üs s e als staatlicher Organe ${ }^{35}$ ) sollte es verbleiben, ja sie sollte sogar m.E. auf alle Betriebserlaubnisse und Bewirtschaftungsmaßnahmen von erheblicher Bedeutung ausgedehnt, die Ausschüsse allerdings dem Vorsitz eines rechtskundigen Beamten unterstellt werden. Auch die Beantwortung der Frage, ob die Ordnungsangelegenheiten auf der Gemeinde-, Amts- bzw. Stadt- oder Kreis- bzw. Großstadt-Stufe zu erledigen sind, wird zweckmäßig nach der Verschiedenheit dieser Angelegenheiten unterschieden. Diejenigen, deren befriedigende Erledigung besondere technische und Rechtskenntnisse erfordern, sind $\mathrm{m}$. E. der Kreisstufe vorzubehalten, wobei ich optimistischerweise davon ausgehe, da $\beta$ in nicht allzu ferner Zeit die Kreisverwaltungen wieder mit fachlich, insbesondere rechtlich voll ausgebildeten leitenden Beamten versehen sein werden. Für Landgemeinden genügen die auf den Hauptgemeindebeamten abzustellenden Buchst. a, bund e des $\$ 5$ prPVG.

Frühere materielle oder auch formelle polizeiliche, insbesondere Kontroll-Zuständigkeiten, deren Ubertragung auf Kommunalorgane auf unüberwindliche Bedenken stoßen sollte (vielleicht z. B. Staatsangehörigkeits- und Ausländerangelegenheiten, Namensänderungen), könnten als formelle L a ndes ordnungs s a chen dem Regierungspräsidenten anvertraut werden.

Die A ufsicht über die Ordnungsverwaltungen gebührt den Regierungspräsidenten und dem Fach-, im Zweifel und im allgemeinen dem Innenminister.

4. Das Problem der ordnungsbehördlichen Zuständigkeit wird sehr an Bedeutung verlieren, wenn, wie ich es für angebracht halte, die in der oben bei III c 1 geschilderten Weise rechtlich spezialisierbaren $Z$ weige der derzeitigen Ordnungsverwaltung den Gemeinden zur Selbstverwal-

-) Das sind sie schon nach geltendem Recht. Sie waren es seit der Gneistschen Reform. Auch brMRVO 141 Art. VIII oder dessen Ausfübrungsverordnungen der Lãnder haben die BeschluBsachen nicht zu Selbstverwaltungsangelegenheiten gemacht, sondern nur Organen der Selbstverwaltungskörperschaften (wie es a.a.O. richtig heißen mub) zur Erledigung übertragen. 
t ung überlassen werden. Dafür spricht nicht nur die aus allgemeinen Erwägungen längst gebotene und vielfach geforderte Dezentralisation und Zusammenfassung möglichst vieler Verwaltungskompetenzen bei den unteren und mittleren kommunalen Selbstverwaltungskörperschaften, sondern insbesondere auch die Tatsache, daß das Schwergewicht der zur Entpolizeilichung reifen Verwaltungsbereiche - mit Ausnahme vielleicht der bisher von den Gewerbeaufsichtsämtern bearbeiteten Angelegenheiten - also das übrige Gewerbe-, das Bau-, Gesundheits-, Veterinär-. Jagd-, Melde- und Fundwesen ganz oder fast ganz örtlich gebunden ist und zumeist mit den Selbstverwaltungsangelegenheiten der Gemeinden und Kreise auf das engste zusammenhängt. Soweit, wie beim Gesundheits- und Veterinärwesen, auch überörtliche Belange einschlagen, kann deren Berücksichtigung den Selbstverwaltungsorganen gesetzlich zur Pflicht gemacht und im Aufsichtswege überwacht werden, wie denn überhaupt die mit der Entpolizeilichung verbundene erschöpfende spezialgesetzliche Regelung sowohl eine entsprechend intensive Kommunal-(Rechts-)Aufsicht als auch gerichtliche Rechtskontrolle ermöglicht. Bedenkt man noch, daB auch die Nichterfüllung einer gesetzlichen Aufgabe und daB zweckwidrige (d.h. nicht nur unzweckmäßige) Maßnahmen ermessensmißbräuchlich und damit rechtswidrig sind, schwinden m. E. die Bedenken, die gegen die Uberlassung bisher anweisungsunterworfener Zuständigkeiten zur Selbstverwaltung sprechen mögen. Darum bedarf es m. E. nicht einmal der Einführung einer „,verstärkten Staatsaufsicht", der der Deutsche Städtetag alle zur Selbstverwaltung überlassenen bisherigen Auftragsangelegenheiten zu unterwerfen bereit ist. Die auf Generalermächtigung gestützte, weisungsgebundene Zuständigkeit der Ordnungsverwaltung zu subsidiären Eingriffen zwecks Abwendung bevorstehender Gefahren bleibt außerdem im Hintergrund. Erfüllt also eine Gemeinde die ihr aus der Durchführung, z.B. des Baugesetzes, erwachsenen Aufgaben unzweckmäßig, so ist das ihre Sache; weder die Aufsichtsbehörde noch ein Gericht ist befugt, ihre (bessere oder schlechtere) Meinung an Stelle der der Gemeindeorgane zu setzen. Erfüllt die Gemeinde jene Aufgaben nicht dem Gesetz entsprechend, zweckwidrig oder gar nicht, dann ist die Aufsichtsbehörde berechtigt, mit den erforderlichen Geboten und Verboten einzugreifen. Entsteht aus der ungenügenden Aufgabenerfüllung seitens der Gemeindeorgane eine Gefahr im Sinne des $\S 14$ prPVG, so ist die Ordnungsbehörde unmittelbar wie auch auf Weisung ihrer Aufsichtsbehörde verpflichtet, die erforderiichen Anordnungen - auch gegen die Gemeindeorgane - zu treffen. Ǔber die Berechtigung jener kommunalaufsichtlichen wie dieser Ordnungs- 
maßnahmen - z. B. über die Widerzwecklichkeit einer Maßnahme oder darüber, ob eine Gefahr vorliegt - entscheidet auf Klage des Hauptorgans der Gemeinde das Verwaltungsgericht.

e) Was endlich die materiellen und formellen $\mathrm{Zu}$ ständigkeiten der Polizei- und der Ordnungsbehörden anlangt, so stimmen sie trotz der hervorgehobenen Unterschiede dieser Verwaltungszweige weitgehend überein.

1. Zwar ist es die Hauptaufgabe der Polizei, die Gefahren abzuwehren, die der öffentlichen und persönlichen Sicherheit drohen. Die Polizeibeamten müssen aber auch berechtigt sein, in allen anderen Gefahrenfällen wenigstens subsidiär einzuschreiten. Entsprechend müssen die Ordnungsbehörden Maßnahmen auch gegen Sicherheitsgefahren treffen können. Da diese wie jene nicht mit Bestimmtheit vorauszusehen sind, lassen sie sich nicht kasuistisch aufzählen. Deshalb muß es m. E. für beide bei der Generalermächtigung des $\S 14$ prPVG verbleiben, zumal dieser interpretativ genügend geklärt ist ${ }^{90}$ ).

Nicht dagegen bedarf es dieser oder einer ähnlichen Generalermächtigung für die zu entpolizeilichenden Sondergebiete. Denn diese sollen gerade gesetzlich speziell geregelt werden derart, daß alle Zuständigkeiten der Verwaltungsbehörden zu Eingriffen in Freiheit und Eigentum der Rechtsunterworfenen an gesetzliche Tatbestände gebunden sind. Eine andere Frage ist, wie genau diese gefaßt werden können und ob nicht in jedem dieser Gesetze auch ungenau gefaßte Tatbestände enthalten sein müssen. Aber auch diese würden den besonderen Erfordernissen des Spezialgebietes enger angepaßt, also immer noch genauer gefaßt sein können als § 14 prPVG.

Erst recht würde ich es nicht für angebracht halten, eine Generalermächtigung zu allen für die Gefahrenabwehr erforderlichen Maßnahmen nach Art des $\$ 13$ prPVG alle n Behörden der kommunalen Selbstverwaltung oder auch nur der Staatsverwaltung in ihren Kompetenzbereichen einzuräumen. Das hätte zwar den Vorteil, daß eine Verbesonderung der Ordnungsverwaltung entfiele und diese insgesamt institutionell ,entpolizeilicht" werden würde. Es hätte aber die Kehrseite, daß die gesamte Verwaltung einschließlich der Wohlfahrtsförderung i.w.S. funktional und funktionell "verpolizeilicht" werden würde, wie das in der vorrechtsstaatlichen Epoche des Verwaltungsrechts der Fall war. In der Tat wäre ein Rückschritt in diese Epoche und damit eine schroffe Verletzung des rechtsstaatlichen Geistes unserer derzeitigen Verfassungen unvermeidlich. Die durch Generalermächtigung gewährte also relativ

4) Der Einwand eines Praktikers, einem Oberkreisdirektor dürfe die starke Waffe des 14 PVG nicht in die Hand gegeben werden, da er damit nicht umzugehen verstehe, trifft einen MiBstand, der auch aus anderen Gründen beseitigt werden mu日. 
unbestimmte Anordnungs- und Zwangsgewalt ist ein allzu scharfes Schwert, als daß seine Handhabung allen Verwaltungsbehörden überlassen werden könnte. Die Anwendung solcher Generalermächtigung erfordert eine Kenntnis des Rechts, der Gesetzgebung und der Rechtsprechung, und einen Uberblick über die sozialen Zusammenhänge, die den Fachbehörden allermeist fehlt; und sie verleitet zum Einsatz „polizeilicher" Mittel schon dann, wenn die besonderen Intentionen der Behörde bedroht erscheinen.

2. Auch bei den Grundsätzen des Vorgehens: der Richtung gegen den Störer, der Entschädigung des Nichtstörers und der Verhältnismäßigkeit, kann es für Polizei- und Ordnungsverwaltung beim Recht des prPVG verbleiben. Selbstverständlich müssen sie auch beide „p olizeiliche Verf üg ung en" - und zwar sowohl die Polizeibehörde schriftliche als auch die Exekutivbeamten der Ordnungsbehörden mündliche - erlassen können. Ob hiergegen Einspruch oder Beschwerde gegeben ist, wird sich nach der allgemeinen Regelung des verwaltungsgerichtlichen Vorverfahrens richten. M. E. sollte der Regierungspräsident über Beschwerden gegen Verwaltungsakte der nachgeordneten Behörden entscheiden, 'gegen Verfügungen der Regierungspräsidenten und der höheren Behörden aber der Einspruch gegeben sein. Es ist wichtig, daß vor Einleitung des verwaltungsgerichtlichen Verfahrens eine rechts- und sachkundige Verwaltungsbehörde, die Uberblick und Vergleichsmöglichkeiten hat, die Rechtmäßigkeit und Zweckmäßigkeit der manchmal von nicht hinreichend rechtskundigen und sachlich befangenen Beamten oder Organen erlassenen Verwaltungsakte prüft, sofern dem nicht das Selbstverwaltungsrecht der Gemeinden und Gemeindeverbände entgegensteht.

3. Der Erlaß von Verordnungen könnte allerdings den Polizeibehörden versagt und den Kreistagen bzw. den Stadträten (bei Magisterverfassung freilich dem Magistrat), den Regierungspräsidenten und den Ministern vorbehalten bleiben. Die Verordnungen der Kreistage, Stadträte und Magistrate sollten, um Fehler zu vermeiden, den Regierungspräsidenten zur Genehmigung (praeventive Rechtskontrolle und Zurückverweisung wegen Unzweckmäßigkeit), die der Regierungspräsidenten vor Erlaß dem Beschlußausschuß für den Regierungsbezirk und die der Minister einem Landtagsausschuß zur Billigung vorgelegt werden, sofern nicht besondere Eilbedürftigkeit dazu zwingt, diese Mitwirkungsakte nachzuholen.

4. Solche Verordnungen sollten, wie nach $\S 33 \mathrm{prPVG}, \mathrm{n}$ i c h t Geldstrafen, sondern nur Zwangsmittel, insbesondere Zwangsgeld androhen. Das gilt auch von den Gesetzen und 
Verordnungen der spezialgesetzlich zu regelnden derzeitigen Ordnungsangelegenheiten, sofern es nicht ausnahmsweise gilt, Menschen wegen ihres verbrecherischen Verhaltens zur Rechenschaft zu ziehen. M. E. wird die Strafgewalt des Staates viel zu sehr überspannt und die Staatsautorität nicht gefestigt, sondern beeinträchtigt, wenn Verstöße gegen Ordnungsregeln oder gar gegen technische Verwaltungsnormen (z. B. Anmeldezwang) unter Strafe gestellt werden. Die Strafe ist kein Zwangsmittel. Strafwürdig ist nur eine Tat, deren Rechtswidrigkeit jedem gesunden Menschen bewußt ist, weil deren Folgen die absoluten Rechtsgüter betrifft. Die Verwaltungsbehörden zielen dagegen auf etwas ganz anderes, nämlich auf die Aufrechterhaltung eines ordnungsgemäßen Zustandes von 'der Sicherheit bis zur ungestörten Abwicklung der Verwaltungsgeschäfte - und zwar notfalls mit Zwang, einem Zwang, der für den Widerstrebenden ebenso unangenehm oder gar noch unangenehmer sein mag als eine Bestrafung, die aber dennoch keine Bestrafung ist, weil es für ihn nur auf die Verantwortung des Pflichtigen, nicht aber auf dessen Verschulden ankommt. Im Hinblick darauf ist es vielleicht schließlich doch zu begrüßen, daß die Strafprozeßnovelle 1950 die polizeiliche Strafverfügung abgeschafft hat, wenn dadurch der Gesetzgeber veranlaßt wird, sogen. Polizeidelikte in Zukunft statt mit Strafsanktionen vielmehr mit Beugesanktionen zu versehen.

5. Man mag einwenden, da $B$ es nicht angehe, den Polizei-, den Ordnungs- und anderen Verwaltungsbehörden eine $Z$ wangsgewalt anzuvertrauen, deren Wirkung der einer Strafe gleichkomme. Das ist $\mathrm{m}$. E. aber nur bei Freiheitsentziehung richtig und nun auch geltenden Rechts. Im übrigen genügt es vollauf, wenn die zwangsandrohenden Verordnungen und die Zwangsmittel festsetzenden Verfügungen durch unabhängige Gerichte $n$ a ch g e p r üft werden können, was nunmehr - mit Ausnahme der abstrakten Verordnungskontrolle in der britischen Zone - auch uneingeschränkt geltenden Rechts ist.

6. Abgesehen von der Anwendung unmittelbaren Zwanges gegen Personen, der m. E. - von Notstand und Notwehr abgesehen - einschließlich der Festnahme und der Verwahrung (§15 prPVG) den Polizeibeamten i. e. S. vorzubehalten ist, sollten also - wie bisher - die $\mathrm{Z}$ w ang s m it t el der Ersatzvornahme, des $\mathbf{Z w a n g s g e l d e s}$ und des unmittelbaren $Z$ wanges gegen Sachen sowohl den Polizei- als auch den Ordnungsbehörden zur Durchsetzung ihrer auf die Generalermächtigung gestützten Maßnahmen zur Verfügung stehen, weil ja einerseits die Polizei mindestens auf dem Gebiete des Straßenverkehrsrechts auch bürokratisch, andererseits die Ordnungsbehörden z. B. auf dem Gebiet der Lebensmittelkontrolle exe- 
kutiv tätig werden. Ich hätte auch keine Bedenken, außer den Polizeibehörden auch den Ordnungsbehörden das Recht zum Erlaß gebührenpflichtiger Verwarnungen und zum Erlaß gerichtlich überprüfbarer Strafverfügungen zuzugestehen. Im Falle der Nichtbeitreibbarkeit eines Zwangsgeldes müßte auf Umwandlung in Haftstrafe schon wegen Art. 104 Abs. 2 Satz 1 GG ein Gericht, und zwar m. E. dasjenige Gericht, das über die Berechtigung der Androhung und der Verhängung zu entscheiden hätte, also das Verwaltungsgericht, zu erkennen haben, um unterschiedliche Beurteilung der Rechtswidrigkeit gänzlich auszuschließen.

Die Zwangszuständigkeiten der Gemeindebehörden bzgl. der ihnen zur Selbstverwaltung überwiesenen Gebiete richten sich nach den diesbezüglichen Gesetzen. Sie werden außer Ersatzvornahme, Zwangsgeld und unmittelbarem Zwang gegen Sachen auch andere, der jeweiligen Materie sachlich angepaßte Zwangsmittel vorsehen können (z. B. Verlust von Vorteilen). Der an § 132 LVG anknüpfbare Einwand, die Gemeinden als solche hätten keinen obrigkeitlichen (besser: hoheitlichen) Charakter, geht fehl. Gewiß liegt ihr Schwergewicht entschieden auf der pflegenden (auch sogen. schlichten Hoheits-) Verwaltung. Sie sind aber sowohl aus $\S 18$ DGO als auch als Anstaltsherren längst und mit Recht zur zwangsweisen Durchsetzung ihrer rechtmäßigen Anordnungen befugt. $\mathrm{DaB}$ es eine Staatsgewalt gibt, schließt nicht aus, daß es auch eine - davon abgeleitete - Gemeindegewalt gibt.

7. Angesichts der weitgehenden Ubereinstimmung der materiell- und formellrechtlichen Zuständigkeiten der Polizeiund der Ordnungsverwaltung bestehen m. E. keine Bedenken, beide, wie im schleswig-holsteinischen und im niedersächsischen Entwurf, in e i n e m Gesetz zusammenzufassen. Die zu „entpolizeilichenden" Gebiete der gegenwärtigen Ordnungsverwaltung müßten aber selbstverständlich in je besonderen Gesetzen geregelt werden.

\section{Leitsätze des Berichterstatters über die Gestaltung des Polizei- und Ordnungsrechts in der britischen Besatzungszone}

a) Da die soziale Geltung der verfassungsmäBigen Ordnung nicht dem Zufall überlassen bleiben darf, muB es eine Polizej geben. Der dem jeweiligen Staatszweck und der BehördenDifferenzierung entsprechende Polizeibegriff faßt gewisse Intensitäts- bzw. Quantitätsgrade folgender Dimensionen zusammen: 
1. funktional: Gewährleistung einer sozialen, politischen und Rechts-Ordnung innerhalb des Staates durch Verwaltungsorgane, erforderlichenfalls unter Machteinsatz auf Grund nicht genau bestimmter Tatbestände;

2. funktionell:

Vermeidung von Mißständen, insbesondere

Bekämpfung akuter oder (und) latenter,

konkreter oder (und) abstrakter Gefahren

oder (und) Herstellung gewisser sozialer Zustände;

3. qualitativ: negativ oder (und) positiv, repressiv oder (und) praeventiv;

4. dispositiv: speziell oder subsidiär oder universal; Subsidiarität besteht hinsichtlich

a) der Rechtsgrundlage (Generalermächtigung),

b) der Zuständigkeit anderer Behörden,

c) der Funktionsbefugnis nur bei dringender Eilbedürftigkeit (erster Zugriff);

5. $\operatorname{modal}:$ konkrete oder (und) abstrakte Anordnungen;

6. eff e ktiv: Ersatzvornahme, Zwangsgeld, unmittelbarer Zwang gegen Sachen oder (und) Personen, vorläufige oder (und) endgültige Bestrafung;

7. sachlich (Kompetenzen): Rechtssicherheitspolizei (z. B. Straßenverkehrspolizei, Kriminalpolizei),

politische Sicherheitspolizei (z. B. Staatsschutzpolizei, Fremden-, PaB-, Vereins-, Versammlungspolizei),

Verwaltungs- (Ordnungs-)polizei (z. B. Gesundheits-, Gewerbe-, Baupolizei),

Wohliahrtspolizei,

Glückseligkeitspolizei;

8. örtlich: Orts- (Land- oder Stadt-), Kreis-, Landespolizei;

9. institutione 11: ordentliche oder Sonder-Polizeibehörden (z. B. Wasserschutz-, Bahn-, Bergpolizei),

Allgemeine oder besondere Polizeibehörden (z. B. Polizeiprösidenten),

Orts-, Kreis- und Landespolizeibehörden, staatliche oder kommunale Polizeibehörden,

Polizei-Verwaltungs-, -Exekutiv- und -Wirtschaftsbehörden,

handelnde und Aufsichtsbehörden;

Sammlungs- und Informationsstellen; 
10. for me 11: Die Zuständigkeit der Polizeibehörden (z. B. auch Tier- und Landschaftspflege, Ausstellung von Quittungskarten).

b) Mit Rücksicht auf den nationalsozialistischen MiBbrauch der Polizeigewalt verlangte die brMR auBer Denazifizierung und Demilitarisierung auch Dezentralisierung der Polizei und verbot deren "gesetzgebende" und "richterliche" Tätigkeit. Ohne Rücksicht auf die zum gröBten Teil fortbestehende deutsche, insbesondere preußische Verwaltungsorganisation und materielle Rechtsordnung wurden die entsprechenden britischen Grundsätze importiert.

1. Die Länder übernahmen die Gliederung in RB- und SKPolizeieinheiten mit je einem Polizeichef und PolizeiausschuB unter nur allgemeiner Aufsicht des Innenministers ohne sonstige Verbindung mit der Staats-oder Selbstverwaltungsorganisation.

2. Trotz z. T. weitgehender Befugnisse beschränkt sich die Tätigkeit der Polizeibehörden auf die Regelung des StraBenverkehrs, die Anwendung unmittelbaren Zwangs zur Behebung akuter Gefahren und - mit Schwergewicht - auf die Strafverfolgung.

3. Die übrigen früheren polizeilichen Zuständigkeiten sind als "Ordnungsverwaltung" den Gemeinderäten, Kreistagen (als Nachfolgern der Bürgermeister bzw. Landräte), Regierungspräsidenten und Ministern nach MaBgabe des prPVG verblieben.

4. Insbesondere die Generalermächtigung des $\$ 14$ prPVG ist weiterhin gesetzliche Grundlage für Maßnahmen der Polizei- und der Ordnungsbehörden, soweit nicht Spezialermächtigungen Platz greifen.

c) Da dieser Rechtszustand nicht befriedigt, werden allseits Pläne für eine Neuordnung erwogen. Dabei sollte auf $\mathrm{Zu}$ sammenfassung technisch und lokal zusammenhängender Funktionen, Leistungsfähigkeit, Ausnutzung vorhandener Kräfte, Eignung der Betrauten, klare Zuständigkeitsabgrenzungen und eindeutige Verantwortung, Billigkeit und Kontrolle gesehen werden. Eine demokratische Organisation der Gefahrenabwehr ist nicht möglich.

ZweckmäBig erscheint, wenn nicht eine Rückkehr zum Rechtszustand von 1931,

1. entpolizeilichende, spezialgesetzliche erschöpfende Regelung derjenigen früher polizeilichen, jetzt 
Ordnungsangelegenheiten, bei denen die Geiahrenbekämpfung hinter der vorsorgenden Gestaltung zurücktritt, (z. B. Bau-, Gesundheits-, Gewerbewesen) und deren Uberlassung an die kommunalen Selbstverwaltungsverbände;

2. Polizei-(Sicherheits) Verwaltung durch zentralisierte Informationsstellen und staatliche Polizeieinheiten zur Bekämpfung von Tumulten und anderen überörtlichen oder speziellen Getahren,

sowie unter Einflußmöglichkeiten der Kreise und kreisfreien Städte durch dekonzentrierte staatliche Kreis- und Stadtpolizeieinheiten zur Beobachtung des öffentlichen Lebens auf und an der Straße, zur Straßenverkehrsregelung, zum ersten Zugriff, zur Anwendung unmittelbaren Zwangs gegen Personen und zur Strafverfolgung mit der Pflicht, mit diesen Mitteln den anderen Behörden - wie der Staatsanwaltschaft - Beistand zu leisten, nebst einigen damit unmittelbar zusammenhängenden Verwaltungsgeschäften (z. B. ehem. Wegepolizei) ohne Polizeiverordnungsrecht;

3. Ordnungsverwaltung in staatlichem Auftrag oder kraft Organleihe durch kommunale Organe zur Abwehr aller übrigen Gefahren (erforderlichenfalls auch auf den spezialgesetzlich geregelten Gebieten) im Aktenbetrieb und durch eigenè sachlich spezialisierte Kontrollund Exekutivbeamte ohne Zwangsrecht unmittelbar gegen Personen. Verordnungsrecht der Kreis- und Stadträte, der Regierungspräsidenten mit BeschluBausschuB und der Minister mit LandtagsausschuB.

d) 1. Der Polizei- und der Ordnungsverwaltung muB eine Ge neralermächtigung nach Art des \$ 14 prPVG und die Befugnis zur Ersatzvornahme, zu unmittelbarem Zwang gegen Sachen sowie zur Androhung und Festsetzung von $Z$ wangsgeld erteilt werden.

2. Polizei- und Ordnungswidrigkeiten sollten nicht mit Strafsanktion, sondern mit Beugesanktion versehen sein. Solange das nicht durchgeführt ist, sollten die Verwaltungs- einschl. der Polizeibehörden Strafverfügungen erlassen dürfen, die auf Antrag gerichtlicher Prüfung unterliegen. 


\section{Die Gestaltung des Polizei- und Ordnungsrechts in den Ländern der amerikanischen und französischen Besatzungszone}

2. Mitbericht von Professor Dr. Otto Gönnenwein, Heidelberg.

I.

Das Polizeirecht der amerikanischen und französischen Zone $^{1}$ ) und innerhalb der französischen Zone das Recht der drei Länder dieser Zone hat sich gründlich auseinander entwickelt. Eine formelle Rechtseinheit ist nur für die Länder der amerikanischen Zone festzustellen. Das ganze hier zu behandelndeGebiet kannte bei aller partikularen Besonderheit bis 1933 einen gemeinsamen Polizeibegriff, der gebildet war durch die Schranken, die $\S 10$ II 17 des Preuß. Allg. Landrechts den Polizeibehorden gesteckt hatte. Die Einrichtungen der zentralistisch verwalteten Deutschen Polizei, die ein Werkzeug des totalen Staates geworden war, wurde mit dem Einmarsch der alliierten Armeen vernichtet. Die neuen Polizeigewalten, die zuerst ganz bei den Militärregierungen lagen, und die dann - zunächst noch unter straffer Beaufsichtigung durch die Militärregierungen - auf die neugebildeten Länder übergingen, wurden unter den drei Gesichtspunkten der Denazifizierung, Demilitarisierung und Dezentralisierung errichtet. Ausgangspunkt für die Organisation der Polizei war nicht der Zustand vor 1933 und nicht der des nationalsozialistischen Regimes, sondern die unmittelbar nach der Besetzung getroffenen Not- und Ubergangslösungen, die wegen Fehlens einer Landesstaatsgewalt unverbunden nebeneinander stehende Gemeindepolizeien, dann auch allmählich Kreispolizeien gebracht hatten.

II.

Das gegenwärtige Polizei- und Ordnungsrecht der $L$ ä $n d$ e $r$ der a merikanischen $\mathrm{Z}$ one hat seinen Ursprung in Anordnungen der Militärregierung. Richtlinien des Hauptquartiers der Streitkräfte der Vereinigten Staaten über die Verwaltung

1) Wie im 1. Bericht wird auf $\mathrm{Hans}-\mathrm{H}$ u g o Pi o ch, Das Polizeirecht, verwiesen; dort ist die Mehrzahl der zu erwähnenden Rechtsquellen abgedrudkt. Seit Erstattung des Mitberichts ist noch ershienen: $R$ o b e r t $\mathrm{Ne} \mathrm{b}$ i $\mathrm{nger}$, Allgemeines Polizeirecht (Shaeffers GrundriB des Rechts und der Wirtschaft Abt. II, 29. Band, 3. Teil), Stuttgart-Düsseldorf 1951 . 
der Militärregierung in der US-Zone Deutschlands vom 7. Juli 1945 lösten die deutschen Polizei- und Feuerwehrverbände auch formell auf; nach bestimmten neuen Grundsätzen wurde eine neue Polizei gebildet. Die neue Polizei durfte keine richterlichen und gesetzgeberischen Funktionen ausüben. Demgemäß ist das $S \mathrm{t} r$ a f verf üg ung s r e c h t der Polizeibehörden aufgehoben worden; dieses Recht ist durch Gesetze der vier Länder auf die Amtsgerichte übergeleitet worden (Württemberg-Baden: Gesetz vom 20. November 1945, Reg.Bl. S. 1; Bayern: Gesetz vom 28. Januar 1946, Ges.u.VOBl. S. 54; Hessen: Gesetz vom 16. Mai 1946, Ges.u.VOBl. S. 164; Bremen: Gesetz vom 30. April 1947, Ges.Bl. S. 66). Bezüglich des Zwangsgeldes hat die Militärregierung Hessen in einem im Ges.u.VOBI. 1947 (S. 94) veröffentlichten Schreiben an den Ministerpräsidenten von Hessen den Standpunkt vertreten, eine Verfügung, die Zwangsgeld oder im Nichtbeitreibungsfalle Haft auferlege, vereitle nicht nur die Beseitigung des Polizeistaates, sondern verstoße gegen das Verbot der polizeilichen Befugnis, Strafen zu verhangen; die Richtigkeit der deutschen Rechtsauffassung, daß Zwangsgeld keine Strafe bedeute, sondern nur ein Mittel darstelle, den Betroffenen zu einem bestimmten Verhalten zu veranlassen, könne dahingestellt bleiben. In Württemberg-Baden galt es dagegen als unbestritten, daß die Landräte und Bürgermeister nach wie vor Ungehorsams- und Ungebührstrafen verhängen können.

Die in Reichs- oder Landesgesetzen enthaltene Ermächtigung der Polizeibehörden zum ErlaB von Poli z e i v e r or d n u ng e n wurde aufgehoben; in Württemberg-Baden erging ein Gesetz Nr. 23 über die Neuordnung des Polizeiverordnungsrechts vom 7. Februar 1946 (Reg.Bl. S. 40). Das Verordnungsrecht ging je nach dem Geltungsbereich einer Verordnung auf die Gemeinderäte, die Kreistage und den Landtag') über.

Der vorläufige Aufbau der Polizei erfolgte in den Ländern im Laufe der Jahre 1945/46. Nach verschiedenen Änderungen

2) Als Polizeiverordnungen im Sinne des Württ.-Bad. Ges. Nr. 23 sind nur diejenigen Rechtsverordnungen zu verstehen, die au g e $n$ e $\mathrm{e}$ ll e Ermachtigungea gestützt werden. Das Gesetz hat daber nur diejenigen Befugnisse auf den $L$ a $n d-$ $t$ a $g$ übertragen, die früher nach Art. 50 a-52 des Württ. und nach $\$ \$ 22,23$ des Bad. PolStGB den obersten Landesbehörden zustanden. Die in anderen Gesetzen enthaltenen Spezi a l e r m a chtigungen blieben unberüht. Durch das Württ.-Bad. Ges. Nr. 234 über Rechtsverordnungen auf Grund ehemaligen Reichsrechts vom 12. 11. 1947 (RegBl. S. 185) sind dazuhin Ermächtigungen, die der früheren Reichsregierung oder einem Reichsminister zustanden, der Landesregierung übertragen worden (zu vgl. auch Art. 129, Abs. 2 GG), ohne daß dabei die Ermähtigung zum ErlaB von Rechtsverordnungen, die die öffentliche Sicherheit und Ordnung betreffen, ausgenommen worden wären. Ein Gesetz Nr. 3020 vom 2. 8. 1951 (RegB1. S. 63) muBte dies durch die folgende Bestimmung karstellen: .Die gesetzliche Ermăchtigung dar Landesregierung oder einer obersten Landesbebörde zum ErlaB der zur Ausführung des Gesetzes erforderlichen Rechtsverordnungen bleibt auch dann bestehen, wenn die Rechtsverordnung die offentliche Sicherheit und Ordnung betrifft." Diese eine athentische Interpretation des Ges. Nr. 23 darstellende Bestimmung steht durchaus in Einklang mit Art. 86 der Württ.-Bad. Verfassung. 
der Grundsätze der Militärregierung brachte der vom öffentlichen Sicherheitswesen handelnde Titel 9 der Military Government Regulations vom 1. Februar 1946, jetzt in einer Fassung vom 22. Mai 1947, einen gewissen Abschluß der Einwirkungen der Militärregierung. Thnen zufolge wurde die Polizei nun in einer auf längere Dauer berechneten Form organisiert.

Die Richtlinien der amerikanischen Militärregie rung bedeuten wie in der britischen Zone eine Einschränkung der Funktionen, die mit dem Worte „Polizei“" bezeichnet werden dürfen. Nach Titel $9-400$ der Richtlinien sind Aufgaben dieser Polizei im engeren Sinne: Aufrechterhaltung von Ruhe und Ordnung, Durchführung der deutschen Strafgesetze und Strafbestimmungen, Durchführung der Gesetze und Befehle der alliierten Kontrollbehörden und der Militärregierungen und die Erfüllung solcher und anderer nicht mit diesen Bestimmungen in Widerspruch stehender Aufgaben, die den deutschen Polizeistellen auf Grund der deutschen Gesetzgebung übertragen sind. Was der neue Polizeibegriff erfassen will, das ergibt sich aus einem Zusammenhalt von 9-400 und 9-235. $9-400$ redet von maintaining law an order, enforcing German criminal law; 9-235 grenzt dann negativ ab: alles was nicht eingeschlossen ist in der polizeilichen Verantwortung für Schutz von Leben und Eigentum, für Friedensbewahrung, für Verbrechensverhinderung und -entdeckung muß aus der Tätigkeit der Polizeibehörden entfernt werden. Daß damit eine klare Aufspaltung möglich gewesen wäre, kann nicht behauptet werden. Praktisch herausgebildet hat sich folgendes: Zur Polizei gehört nur noch die unmittelbare, allgemeine Aufrechterhaltung von Ruhe und Ordnung sowie die Beseitigung akuter Gefahren durch Befehl und Zwang; es handelt sich also um die Sicherheitspolizei im engeren Sinne, die äuBerlich in Gestalt der uniformierten Schutzpolizei in Erscheinung tritt; hinzu kommt die Kriminalpolizei. Weil das Strafverfügungsrecht der Polizei genommen ist, spricht neben den Betätigungsformen des Befehls und des Zwanges die Anzeige an die Strafverfolgungsbehörden heute eine wesentliche Rolle.

Alle früheren, von der deutschen Polizei wahrgenommenen Aufgaben, die keinen un mit te l baren Zusammenhang mit dem Schutz von Leben und Eigentum, der Aufrechterhaltung der öffentlichen Ordnung, der Verhütung und Entdeckung von Straftaten stehen, wurden dem polizeilichen Tätigkeitsgebiet entzogen. Diese über den verengten Aufgabenkreis der Polizei hinausgehenden früheren Polizeiaufgaben dürfen von anderen geeigneten Behörden erfüllt werden; doch ist es untersagt, die Bezeichnung „Polizei“ für solche Funktionen oder ihre persön- 
lichen Träger zu benützen. Völlig verboten ist eine besondere Sicherheits- und Geheimpolizei (9-234).

Innerhalb des Gesamtgebietes der inneren Verwaltung soll gewissermaßen eine gegenseitige Hemmung von allgemeiner Verwaltung und Polizei stattfinden, die eine allzu starke Machtentwicklung der Polizei verhindert. Es bestehen $\mathbf{z}$ w e i Polizeiorganisationen, die weithin gegeneinander abgekapselt sind. Der abgetrennte Teil des früheren materiellen Polizeibegriffs verhält sich aber zum eingeengten neuen Polizeibegriff nicht wie Anordnung und gebundene Ausführung. Wäre dem so, dann wäre die neue Polizei ein Arm, der von keinem Kopf mehr gelenkt wird. Die Polizei soll aber nach dem Willen der Besatzungsmacht aus eigenem Antrieb tätig werden; sie soll innerhalb ihres Wirkungsbereiches vom Recht des ersten Angriffs Gebrauch machen; sie soll dabei unabhängig') von der allgemeinen inneren Verwaltung sein. Andererseits dient auch die Verwaltungspolizei der Ordnungsbewahrung und Gefahrenabwendung. Zu ihrem Bereich - die amerikanischen Richtlinien üherschreiben 9-235 selber mit dem Wort „Verwaltungspolizei" - gehört vor allem die fördernde Tätigkeit zur Aufrechterhaltung der Ordnung und Sicherheit auf bestimmten Lebensgebieten; sie wird tätig vor allem in der Form des Verwaltungsaktes; gedacht ist an das Gewerberecht, das Baurecht und das Gesundheitswesen, dann an das $\mathrm{PaB}$ - und Meldewesen, die Fremdenaufsicht und das Verkehrswesen (Führerscheinerteilung). Die Verwaltungspolizei ist bei den seitherigen staatlichen und kommunalen Behörden geblieben.

Organisatorisch hat $(9-211)$ jede Gemeinde mit mehr als 5000 Einwohnern eine gesonderte Gemeindepolizeiabteilung (a unified municipal police department) als Glied der Gemeindeverwaltung') zu unterhalten; es steht ihr ein Polizeiverwalter vor. Dieser Polizeiverwalter hat alle polizeilichen Aufgaben im eingeschränktem Sinn innerhalb der Gemeinde wahrzunehmen. Jede Polizeibehörde stellt eine gesonderte Einheit dar; sie ist nur gegenüber der Verwaltungsbehörde, in deren Dienst sie steht, also Gemeinderat und Bürgermeister, verantwortlich, und darf nicht - hierin kommt der Gedanke der Dezentralisation besonders scharf zum Vorschein - der Befehlsgewalt oder Dienstaufsicht einer anderen Amtsstelle unterliegen. Die Gemeindebehörde trägt die volle verwaltungsmäßige Verantwor-

") Von amerikanischer Selte wird bei der ,independant police" an ein Gegenstad der richterlichen Unabhangigkeit gedacht; zu vgl. Stadtverwaltung und Polizei in den siddeutschen Landern, Bericht über eine Arbeitstagung des Instituts zur Förderung Sffentlicher Angelegenheiten, Frankfurt a. M. 1950, S. 38.

4) Titel 9-300 der Fassung von 1946 hatte den Bürgermelster als oberste Dienstaufsicht vorgesehen. 
tung für die Polizeiabteilung; sie ist Trägerin der Polizeiverwaltung und auch für Klagen gegen die Polizei passiv legitimiert. In Gemeinden, die keine selbständige Polizeiverwaltung einrichten (Gemeinden mit weniger als 5000 Einwohnern können im Falle ihrer Leistungsfähigkeit eine eigene Gemeindepolizei errichten), werden die polizeilichen Aufgaben von der Landespolizei erfüllt (9-212). Die Landespolizei ist nur der obersten Landesbehörde verantwortlich. Sie kann ihre Verantwortlichkeit an Regierungsbezirke oder Landkreisbehörden übertragen.

Diesen Richtlinien folgend sind die Polizeiverwaltungen in den Ländern der amerikanischen Zone mit nur geringen $\mathrm{Ab}-$ weichungen auf Grund von Verordnungen oder internen Erlässen der Regierungen aufgebaut worden. Eine gewisse Sonderstellung nimmt Bremen ein.

In den Gemeinden mit mindestens 5000 Einwohnern ist im allgemeinen ${ }^{5}$ ) eine Gemeindepolizei eingerichtet worden, für die der Bürgermeister die Verantwortung übernimmt, soweit nicht nach der Gemeindeverfassung (namentlich in haushaltrechtlicher Beziehung) die Zuständigkeit der Gemeindevertretung begründet ist. Die Gemeindeverwaltung hat die Pflicht, diese Polizeidienststellen einzurichten, zu versorgen und $\mathrm{zu}$ uniformieren; sie ernennt und entläßt auch die Beamten und Angestellten. Die Polizei steht im übrigen unter ihrem besonderen Leiter; sie bildet innerhalb der Verwaltung der Gemeinden eine besondere Einheit, das heißt, sie darf nicht mit Dienststellen der übrigen Gemeindeverwaltung verbunden werden. Im Interesse der Dezentralisation ist in 9-200 der amerikanischen Richtlinien angeordnet, daß die Polizeiverwaltung nur der Dienstaufsicht der Körperschaft, der sie dient, unterstellt sein darf. Sie muß frei sei von der Weisungsbefugnis anderer Behörden (free from command or supervision). $\mathrm{Da} \beta$ die Gemeindepolizei der Kommunalaufsicht, d. $h$. also einer Rechtskontrolle unterliegt, ist nicht zu bezweifeln. Das Wort supervision ist wohl mit „Dienstaufsicht" zu übersetzen.

Die Polizei darf nicht zur Bearbeitung von Aufgaben der Verwaltungspolizei herangezogen werden; dieses Verbot ist z. B. in Württemberg-Baden für das Einwohnermeldewesen, die Ausstellung von Kennkarten und einige andere Aufgaben besonders hervorgehoben.

Die früheren staatlichen Polizeiämter (Polizeidirektionen, Polizeipräsidien), in denen Verwaltungs- und Vollzugspolizei vereinigt waren, sind bei Neuaufbau der Polizei folgerichtig aufgelöst worden. Die Aufgaben der Verwaltungspolizei gingen

b) In Württemberg-Baden konnten sich Gemeinden bis zu 20000 Einwohnern der Landespolizei anschlieBen, hiervon ist vielfach Gebrauch gemacht worden. 
in den kreisangehörigen Städten auf die Landräte und Bürgermeister, in den Stadtkreisen auf die Oberbürgermeister über; sie sind dort häufig in besonderen Verwaltungsstellen, die den Namen „Amt für öffentliche Ordnung“ führen, zusammengefaßt.

In den Gemeinden ohne eigene Polizeiverwaltung werden die polizeilichen Aufgaben von der Landespolizei (in Bayern Landpolizei; in Hessen Landesgendarmerie) erfüllt; der Chef der Landespolizei (in Bayern Präsident der Landpolizei, in Württemberg-Baden der Landespolizeidirektor, in Hessen der Chef der Landesgendarmerie) untersteht dem Innenministerium. Die Untergliederung der Landespolizei ist der Verwaltungsorganisation des Landes, also den Regierungsbezirken und Kreisen, angepaßt. In Bayern stehen dabei den Regierungspräsidenten und Landräten kein Weisungsrecht gegenüber der Landpolizei ihres Bezirkes zu; sie haben nur ein Anforderungsrecht. Dieses Anforderungsrecht bewegt sich aber nur im Rahmen der eingeengten Polizeiaufgaben; der Landrat kann also die Polizei anfordern, wenn eine andere Gemeinde seines Kreises etwa bei Tumulten mit eigenen Kräften die öffentliche Ordnung nicht wiederherstellen kann. In Württemberg-Baden dagegen stehen den Landräten beim Vollzug ihrer v e r w a l$t$ ung s polizeilichen Aufgaben die Landespolizei und die Gemeindepolizei zur Verfügung (Erlaß des Innenministeriums vom 22. Dezember 1947, Amtsbl. 1948 S. 17). Die Landräte sind daher berechtigt, den Dienststellen der Landespolizei ihres Kreises die zum Vollzug ihrer Anordnungen verwaltungspolizeilichen Inhalts erforderlichen Weisungen zu erteilen. Auch die Bürgermeister der Gemeinden ohne Gemeindepolizei können der Landespolizei die für den Vollzug ihrer verwaltungspolizeilichen Anordnungen erforderlichen Weisungen geben. Die erwähnte Abkapselung der beiden Polizeisparten ist also in Württemberg-Baden wieder weithin beseitigt.

Bei jeder Gemeindepolizei und jeder Dienststelle der Landespolizei kann neben den Schutzpolizeieinheiten eine $\mathrm{krimi-}$ nalpolizeiliche Ermittlungsstelle gebildet werden. Diese muß aber Teil der Gemeindepolizei oder der landespolizeilichen Dienststelle sein; Sicherheits- und Kriminalpolizei müssen einen einheitlichen Leiter stellen.

Sonderpolizeibehörden sind vor allem die Wasserschutzpolizei (so in Hessen), die Bahnpolizei u. a., dann in Bayern die Landesgrenzpolizei; in Bremen erging am 11. Januar 1946 (GesBl. S. 11) eine Verordnung über die Verwaltung der Hafenpolizei. Diese Sonderpolizeibehörden sind nach den amerikanischen Richtlinien 9-214 zulässig. Sie müssen den allgemeinen Vorschriften für die Polizei entsprechen. 
III.

Die französische Militärregierung verzichtete auf allgemeine Richtlinien für die Neuordnung des Polizeiwesens in ihrer Zone; sie beschränkte sich auf die Beseitigung der nationalsozialistischen Gesetze und Verordnungen. Der Aufbau der Polizei in den Ländern der französischen Zone geschah daher uneinheitlich. Er war lediglich unter das gemeinsame Gebot der Denazifizierung, der Demilitarisierung und der Dezentralisierung gestellt.

Wür t t e m b e r g- Hoh en z oller n ging mit einer Rechtsanordnung über die Einrichtung einer Landespolizei vom 18. Januar 1946 (Amtsbl. S. 2) voran. Sie spricht in ihrem $\S 1$ aus, daß die gesamte Polizei des Landes verstaatlicht ist. Die Landespolizei hat ,für die Erhaltung der örfentlichen Ruhe, Ordnung und Sicherheit sowie für die Abwendung der Gefahren zu sorgen"; in ihre Zuständigkeit fällt auch die Uberwachung des Straßenverkehrs und die Ausübung der Grenzpolizei. Sie hat ferner die Aufgabe der Kriminalpolizei zu übernehmen.

Diese Aufgabenzuweisung enthält nichts anderes als den allgemeinen materiellen Polizeibegriff; sie läßt nicht ahnen, daß diese Landespolizei Polizei im anglo-amerikanschen Sinne ist, also nur der allgemeinen und unmittelbaren Ordnungsbewahrung und der Abwendung akuter Gefahren dient. Erst einem Rundschreiben der Landesdirektion des Innern und der Finanzen vom 25. September 1946 (Amtsbl. S. 19) ist zu entnehmen, daß die Funktionen der Polizei im oben erwähnten Umfange eingeengt sind.

Die Sicherheitspolizei im engeren Sinn und die Kriminalpolizei also sind verstaatlicht. Sie haben ihre Spitze in einer Landespolizeidirektion, unter der für die Gebiete der Kreise Oberpolizeikommissariate, und für einzelne Gemeinden oder Gruppen von Gemeinden, Landespolizeikommissariate gebildet wurden. Die sogenannte Verwaltungspolizei blieb bei den Landrats- und Bürgermeisterämtern. Die in einzelnen (durchweg kreisangehörigen) Städten nach der früheren Polizeiorganisation (Gesetz vom 16. Dezember 1921) gebildeten staatlichen Polizeiämter, deren Aufgabenkreis sich auf die Schutz- und Verwaltungspolizei erstreckte, wurde durch eine Rechtsanordnung vom 25. September 1946 (Amtsbl. S. 247) aufgelöst. Die sogenannte Verwaltungspolizei ging als Ordnungspolizei an die Bürgermeisterämter und Landratsämter über. Das Recht, Strafverfügungen zu erlassen, blieb bis zum Ergehen der neugefaßten Strafprozeßordnung gleichfalls bei den Behörden der allgemeinen Verwaltung, also den Landrats- und Bürgermeisterämtern. Die strengen Anforderungen an die Durchführung des 
Gewaltentrennungsprinzips sind also vom französischen Oberkommando nicht gestellt worden. Dagegen ist durch ein Rundschreiben bestimmt worden, daß der Ausdruck „Polizei“" ausschließlich für die Bezeichnung derjenigen Angelegenheiten vorbehalten bleibe, die in die Zuständigkeit der Landespolizei fallen.

Das Land Württemberg-Hohenzollern hat also, wie die Länder amerikanischen und britischen Zone die Funktionen der Polizei auf die Sicherheitspolizei im engeren Sinne beschränkt. Die Organisation der Polizei unterscheidet sich in diesem Lande von der amerikanischen Zone durch die keine Ausnahme zulassende Verstaatlichung und Zentralisierung der Sicherheitspolizei. Die Annäherung an die anglo-amerikanische Auffassung vom Polizeibegriff erfolgte nicht ganz ohne Mitwirkung der französischen Militärregierung, hauptsächlich aber von deutscher Seite her in dem Bestreben, die Rechtsgleichheit mit dem Landesbezirk Württemberg des Landes WürttembergBaden nicht völlig zu verlieren.

Wenig von den anglo-amerikanischen Vorstellungen beeinflußt, vielmehr weitgehend an die Organisation vor 1933 angelehnt ist das neue Polizeirecht des Landes Rheinland$P f$ a lz. Schon eine Rundverfügung des Oberregierungspräsidiums Hessen-Pfalz, das mit dem Oberpräsidium RheinlandHessen-Nassau am 30. August 1946 zum Lande Rheinland-Pfalz zusammengeschlossen wurde, und dessen Gebietsteile unmittelbar nach dem Einmarsch der Alliierten zum größten Teil unter der Herrschaft der amerikanischen Besatzungsmacht standen, vom 1. Oktober 1945 (Amtl. Mitteilung 1945, S.19) hatte die staatlichen Polizeiverwaltungen aufgelöst und angeordnet, daß eigene Ortspolizeidienststellen nur in Gemeinden mit mehr als 5000 Einwohnern eingerichtet werden dürfen. Bineweitere Rundverfügung vom 1. Oktober 1946 (Amtl. Mitteilung S. 555) gliederte die allgemeine Polizei in Ordnungspolizei, Kriminalpolizeit, Gendarmerie, sowie Grenz- und Strompolizei. Die gleiche Gliederung übernahm dann eine Landesverordnung von Rheinland-Pfalz vom 14. Mai 1947 (Verordnungsbl. S. 142) für das ganze Land, eine Verengerung des materiellen Polizeibegriffs fand nicht statt; eine besondere Verwaltungspolizei wurde nicht a usgeschieden. Eine Ordnungspolizei darf grundsätzlich nur in Gemeinden mit mehr als 5000 Einwohnern eingerichtet werden. Es können aber staatliche Ortspolizeibehörden an die Stelle der Gemeindepolizeibehörden treten. Hiervon ist für die Städte mit mehr als 10000 Einwohnern Gebrauch gemacht worden. Die Aufsichtsbehörden können den Polizeiämtern, und zwar auch den kommunalen, Weisungen erteilen. 
Daß das französische Oberkommando auch noch anderen Lösungen der Polizeifrage zuzustimmen bereit war, beweist das Recht $B$ a dens. Ein nicht veröffentlichter Runderlaß vom 23. März 1946 (Nr. 807) hat die Ortspolizei in den beiden Stadtkreisen Freiburg und Baden-Baden sowie in drei, später vier kreisangehörigen Städten auf das Land übertragen. Die Verwaltung dieser verstaatlichten Ortspolizei wurde in den beiden Stadtkreisen Polizeidirektionen, in den kreisangehörigen Städten, alter badischer Tadition entsprechend, den Landratsämtern übertragen; ausgenommen von dieser verstaatlichten Ortspolizei wurde in den beiden Stadtkreisen die Bau- und Feuerpolizei, die den Stadtverwaltungen als Auftragsangelegenheiten verblieben, in den anderen Städten mit verstaatlichter Polizei die Feld- und Gemarkungspolizei. Die staatlichen Ortspolizeiverwaltungen umfassen in Baden nach wie vor die Verwaltungs- und Sicherheitspolizei im hergebrachten Sinne; irgendeine organisatorische Trennung ist nicht vorgesehen. Die Polizeidirektionen sind staatliche Verwaltungsbehörden.

In den größeren Gemeinden mit nicht verstaatlichter Polizei wird die Sicherheitspolizei durch eine kommunale Schutzpolizei ausgeübt, die allerdings stark eingeschränkt werden soll ${ }^{\natural}$ ), in den kleineren Gemeinden durch die Gendarmerie. Die Schutzpolizei, sowohl der Gemeinden wie der staatlichen Ortspolizeiverwaltungen, ist seit einem Runderla $\beta$ vom 28 . Februar 1950 in 5Schutzpolizeidistrikten zusammengefaßt. Die Distriktsführer haben die allgemeine Dienstaufsicht über die ihnen unterstellten Einheiten. Doch sind die Landräte und die. Polizeidirektoren die gesamtverantwortlichen Leiter der Polizei innerhalb ihres Verwaltungsbezirkes. Sie sind die Dienstvorgesetzten aller Polizeibeamten ihres Bezirkes, die Landräte also sowohl der Schutzpolizei als auch der Gendarmerie und der Kriminalpolizei. Nur die drei Gendarmeriedistriktsführer unterstehen unmittelbar dem Innenminister.

IV.

Das heutige Polizeirecht ist zum größten Teil Landesrecht; auf die Rechtssätze des Bundes (Art. 87 Abs. 1 und 91 des Grundgesetzes) hat der Herr Vorredner hingewiesen.

Die Ermächtigungen zum Eingreifen der Polizei ${ }^{7}$ ) sind in den alten allgemeinen Polizeigesetzen der früheren Länder enthalten; es handelt sich bekanntlich teils um General-, teils um

7) MaBgebend ist eine Note der Direction de la Sureté, derzufolge eine Gemeindeschutzpolizei zunächst nur für 35 Gemeinden genehmigt wurde.

7) Dazu jetzt: Der polizeiliche Eingriff in Freibeiten und $R$ e chte, bearb. von Horst Blomeyer-Bartenstein, Günter Olzog u. a. unter der Leitung von Erich Kaufmann (Wissenschaftliche Schriften des Instituts zur Förderung offentlidier Angelegenheiten in Frankfurt a. M.), Frankfurt a. M. 1951. 
Spezialermächtigungen. So gilt beispielsweise nach wie vor die Generalermächtigung des $\S 30$ des Bad. Pol. St.G.B. als Grundlage für polizeiliche Maßnahmen, im ehemaligen Land HessenDarmstadt Art. $129 \mathrm{~b}$ der Städteordnung und Art. 64 der Kreisund Provinzialordnung, in den ehemals preußischen Gebieten der heutigen Länder Hessen, Rheinland-Pfalz und WürttembergHoherizollern der $\S 14$ des Preuß. Pol. Verwaltungsgesetzes von 1931. In Württemberg hat man seit langem bezüglich der Rechtsgrundlage polizeilichen Einschreitens zu vorkonstitutionellen Ermächtigungen Zuflucht genommen. Dazuhin gelten überall die Ermächtigungen zahlloser Reichs- und Landesgesetze des besonderen Polizeirechtes weiter.

Nicht zu vergessen ist die Schranke, die das Grundgesetz in Art. 104 Abs. 2 der Polizei gesetzt hat; die Polizei darf aus eigener Machtvollkommenheit niemanden länger als bis zum Ende des Tages nach dem Ergreifen im eigenen Gewahrsam halten.

Kurz erwähnt sei, daß die Bestimmungen der alten Polizeivarveltungsgesetze über den Aufbau und die Bezeichnung der Polizeibehörden, vor allem aber auch im Geltungsbereich der Verwaltungsgerichtsgesetze der amerikanischen, britischen und französischen Zone die Vorschriften über die Rechtsmittel außer Wirkung gesetzt sind.

Auch für das Polizei verordnungsrecht gelten, abgesehen vom Ubergang auf andere Stellen, die alten Ermächtigungen; im preußischen Rechtskreis, der noch Teile der heutigen Länder Hessen, Rheinland-Pfalz und Württemberg-Hohenzollern umfaßt, die Generalermächtigung, in den Gebieten der alten Länder Bayern, Württemberg und Baden Sonderermächtigungen, vor allem in den Polizeistrafgesetzbüchern. Das Württ.-Bad. Gesetz Nr. 23 über die Neuordnung des Polizeiverordnungsrechts vom 7. Februar 1946 verweist ausdrücklich auf die Artikel $50 \mathrm{a}-52$ des Württembergischen und die $\$ \S 22-23$ des Bad. Polizeistrafgesetzbuches als Rechtsgrundlage.

Unanwendbar geworden ist die Verordnung des Reichsministers des Innern über die Polizeiverordnungen der Reichsminister vom 14. November 1938 (RGBl. I S. 1582). Sie enthielt eine echte Generalermächtigung, deren Inhalt und Schranke sich aus dem materiellen Polizeibegriff ergab, und stützte sich auf das Gesetz über den Neuaufbau des Reichs vom 30. Januar 1934, war also nur im Einheitsstaat denkbar. Die Verordnung ist keine Rechtsvorschrift, die als Landesrecht fortgilt (Art. 129, Abs.2 GG); ihre Ermächtigung ist deshalb nicht auf die Landesminister übergegangen; für die Landesregierungen und Landesbehörden gelten vielmehr die alten General- und Spezialermächtigungen weiter. Die Bundesminister aber können aus 
der Verordnung vom 14. November 1938 keine Befugnisse ableiten, weil eine allgemeine Zuständigkeit des Bundes zur Aufrechterhaltung der öffentlichen Ordnung und Sicherheit nicht gegeben ist, die der konkurrierenden Gesetzgebung des Bundes unterliegenden Gebiete des materiellen Polizeirechtes (Art. 74 Ziff. 3, 4, 19, 20, 22; Art. 75 Ziff. 2, 3, 5 GG) aber nur auf Grund von Spezialermächtigungen der Gesetze im Verordnungswege geregelt werden können (Art. $80 \mathrm{GG}$ ).

V.

Die Frage, ob die Polizei $S t$ a ats a $u$ fga be oder Selb $\mathbf{~ t ~ - ~}$ verwaltungsangelegenheit ist, wurde im neuen Polizeirecht der amerikanischen und französischen Zone erneut von aktueller Bedeutung; vor allem in Bayern und Württemberg-Hohenzollern, wo in den Verfassungen der Versuch einer Umschreibung des eigenen Wirkungskreises der Gemeinden unternommen worden ist.

Nach Art. 83 Abs. 1 der Bayerischen Verfassung fällt in den eigenen Wirkungskreis der Gemeinden insbesondere auch die „örtliche Polizei“. Der mehrfach geäußerten Meinung, daß hier in dem Wort "Polizei“ noch der alte umfassende Begriff steckt, wird beizupflichten sein. Die Sicherheitspolizei hat in den Gemeinden mit mehr als 5000 Einwohnern nach den Richtlinien der amerikanischen Militärregierung ihre Tätigkeit als gesonderte Einheit innerhalb der Gemeindeverwaltung auszuüben; sie ist nur Gemeinderat und Bürgermeister verantwortlich und darf nicht der Befehlsgewalt einer anderen Amtsstelle unterliegen. Damit sind für die Gemeindepolizei in den Ländern der amerikanischen Zone die Merkmale des eigenen Wirkungskreises der Gemeinden gegeben. So ist jedenfalls die Auffassung in Bremen, auf dessen Polizeigesetz noch einzugehen sein wird. In Bayern wacht nach Artikel 83 Abs. 4 der Verfassung der Staat in Angelegenheiten des eigenen Wirkungskreises der Gemeinden über die Erfüllung der gesetzlichen Pflichten und Vorschriften. Die Gemeindepolizei erscheint daher auch im Hinblick auf diese Verfassungsbestimmung in Bayern als eine Angelegenheit des eigenen Wirkungskreises der Gemeinden. Die Tätigkeit der staatlichen Landpolizei in den kleinen Gemeinden widerspricht dem Artikel 83 Abs. 1 der Bayerischen Verfassung deshalb nicht, weil die Gemeinden nach Artikel 11 Abs. 2 der Verfassung nur das Recht haben, ihre Angelegenheiten i m $R$ ahmen der Gesetze selber zu verwalten. Bezüglich der Verwaltungspolizei dürfte Artikel 83 Abs. 1 gerade im Hinblick auf Artikel 11 Abs. 2 der Verfassung zur Zeit keine praktische Anwendbarkeit haben; die Verwaltungspolizei ist nach den Gesetzen Auftragsangelegenheit. 
Nach Art. 85 Abs. 1 der Verfassung von Wür $t$ temberg-Hohenzollern fallen in den eigenen Wirkungskreis der Gemeinden alle öffentlichen Aufgaben, die nicht nach gesetzlicher Vorschrift anderen Stellen ausdrücklich zugewiesen sind oder auf Grund gesetzlicher Vorschrift von anderen Stellen übernommen werden. $\mathrm{Zu}$ diesen Aufgaben gehört, genau wie in Bayern, u. a. auch die örtliche Polizei. Eine gesetzliche Vorschrift, die eine Angelegenheit des eigenen Wirkungskreises der Gemeinden einer anderen Stelle zuweist, ist u. a. auch $\S 1$ der Rechtsordnung vom 18. Januar 1946 (Amtsbl. S. 2), der bestimmt: „Die gesamte Polizei wird verstaatlicht.“ Ob der Verfassungsgeber mit den Worten „örtliche Polizei" schon den verengerten Polizeibegriff im Auge hatte, ist daher unwesentlich. Dagegen kann sich $\S 57$ der Württ.-Hohenz. Gemeindeordnung vom 14. März 1947, demzufolge die Ortspolizei vom Bürgermeister nach den gesetzlichen Vorschriften verwaltet wird, nur auf die Verwaltungspolize1 beziehen, denn die Sicherheitspolizei ist ja ausnahmslos verstaatlicht. Die Ubertragung der verwaltungspolizeilichen Aufgaben der aufgelösten staatlichen Polizeiämter war am 25. September 1946 an die Bürgermeisterämter, nicht an die Gemeinden erfolgt; es liegt also eine Organleihe vor, die den Bestimmungen der Gemeindeordnung entspricht.

Ähnlich ist auszulegen die Bestimmung des $\S 46$ der GO von $R$ heinland-P $f$ a l z vom 27. September 1948, die zeitlich nach der Landesverordnung über die Verstaatlichung und den Aufbau der Polizei vom 14. Mai 1947 (Verordn.Bl. S. 142) ergangen ist. Nach der GO hat der Bürgermeister, soweit nicht ein besonderer Beamter bestellt ist, die ordentlichen Geschäfte der allgemeinen Staatsverwaltung, insbesondere die Ortspolizei zu handhaben. Die Polizei ist aber nach $\S 1$ der erwähnten Landesordnung Angelegenheit des Staates. Die Vorschrift der GO kann sich daher nur auf die Verwaltungspolizei als Auftragsangelegenheit und auf die Sicherheitspolizei in den Gemeinden über 5000 Einwohner beziehen, die nach $\S 9$ der Landesverordnung eine eigene Ordnungspolizei als Auftragsangelegenheit eingerichtet haben. Die Gemeindeordnung ergänzt also die Landesordnung, indem sie ein einzelnes $\mathrm{Ge}-$ meindeorgan, nicht die Gemeinde selber, zum Träger der Auftragsverwaltung auf polizeilichem Gebiete macht.

Unkomplizierter ist $\S 2$ Abs. 5 der Badischen Gemeindeordnung vom 23. September 1948, der es bezüglich der Polizeiverwaltung der Gemeinden bis zu einer anderweitigen Regelung bei den bisherigen Vorschriften beläßt.

Das Bremische Gesetz über die Rechtsverhältnisse der Polizei vom 2. August 1947 (Ges.Bl. S. 128) macht in seinem 81 die Polizei zur Selbstverwaltungsangelegenheit der Stadt- 
gemeinden Bremen und Bremerhaven. Die beiden Stadtgemeinden üben in ihrem Gebiet die Aufgaben der Polizei aus, sie unterhalten die erforderlichen Polizeikräfte und erlassen die polizeilichen Gesetze und Verordnungen nach Maßgabe der Gemeindeverfassungen. Daß die Sicherheitspolizei im engeren Sinne gemeint ist, kann bei der Zugehörigkeit der Hansestadt Bremen zur amerikanischen Zone nicht zweifelhaft sein; Titel 9 der Regulations war anzuwenden ${ }^{\mathbf{b}}$ ). Die Polizei in den beiden Städten ist den Richtlinien der Militärregierung entsprechend errichtet und wurde daher angesichts ihrer Unabhängigkeit von staatlichen Stellen zur Selbstverwaltungsangelegenheit erklärt.

Verstaatlichung und Kommunalisierung der Polizei überkreuzten sich in der jüngsten Vergangenheit in merkwürdigster Weise. Während in der Zeit vor 1933 in Süddeutschland die Polizei, mochte man sie zum eigenen oder übertragenen Aufgabenkreis der Gemeinden rechnen, nur in den größeren Städten - man ging bis zu einer Einwohnerzahl von 10000 herunter - durch staatliche Behörden verwaltet wurde, haben in der amerikanischen Zone jetzt gerade die größeren Gemeinwesen Recht und Pflicht zur Errichtung einer Gemeindepolizei, während die kleinen Gemeinden - hierin folgt die neue Entwicklung dem nationalsozialistischen Polizeirecht - von staatlichen Polizeistellen betreut werden. In der französischen Zone folgt Baden ganz und Rheinland-Pfalz teilweise dem alten Recht, in dem in den ganz kleinen und in größeren Gemeinden Staatspolizei besteht.

Wo, wie in Württemberg-Hohenzollern, die Sicherheitspolizei ausnahmslos verstaatlicht ist, und wo die Landespolizei den Gemeinden eine Amtshilfe nur innerhalb des Rahmens ihrer verringerten Zuständigkeit leisten darf, sind Lücken in der Aufgabenerledigung entstanden, die den Ruf nach kommunaler Orstpolizei begreiflich erscheinen lassen. Man muß sich allerdings bei der Kritik vor Augen halten, daß auch nach altem Recht in Orten mit verstaatlichter Polizei die Amtshilfepflicht der Polizei gegenüber der Gemeindeverwaltung keine unbegrenzte war, sondern daß sie Botengänge und andere untergeordnete Verrichtungen ausschloß. Aber das spannungsreiche, dem Finanzausgleich zwischen Land und Gemeinden angehörige Thema der Polizeik osten wird durch die Entblößung der Gemeinden von Vollzugspolizeibeamten doch beschwert, weil solche Gemeinden zu Mehrausgaben für Amtsboten, größere Gemeinden auch zur zusätzlichen Anstellung besonderer Voll-

\footnotetext{
9) Nach Pioch a.a.O. S. 140 werden in einer Verwaltungsabteilung" des Polizeichefs von Bremen zahlreiche Angelegenheiten der Verwaltungspolizei (so GesundheitsLebensmittel- und Veterinărwesen) mitbehandelt; daneben gibt es aber .Ordnungsangelegenheiten", die auf Verwaltungsbehörden übergingen; es liegt also keineswegs der ganze Kreis der materiellen Polizeiangelegenheiten beim Polizeichef.
} 
zugsbeamter für die einzelnen Zweige der Verwaltungspolizei genötigt sind. Württemberg-Baden hat aus diesen Gründen die Kosten der Landespolizei in den kleinen Gemeinden im Finanzausgleichsgesetz ganz auf die Staatskasse übernommen; im übrigen erhalten in der amerikanischen Zone die Gemeinden mit Gemeindepolizei einen Polizeikostenzuschuß für ihre Polizeibeamten. Nach dem hessischen Gesetz zur Regelung der Polizeikosten vom 9. Juli 1949 (Ges. und Verordng.Bl. S. 87) bewegt sich dieser staatliche Zuschuß zwischen 2650 und 3000 DM für die besetzte Polizeivollzugsbeamtenstelle.

Die Aufgabe, die verfassungsmäßige Ordnung im Lande aufrecht zu halten, ist eine Funktion des $\mathrm{S} t \mathrm{a}$ a te $\mathrm{s}$. Das schlieBt nicht aus, daß die Gemeinde in einzelnen Bezirken ihres Wirkungskreises eigenständig die Aufgaben der nachbarlichen Friedenswahrung wahrnimmt. Ich erinnere an die Feld- und Gemarkungspolizei, auch Marktpolizei. Solche Aufgaben können ruhig zum eigenen Wirkungskreis der Gemeinden erklärt werden, und den Gemeinden muß es gestattet sein, unabhängig von der staatlichen Polizei für solche Zwecke uniformierte Vollzugsbeamte anzustellen.

Die Sicherheitspolizei im engeren Sinne muß aber in den Händen des Staates liegen; die Gemeinden haben, abgesehen von den Großstädten, nicht die Kraft, den technischen Apparat, der heute zur Aufrechterhaltung der Ordnung und Sicherheit und zur Gefahrenabwendung erforderlich ist, zu beschaffen und auf der nötigen Höhe zu halten; dazuhin treten die unerfreulichen Abhängigkeiten der Sicherheitspolizisten von politischen Mehrheiten in den Gemeindevertretungen. Wohl ist eine staatliche Sicherheitspolizei ein bedauerlicher Einbruch in die Einheit der örtlichen Verwaltung, zu der sich die neuen Gemeindeordnungen wieder durchweg bekennen; kommunalpolitisch betrachtet ist aber die Ubertragung der Verwaltungspolizei an die Gemeinden wieder ein Gewinn, der gerade in der Richtung der Herstellung einer Einheit der örtlichen Verwaltung liegt.

Auf alle Fälle ist es eine auf die Dauer nicht erträgliche Systemlosigkeit, wenn in der amerikanischen Zone die Aufrechterhaltung der öffentlichen Ordnung und Sicherheit als Staatsaufgabe in den kleinen Gemeinden durch staatliche Organe und in den Gemeinden von 5000 Einwohnern an durch Gemeindebeamte wahrgenommen wird. Das klare System der rein staatlichen Sicherheitspolizei in Württemberg-Hohenzollern, auch die in Rheinland-Pfalz gegebene Möglichkeit, in Gemeinden mit mehr als 10000 Einwohnern eine staatliche Sicherheitspolizei einzurichten, verdient den Vorzug. Die unglückliche Regelung der amerikanischen Zone ist aus Gründen der De- 
zentralisation, also aus politischen Gründen, erfolgt; man ging, wie ich eingangs bemerkte, viel zu sehr vom Zustande der ersten Notzeit nach dem Zusammenbruch des 3. Reiches aus; man wollte einem neuen Polizei- oder SS-Staat vorbeugen. Seit in unseren Tagen von einer einheitlichen Bereitschaftspolizei, die in irgendeiner Form dem Bunde unterstehen soll, geredet wird, sollten die Forderungen einer Dezentralisierung der örtlichen Sicherheitspolizei als überholt angesehen werden. In der Uberwindung der aus dem Mißtrauen geborenen Dezentralisation stehen wir bereits mitten drin.

VI.

Der alte verwaltungsrechtliche Begriff der Polizei ist mit der Verwirklichung der Richtlinien der amerikanischen Militärregierung nicht zerstört worden. Das polizeirechtliche Naturschutzgebiet Baden mit seinen staatlichen Polizeidirektionen im alten Sinne zeigt, daß der Weltfriede nicht gefährdet wird, wenn die Aufgaben der Ordnungs- und Sicherheitspolizei in einer Behörde vereinigt sind. Der alte materielle Polizeibegriff muß auch in der amerikanischen und französischen Zone aufrechterhalten werden, weil zahlreiche noch anwendbare Gesetze und Verordnungen nur diesen Begriff kennen. Im übrigen erhebt sich die alte Frage, was der Polizeibegriff für die Verwaltungsrechtswissenschaft überhaupt zu leisten vermag; es ist mit Otto Mayer daran festzuhalten, daß die Polizei eine besondere Art der inneren Verwaltung darstellt. Wer aus Abneigung gegen Generalklauseln die heutige Trennung als eine Verwirklichung der Forderungen des Rechtsstaates empfindet, täuscht sich. Vorhandene Generalklauseln für polizeiliches Einschreiten decken nötigenfalls auch Maßnahmen der Verwaltungspolizei, wenngleich die Verwaltungspolizei in ungleich höherem Maße als die Sicherheitspolizei mit Einzelermächtigungen arbeiten kann.

Die Polizeifrage der amerikanischen Richtlinien ist $\mathrm{nicht}$ $\mathrm{n}$ u $\mathrm{r}$ ein Wortstreit. Sie ist es allerdings a $\mathrm{u} \mathrm{ch}^{\mathrm{\rho}}$ ). Wenn Titel 9-235 der Richtlinien im englischen Text als therschrift das deutsche Wort „Verwaltungspolizei" verwendet, hätten keine Bedenken dagegen bestehen dürfen, im amtlichen deutschen Sprachgebrauch dieses Wort als Aufgaben- und Behördenbezeichnung zuzulassen. Das verkrampfte Suchen nach Bezeichnungen, die das Wort Polizei vermeiden, führte zu den unglücklichen Wortbildungen wie "Ordnungsrecht" und "Amt für öffentliche Ordnung". Nach dem Kennzeichen der "Ordnung"

- Dazu: Fritz Gut, Polizei oder Recht der öffentlichen Ordnung und Sicherbeit, Die Offentliche Verwaltung, 1949, S. $463 \mathrm{ff}$. 
läßt sich Sicherheitspolizei und Verwaltungspolizei nicht voneinander scheiden.

Die Durchführung der amerikanischen Richtlinien hat Änderungen im Behördenaufbau mit sich gebracht; sie hat getrennt, was früher als notwendigerweise zusammengehörend betrachtet wurce. Aber man darf nicht vergessen, da $B$ auch in der früheren Polizeiorganisation niemals alle polizeilichen Funktionen in einer staatlichen oder kommunalen Polizeibehörde vereinigt gewesen sind. Auch in Städten mit verstaatlichter Polizei mußte eine Zuständigkeitsabgrenzung zwischen Polizeiverwalter und Oberbürgermeister stattfinden. Die ganze Entwicklung ging eher auf die Rückübertragung von Polizeiaufgaben auf die Gemeinden als auf Vermehrung der Zuständigkeit der staatlichen Polizeiämter.

Im übrigen gebe ich dem Herrn Vorredner völlig recht, wenn er meint, daß einzelne Zweige der Verwaltungspolizei, namentlich soweit sie gesetzlich abschließend geregelt sind, endgültig entpolizeilicht und der allgemeinen Verwaltung zugeschlagen werden sollten. Ich erinnere hauptsächlich an die Baupolizei, bei der die Aufrechterhaltung der öffentlichen Sicherheit und die Gefahrenabwendung gegenüber den Gesichtspunkten der Stadtplanung und der Entwicklung eines Städtebildes, also gegenüber ästhetischen Werten, ziemlich in den Hintergrund getreten sind. Auch Wasser-, Jagd- und Fischereipolizei geben hierfür geeignete Beispiele.

Die Ubertragung des Polizeiverordnungsrechtes auf die Vertretungsorgane der Gemeinden und der Kreise wird eine dauernde Einrichtung bleiben müssen.

Die polizeirechtliche Entwicklung der zurückliegenden fünf Jahre hat in der amerikanischen und französischen Zone manche Verschlechterung gebracht, sie hat aber nichts zerschlagen, was nicht auf einfache Weise wieder zusammengebracht werden könnte, um eine Polizei mit allen Durchsetzungsmöglichkeiten zu schaffen. Was not tut, ist die Ausstattung der Polizei mit einem technisch vollkommenen Apparat und die Beseitigung einer die Gefahrenabwendung im großen unmöglich machenden Dezentralisation. Den Fordorungen des Rechsstaates ist mit der Möglichkeit der Anftintungsklage gegen Polizei- und Ordnungsverwaltungsakte Rechnung getragen. Wo eine Generalklausel für polizeiliches Einschreiten gegeben ist, steht ihr die Generalklausel der Verwaltungsgerichtsgesetze (gegebenenfalls ergänzt durch Art. 19, Abs. 4 des Grundgesetzes) gegenüber. Die deutsche Polizeifrage der Gegenwart ist in erster Linie eine Organisationsfrage; sie kann zur Schicksalsfrage für die Bundesrepublik werden. 


\section{Leitsätze des Mitberichterstatters über dieGestaltung des Polizei- und Ordnungsrechts in den Ländern deramerikanischen und französischen Besatzungszone}

1. In den sämtlichen Gebieten der heutigen Länder der amerikanischen und französischen Besatzungszone war vor 1933 der materielle Polizeibegriff des $\$ 10$ II 17 des PreuB. Allg. Landrechts anerkannt. Die Neuordnung des formellen Polizeirechts erfolgte unter den obersten Gesichtspunkten der Denazifizierung, Demilitarisierung und Dezentralisierung.

2. Die amerikanische Militärregierung hat tiefgreifende Anderungen im Recht und in der Organisation der Polizei angeordnet.

a) Sie hat vor allem der Polizei jede gesetzgeberische und richterliche Tätigkeit untersagt. Infolgedessen ist das Recht, Polizeiverordnungen zu erlassen, auf die Gemeinderäte und Kreistage übergegangen; das Strafverfügungsrecht wurde auf die Amtsgerichte übergeleitet.

b) Innerhalb der inneren Verwaltung sind nur die Funktionen der unmittelbaren Ordnungs- und Sicherheitsbewahrung und des kriminellen Ermittlungsverfahrens unter der Bezeichnung

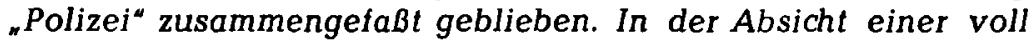
wirksamen Dezentralisation sind in Gemeinden mit mindestens 5000 Einwohnern als besondere Verwaltungseinheiten Polizeiabteilungen gebildet worden, die unter der Leitung eines Chefs in Tätigkeit treten, aber den Gemeindeorganen verantwortlich sind und somit nicht außerhalb der Gemeindeverwaltung stehen. In den kleineren Gemeinden übt die Polizeigewalt eine Landespolizei aus, die unter der Verantwortung der obersten Landesbehörde einheitlich organisiert ist und sich in ihrer Gliederung der Einteilung der Länder in Bezirke und Kreise anpaBt.

c) Alle über die unmittelbare Ordnungs- und Sicherheitsbewahrung hinausgehenden, im alten deutschen Polizeibegriff liegenden Aufgaben, also vor allem die fördernden und vorbeugenden Funktionen der sog. Verwaltungspolizei dürfen nicht mehr mit dem Wort "Polizei" bezeichnet werden. Sie werden von den seitherigen kommunalen und staatlichen Behörden, sog. Ordnungsbehörden (kommunale Amter für öffentliche Ordnung) wahrgenommen.

3. Das Oberkommando der französischen Besatzungsmacht hat auf die Aufstellung einheitlicher Grundsätze für das neue Polizeirecht verzichtet.

a) In der organischen Trennung von Verwaltungs- und Sicherheitspolizei im engeren Sinne kommt das Land Württemberg-Hohenzollern den Verhältnissen in der amerikanischen Zone nahe. Die Sicherheitspolizei, die allein den Namen "Polizei" 
führen darf, ist aber durchweg staatlich. Die Verwaltungspolizei ist bei den Gemeindebehörden und Landratsämtern geblieben.

b) Ganz der Organisation der Zeit vor 1933 angenähert ist der Aufbau der Polizei in Rheinland-Pfalz. Dabei ist in diesem Lande die Möglichkeit gegeben, die Polizei in Gemeinden mit mehr als 10000 Einwohnern zu verstaatlichen. Sicherheitspolizei und Verwaltungspolizei sind vereinigt.

c) In Baden hat eine organische Trennung der Polizeifunktionen nach anglo-amerikanischem Vorbild nicht stattgefunden So sind namentlich die staatlichen Polizeidirektionen nach wie vor Behörden der inneren Staatsverwaltung, die ungetrennt die Verwaltungs- und Sicherheitspolizei ausüben.

4. Grundlage für Maßnahmen der Polizei- und Ordnungsbehörden ist das alte Recht, also entweder General- oder Spezialermächtigungen, wie sie $\$ 30$ Bad.Pol.St.G.B. und $\$ 14$ des PreuB. Pol.-Verwaltungsgesetzes, das in den früheren preußischen Gebietsteilen der neuen Länder noch gilt, enthalten sind, oder vorkonstitutionelle Befugnisse wie in Württemberg.

5. Das Verhältnis von Polizei und kommunaler Selbstverwaltung hat mannigfache Wandlungen erfahren. Zufolge der Richtlinien der amerikanischen Militärregierung, die die Gemeindepolizei nur den Organen der Gemeinde verantwortlich sein läßt, ist die Polizei in Gemeinden von mehr als 5000 Einwohnern zur Selbstverwaltungsaufgabe geworden. In den Ländern der französischen Zone, die auch eine Gemeindepolizei zulassen (Rheinland-Pfalz und Baden), gehört die Ausübung dieser Polizeigewalt zum übertragenen Wirkungskreis. Eine ausnahmslose Verstaatlichung ist in Württemberg-Hohenzollern, eine reine Kommunalisierung ist in Bremen durchgeführt.

6. Die eingeschränkte Anwendungsmöglichkeit des Wortes "Polizei" und die Verselbständigung der Sicherheitspolizei im engeren Sinne hat den deutschen Begriff der Polizei nicht zerstört. Er wird weiterhin noch benötigt, weil alle früheren Gesetze ihn noch voraussetzen, und weil auch die Ordnungsbehörden ihre Ermächtigung noch zum Teil aus den Generalklauseln zu entnehmen haben. Ein Aufgehen von Teilen der sog. Verwaltungspolizei, bei denen der Sicherheitsgedanke hinter anderen Zielen zurücktritt, in der allgemeinen inneren Verwaltung ist zu befürworten.

7. Die unter dem Gesichtspunkt der Dezentralisation erfolgte Einrichtung kleinster Polizeieinheiten in den Gemeinden der amerikanischen Zone ist als MiBgriff zu bezeichnen. Die Regelungen in Württemberg-Hohenzollern und Rheinland-Pfalz verdienen den Vorzug. Wenn schon die Sicherheitspolizei im engeren Sinne verselbständigt wird, muB offenbar werden, daB sie Staaisaufgabe ist. 


\title{
Die Gestaltung des Polizei- und Ordnungsrechts in den einzelnen Besatzungszonen
}

\author{
(3. Aussprache)
}

M i r b t - Halle ${ }^{1}$ ): Es soll versucht werden, das über die Entwicklung des Polizeirechts in der Bundesrepublik Dargelegte durch einige Bemerkungen über die Verhältnisse in der DDR zu ergänzen. Deren Eigenart gestattet freilich nicht, in der exakten Weise der heute früh gehörten Referate eine positivrechtliche Analyse zu geben. Dafür müssen andere Seiten des Polizeiproblems, die bei der betonten, ja überbetonten Rechtsstaatlichkeit des Westens dort keinen AnlaB zu kritischen und besorgten Fragen geben, erörtert werden, um so das Besondere der sowjetzonalen Entwicklung aufzeigen zu können. Sich über die polizeiliche Ordnung innerhalb der bisherigen Sowjetzone zu unterrichten, ist nicht ganz leicht. Es gibt zwar einige wenige Gesetze, es gibt Verordnungen, die man nicht kennt, denn sie sind nicht veröffentlicht; es gibt die „Neue Justiz“, die sich nicht nur mit Rechtsfragen beschäftigt, aber nichts über Polizeirecht bringt; wir haben die Zeitschrift „Demokratischer Aufbau", die sehr viel über Verwaltung und Verwaltungsrecht bringt, sich über die Polizei aber ausschweigt; die dritte in Betracht kommende Zeitschrift ist „Der Volkspolizist", im wesentlichen bestimmt zur politischen und spezialfachlichen Schulung der jungen Volkspolizisten; sie ist nicht ohne weiteres zugänglich. In allen diesen Blättern können wir über die Dinge, die uns als Juristen interessieren, eigentlich nichts lesen, höchstens manchmal zwischen den Zeilen. Schließlich haben wir auch nur sehr wenige für das Polizeirecht ergiebige Urteile, da die Verwaltungsgerichte eine sehr beschränkte Zuständigkeit haben. Es ist also nur in einer unbestimmten Weise möglich, die Verhältnisse in der Zone zu schildern.

Zunächst ist darauf hinzuweisen, daß ähnlich wie aus den Referaten, besonders von dem des Herrn Wolff, zu sehen war, auch im Gebiet der DDR der Polizeibegriff verändert ist. Jahrzehntelang stellte die Einbeziehung z. B. des Verkehrswesens,

\footnotetext{
1) Bel der Durchsicht des Stenogramms waren die fôr den Diskussionsbeitrag benutzten Aufzeichnungen mir nicht mehr zuglinglich, da ich Halle im November 1950 sehr eflig verlassen muBte. Mirbt.
} 
des Gewerbe-, Bau-, Gesundheitswesens in den Kreis der polizeilich überwachten Betätigung und die Herausarbeitung von Gefährdungstatbeständen den Weg dar, auf dem ein Tätigwerden der öffentlichen Gewalt überhaupt erst ermöglicht wurde. Die allgemeine Richtung einer zunehmenden Beschränkung der individuellen Handlungsfreiheit war erkennbar. Es wurde uns nun heute morgen sehr lebendig verdeutlicht, daß die stets an Gefährdungen anknüpfende polizeiliche Denkweise nicht mehr ausreicht, um den Ordnungsbedürfnissen zu genügen, welche sich aus den veränderten sozialen, wirtschaftlichen, technischen Lebensverhältnissen ergeben. Diese vielfältigen Ordnungsaufgaben sind von dem Begriff der öffentlichen Sicherheit her schon längst nicht mehr erfaßbar; sie haben sich verselbständigt, werden vielfach von eigenen $\mathrm{Be}-$ hörden wahrgenommen, so daß nunmehr wissenschaftlich und gesetzgeberisch die Rückkehr zu dem älteren Polizeibegriff erkennbar ist. Diese positiv gestaltende und nicht mehr einzelne Gefahren abwehrende Verwaltung hat mit der Polizei höchstens noch deren Durchsetzungsmittel gemein. Diese Veränderung, die ja schon 1914 beginnt - die letzte meines Wissens 1928 erschienene Neubearbeitung von Fleiners Verwaltungslehrbuch zeigt die Schwierigkeiten, welche dem systematischen Einbau dieser Wandlungen in das bisherige System entgegenstehen -, hat in der sowjetzonalen Entwicklung einen entschiedeneren Charakter. Das Anderssein wird grundsätzlich scharf betont. Die Grundsätze, welche von 1945 an den Aufbau der rekonstruierten Verwaltungskompetenz oder noch deutlicher gesagt, das Verhältnis der Verwaltung und des Staates zum Bürger bestimmt haben, gehen bewußt und eindeutig dahin, die liberalen Reste in der Bestimmung der Aufgabe der Obrigkeit zu beseitigen. Viele der Maßnahmen, mit denen so gewaltsam und gewaltig in die bisherige Wirtschafts- und Sozialordnung eingegriffen wurde, hätten durch Erweiterung der Polizeigewalt getroffen werden können, aber man hat diesen Weg nicht beschritten, hat den Umfang dessen, was die Polizei zu tun hat, vielmehr verengert. Auch die Polizei ist im wesentlichen auf Sicherheitspolizei, auf Gefahrenabwehr beschränkt. Man kann hinsichtlich des gegenwärtigen Verhältnisses von Polizei und Ordnungsverwaltung sagen, daß die Regelung, welche 1938 in einer Preußischen Verordnung über die Zuständigkeit der staatlichen Polizeiverwaltung vorgenommen worden ist, von größtem Einfluß auf die Kompetenzabgrenzung der beiden Verwaltungsgebiete gewesen ist. Eine eigentliche Regelung dieser neuartigen Abgrenzung gibt es nicht. Wir haben kein Gesetz, keine Verordnungen, sondern es sind das im Fluß befindliche Abgrenzungen zwischen den in 
Betracht kommenden Ministerien. Der Polizeiverwaltung sind aus diesem genannten Katalog bestimmte Gebiete vorbehalten, wie die echte Sicherheitspolizei, die Preisüberwachung, das ambulante Gewerbe, die Verkehrspolizei. Hier ist die Polizei als Polizeibehörde unmittelbar und allein tätig. Verwaltungspolizeiliche Angelegenheiten wie Bauwesen, Gesundheitswesen, Obdachangelegenheiten, Wohnungswesen, vor allem gewerbliche Angelegenheiten werden jetzt außerhalb des Bereiches der Polizei verwaltet. Die Polizei ist mit ihren Angelegenheiten völlig selbständig, hat ihren eigenen Instanzenzug und hat mit derjenigen Einrichtung, welche grundsätzlich nach dem Gesetz die Hauptstelle für die öffentliche Verwaltung sein soll, tatsächlich nichts zu tun. Diese Gestaltung ist rechtlich kaum erfaßbar. Denn nach den demokratischen Gemeinde- und Kreisordnungen (§4) übernehmen die Gemeinden bzw.Kreise als Selbstverwaltungsangelegenheiten auf wirtschaftlichem, sozialem und kulturellem Gebiet alle Aufgaben, die das Wohl der betreffenden Gemeinschaft zum Ziel haben. Nach dem gleichen $\S 4$ aber gehören zu den Selbstverwaltungsangelegenheiten auch die Aufrechterhaltung der öffentlichen Sicherheit und Ordnung im Verbandsgebiet, dies freilich im Rahmen der Weisungen der zuständigen übergeordneten Organe; danach erläßt die Gemeinde Ortspolizeivorschriften nach dem geltenden Bestimmungen und führt der Bürgermeister die Geschäfte der Ortspolizei. $\S 4$ ist, wie ohne weiteres erkennbar, in sich widerspruchsvoll. Er enthält einander nicht entsprechende Grundsätze. Zwar sind die Angelegenheiten der Ortspolizei als Selbstverwaltungsangelegenheiten bezeichnet, aber sie werden zugleich den tberwachungs- und Weisungsrechten der Landesregierung unterstellt. Diese an sich schon wegen ihrer inneren Gegensätzlichkeit bedenkliche gesetzliche Regelung, ist aber, wie auch in Werner Webers Schrift über den Verwaltungsaufbau schon angedeutet ist, in der tatsächlichen Entwicklung nicht beachtet worden. Die kommunale Polizeiverwaltung, deren Träger der Bürgermeister bzw. der Landrat war, ist beseitigt, und zwar nicht durch Gesetz, sondern durch Verwaltungsmaßnahmen, deren Form man nicht kennt. Es gibt keinerlei Kreis- und Gemeindepolizei mehr, sondern es ist entstanden eine von der Selbstverwaltung äußerlich völlig geschiedene Volkspolizei, welche als solche dem Minister des Inneren untersteht. Unter ihm stehen dann in den kreisfreien Städten die Volkspolizeipräsidenten, in den Landkreisen die Kreispolizeiämter, in den Gemeinden erforderlichenfalls Außenstellen. In welchem Umfang es neben dieser ordentlichen Volkspolizei noch Sonderformationen gibt, entzieht sich meiner Kenntnis. Inwieweit unter der Bezeichnung Wasser-, Eisenbahn- und 
Grenzpolizei noch etwas existiert, wei $\beta$ man im Westen besser als innerhalb der DDR. Daneben steht die Staatssicherheitspolizei, von der wir hier nicht sprechen wollen.

Das, was man bisher als Verwaltungspolizei bezeichnete, ist jetzt Sache der einzelnen Ämter innerhalb der kommunalen Organisation. Wenn man ein Blatt wie die "Amtlichen Mitteilungen für Halle" verfolgt, sieht man, wie die beiden Bereiche langsam auseinandergerückt sind. Die Gemeinde erläßt heute noch Polizeisatzungen; das sind dann Polizeiverordnungen im Sinne des jetzt nicht mehr als Polizei bezeichneten Verwaltungsbereiches. Wer auf diesem Gebiete verordnungsberechtigt ist, war zweifelhaft. Es nehmen die Gemeinden und die Kreise für ihre Vertretungskörperschaften dieses Recht für sich in Anspruch. Daneben erlassen die Minister für ihre einzelnen Fachgebiete Polizeiverordnungen, sich dabei manchmal zur Legalisierung auf das preußische Polizeiverwaltungsgesetz berufend. Vereinzelt ist auch das ministerielle Verordnungsrecht ausdrücklich anerkannt, so für Sachsen-Anhalt durch einen Lindtagsbeschluß.

Dieses Auseinanderwachsen ohne klare gesetzliche Regelung hat sich besonders stark im Bereich der Rechtsbehelfe ausgewirkt. Soweit es sich um Akte der Volkspolizei handelt, beschränken sie sich auf die Möglichkeit, Beschwenden einzureichen. Bei den jetzt den Kommunalverbänden zufallenden früheren Polizeiangelegenheiten ist die Regelung in den einzelnen Teilen der DDR noch verschieden. Sie ist davon abhängig, wie sich die Verwaltungsgerichtsbarkeit entwickelt hat. Die grundsätzliche Ablehnung der Generalklausel im Gebiet der DDR dürfte bekannt sein. Dasjenige Land, welches an letzter Stelle die Verwaltungsgerichtsbarkeit gesetzlich geregelt hat, ist Sachsen-Anhalt. In dem Gesetz von 1950 ist vorgesehen, daß die Zuständigkeit der Verwaltungsgerichte durch eine Verordnung der Landesregierung näher bestimmt wird, und nach dieser Verordnung kommen in Betracht Wasser- und Deichangelegenheiten, Fischerei, Bauaufsicht, Straßen- und Baufluchtliniengesetz, Jagdaufsicht, Streitigkeiten über §132 LVG und schließlich Gewerbeangelegenheiten, soweit sie nicht nach dem Gesetz vom 28. Juni 1947 zur Zuständigkeit anderer Behörden gehören. Ein solches Gesetz gibt es aber für SachsenAnhalt überhaupt nicht. Ich habe mich mehrfach bei den zuständigen Stellen danach erkundigt und schließlich festgestellt, daß dieses angebliche sächsisch-anhaltinische Gesetz in Wirklichkeit ein solches ist, welches unser Nachbar, der Freistaat Sachsen, erlassen hat und in welchem für diesen ein besonderer Ausschu $B$ für Gewerbeangelegenheiten besteht. Man hat in Sachsen-Anhalt inzwischen bemerkt, da $B$ die Sache nicht in 
Ordnung ist. Und so ist diese Verordnung zwar durch den Landtag genehmigt, aber noch nicht verkündet worden. Was zur Folge hat, daß die Verwaltungsgerichtsbarkeit in SachsenAnhalt auch weiterhin nicht funktioniert. - Soweit eine verwaltungsgerichtliche Zuständigkeit nicht existiert, gehen die Beschwerden nicht an die Vertretungskörperschaften, sondern an den jeweiligen Fachminister. Was dieser Zustand ungeklärter Kompetenzverhältnisse tatsächlich bedeutet, wird erkennbar, wenn wir die sonstige Struktur der Ostzone ein wenig betrachten. Sie ist wichtiger als Organisations- und Kompetenzfragen, aber juristisch schwer zu erfassen; denn die gesetzlichen Regelungen und das tatsächliche Verwaltungsleben klaffen auseinander.

Sehr umstritten ist zunächst die Frage nach dem Verhältnis von Gemeinde und Staat. Hier bestehen erhebliche Spannungen und Meinungsverschiedenheiten, die sich nicht mit schönen Worten beseitigen lassen. Es führt etwa der gegenwärtige Justizminister Fechner aus, daß im großen ja alle öffentlichen Angelegenheiten Selbstverwaltungsangelegenheiten des Volkes seien und die ganze dualistische Fragestellung überholt sei. Oder Zuckermann schreibt im „Demokratischen Aufbau", daß Gemeindefreiheit den EinfluB des amerikanischen Monopolkapitalismus stärke. Gegenüber solchen Gefahren, die der Selbstverwaltung von oben drohen, treten natürlich im Bereich der gemeindlichen Atmosphäre immer wieder starke anti-zentralistische Kräfte auf, welche Selbständigkeit der gemeindlichen Entschließungen sowohl bei der Vertretungskörperschaft wie auch bei den Stadträten fordern. Man muß sich freilich darüber klar sein, daß die Selbständigkeitsmöglichkeiten nach zwei Richtungen hin von vornherein beengt sind. Einmal sind umfassende Planungen nicht bloß auf wirtschaftlichem Gebiet undurchführbar, wenn die einzelnen öffentlichen Verwaltungsträger die Selbständigkeit des 19. Jahrhunderts behalten. Die andere Beschränkung ist mindestens ebenso wichtig wie die aus der allgemeinen Zielsetzung sich ergebende: Die ganze öffentliche Verwaltung steht unter der unmittelbaren Beeinflussung durch parteidisziplinär gebundene parteipolitische Kräfte. Sie machen sich überall auf das Deutlichste bemerkbar, nicht bloß in Vertretungskörperschaften. Vielmehr stehen neben diesen Einrichtungen wie die Ausschüsse der Nationalen Front, die sich ja nicht auf spezifisch politische Fragen beschränken, sondern in zunehmendem Maße für Verwaltungsaufgaben verwendet werden. Es sind ferner zu nennen die Massenorganisationen VVN, FDJ, FDGB, dann die "spon$\tan ^{\prime}$ entstandenen Volkskontrollausschüsse, vor allem die straff geleiteten staatlichen Kontrollkommissionen mit um- 
fassenden Befugnissen. Eine nähere Darlegung ist hier nicht möglich, aber es darf darauf hingewiesen werden: staatliche und nichtstaatliche Organisationsformen sind hier so stark und vielfältig miteinander verzahnt worden, daß sehr schwer zu sagen ist, wo die wirkliche Entscheidung fällt. Am einflußreichsten sind diese Organisationen da, wo Ermessensfragen mit all ihren Abstufungen von Bedeutung sind, insbesondere bei der gesamten Personalverwaltung. Angesichts der überall erkennbaren Einschränkung der individuellen Entscheidungsmöglichkeit und der Verantwortungsfreudigkeit der Funktionäre ist die letzlich maßgebliche Stelle sehr oft nicht diejenige, die äußerlich ihren Namen hergibt. Es haben daher horizontale und vertikale Zuständigkeitsfragen nicht das Gewicht wie im Westen.

Und dann ist selbstverständlich noch ein sehr ernstes Problem gegeben, an dem wegen seiner fundamentalen Bedeutung nicht vorübergegangen werden kann. Wir stehen vor einer sehr starken Aktivität, vor einem Streben nach Intensivierung aller Leiveriväuß3erungen der öffentlichen Gewalt. Wir haben andererseits eine geschriebene Verfassung, welche an zahlreichen Stellen eindeutig die öffentliche Gewalt, insbesondere die Exekutive bindet. Die erwähnte gesteigerte Aktivität aber ist sehr groß; es besteht daher die Gefahr, daß die Kraft des Gesetzes in ihrem vollen Wert, in ihrer Autonität gegenüber dem reinen Machtstreben der Verwaltung nicht voll beachtet wird. Wir können eindrucksvolle Formulierungen maßgebender Persönlichkeiten lesen, in denen Achtung vor dem Gesetz und strenges Rechtsbewußtsein immer wieder gefordert wird. Aber andererseits wird z. B. in einer Abhandlung über demokratische Gesetze durch einen Lehrer an der Verwaltungsakademie Forst Zinna herausgearbeitet, die alte Bindung der Exekutive an den gesetzgeberischen Willen des Parlaments habe den Zweck gehabt, zunächst die im Parlament dominierenden besitzbürgerlichen Einflüsse zu sichern, um damit ein möglichst schlagkräftiges Instrument gegen die Arbeiterklasse zu haben. Nunmehr sei aber durch die gesellschaftliche Entwicklung der früher notwendige Grundsatz der Gesetzmäßigkeit der Verwaltung überholt. Derartige Außerungen müssen sehr sorgfältig geprüft werden, und es ist nicht leicht, den letzthin wirklichen Sinn zu erfassen, zumal wenn man dann weiter liest, daß zwar jeder neuer Rechtssatz als echte Volksentscheidung zu werten ist, da $B$ alle staatlichen Organe zur unbedingten Achtung und Annahme verpflichtet sind, daß aber schließlich in dieser neuen Rechtsordnung der Verwaltung die Hauptsache der Aufbau, die Kontrolle und der Schutz der Wirtschaft usw. sei. Es dürfe diese neue demokratische Gesetzlichkeit nicht formal betrachtet wer- 
den, sondern erforderlich sei eine sinnvolle, aus verantwortungsvoller Denkart und verständnisvoller Einsicht in die ökonomischen und politischen Gesamtzusammenhänge heraus erfolgende Gesetzesanwendung. Und wenn man diese Worte genauer analysiert, so muß man doch zu dem Ergebnis kommen, daß die echte Achtung vor dem Gesetz als der Entscheidung des souveränen Volkes nicht gefordert wird. Aber: da das Gesetz Volksentscheidung ist, steht es über den Parteien und dem entsprechend heißt es auch in Artikel 3: Die im öffentlichen Dienst tätigen Personen sind Diener der Gesamtheit und nicht einer Partei. Zwischen der in dieser Weise präzisierten Stellung der Angestellten der öffentlichen Verwaltung und dem Verwaltungswege selbst besteht keine volle Harmonie. Es bestehen nur unzweifelhaft Spannungen. Die Gesetze enthalten eindeutige Bindungen der öffentlichen Gewalt. Die Verfassung legt dem, der innerhalb der öffentlichen Verwaltung tätig ist, Verpflichtungen auf. Sie beginnt mit den Worten, daß alle Maßnahmen der Staatsgewalt den Grundsätzen entsprechen müssen, die in der Verfassung zum Inhalt der Staatsgewalt erklärt sind. Widerstandsrecht und Grundrechte sind kraft der Verfassung geltendes Recht. Und so steht man immer wieder vor der Frage, in welchem Umfange diese nach 1945 formulierten Gesetze auch maßgebend sind für die Führung der Verwaltung selbst. Man kann nur die Hoffnung haben, daß die Stunde nicht zu fern ist, in welcher diese in der Verfassung der DDR so eindeutig und klar formulierten Grundsätze auch in ganz Deutschland die maßgebliche Richtschnur des Handelns sein werden. Das ist natürlich der heiße Wunsch aller derer, die unter dieser Verfassung leben. Und so werden Sie die Hoffnung verstehen, daß diese Verfassung, welche die Freiheit und die Rechte des Menschen verbürgt, einmal in ganz Deutschland gilt.

W a cke-Marburg: Das Bild, das Herr Kollege Mirbt in seinem Referat so anschaulich gezeichnet hat, möchte ich noch etwas von anderer Seite her beleuchten, das Bild nämlich vom Polizeirecht des sowjetisch besetzten Mitteldeutschland. Es sind dabei zwei Punkte, die ich hervorheben möchte, beide hängen mehr mit dem materiellen Polizeibegriff zusammen als mit dem formellen.

Frstens möchte ich betonen, was schon einmal hier anklang, daß der Bereich des Polizeirech ts immer kleiner wird. In diesen Ländern nun sieht man aufs deutlichste, wie die Gebiete hoheitlicher Eingriffe dem überkommenen Polizeirecht und seinen Garantien entfremdet werden. Im sowjetisch besetzten Mitteldeutschland ist dabei zunächst zu denken an 
den Geschäftskreis des früheren Generalstabschef der Roten Brigade in Spanien, des heutigen Ministers für den Staatssicherheitsdienst, mit seinen Dienststellen der ehemaligen Kriminalpolizei, Abteilung 5 (K 5); dort ist selbstverständlich für das normale Polizeirecht ebensowenig Raum wie seinerzeit in der entsprechenden Einrichtung des Dritten Reiches. Es kommen dann hinzu die vielen Arbeitsgebiete, in denen sich für uns der ganze dortige Staatsaufbau charakterisiert, Bereiche also, auf denen sich die permanente proletarische Revolution abspielt, der Vorgang der Homogenisierung der Gesellschaft, wie es Herr $S$ te i n i g e r einmal in Hamburg gesagt hat. Dazu gehört das uns bekannte Gebiet der Entnazifizierung, das dort ein Kampfmittel der Proletarisierung war; dann der große Bereich der Sequestrierungsbefehle 124/126 für die Industrie, und schließlich das Gebiet der Bodenreform. Als die Entnazifizierung als abgeschlossen bezeichnet wurde, kam der Befehl 202 mit der gleichen Zielsetzung. Für alle diese Gebiete hat man als Behörden besondere Ausschüsse eingesetzt, die als nichts anderes denn als spezielle Fachsowjets bezeichnet werden können, Kreiskommissionen und Landeskommissionen, die fast ausschließlich mit Angehörigen der SED und deren Gliederungen, unter Zuziehung einiger Mitglieder der sogenannten bürgerlichen Parteien besetzt wurden. Da z. B. nach Thüringischem Polizeirecht ( $\$ 32$ Landesverwaltungsordnung), entsprechend der Auffassung Otto M a y e r $\mathbf{s}$, die Polizei nur eine Seite jeder Verwaltungsbehörde darstellt, wären dies alles Verwaltungsgebiete gewesen, in denen das normale Polizeirecht hätte Platz greifen müssen.

Auf keinem dieser Bereiche obrigkeitlicher Staatseingriffe war es jedoch möglich, zu einem justitiablen Verfahren zu kommen. Ein einziges $\mathrm{Mal}$ ist es gelungen, eine Sache der Bodenreform vor ein oberes Gericht, das Thüringische Oberverwaltungsgericht, zu bringen, ein Fall, in welchem der Kläger, ein bekannter Züchter, auf Rückgabe seiner Domänen klagte mit der Behauptung, daß sie ihm auch nach dem Bodenreformgesetz zu Unrecht entzogen worden seien. Diese Gerichtsverhandlung war denkwürdig; der Leiter der Landeskommission für die Bodenreform, ein junger sogenannter Regierungsrat, dirigierte den Rechtsberater der Landeskommission, welcher allein sprach, einen ehemaligen Landgerichtsdirektor, der in dieser Kommission sein Gnadenbrot ißt - von einer solchen juristischen Berufsschande muß berichtet werden -, durch Zeichen. Dieser Jurist legte das Bodenreformgesetz z. B. so aus, daß er Flüchtlingen, die mit nichts anderem als einem Pferd nach Thüringen kamen, dieses Pferd fortnahm mit folgender Begründung: Du bist zwar kein Grundbesitzer, aber Dein Onkel war 
einer, von dem Du das Pferd geerbt hast; der Grundbesitz, auf dem das Pferd arbeitete, lag zwar nicht in Thüringen, wo das Bodenreformgesetz allein gilt, er lag auch nicht einmal in der Ostzone, sondern in Schlesien; aber wenn er in Thüringen gelegen hätte, oder wenn das Gesetz in Schlesien gegolten hätte, dann wäre das Pferd Inventar dieses Gutes gewesen und wäre mit diesem dortigen Gute in die Bodenreform gezogen worden; also wird Dir das Pferd auch hier auf Grund des thüringischen Bodenreformgesetzes enteignet. Unter dem Druck derartiger Auffassungen ist auch das Thüringische Oberverwaltungsgericht einer materiellen Entscheidung ausgewichen und hat den Rechtsstreit wegen Unzulässigkeit des Verwaltungsrechtswegs abschlägig entschieden, man kann die Entscheidung heute in seinem Jahrbuch Band 18 nachlesen. Es war vielleicht gut so, denn das Gericht wäre fortgefegt worden, wenn es anders gehandelt hätte. Auf allen Arbeitsgebieten dieser speziellen Sowjets war also jede richterliche Nachprüfung der Staatseingriffe unmöglich.

Auf der anderen Seite, es ist dies das Zweite, das ich hervorheben möchte, ist die rechtliche Umschreibung der Polizei, der Polizeibegriff, noch die gleiche wie bisher und wie in Westdeutschland. Unbestrittenermaßen gilt das Preußische Polizeiverwaltungsgesetz auch dort weiter, so in Ostberlin und in Brandenburg, in der früheren Provinz Sachsen, in Rest-Schlesien und in Rest-Pommern; aber auch in dem ehemaligen Königreich Sachsen und in Mecklenburg und Anhalt, wo der Polizeibegriff gewohnheitsrechtlich aus der klassischen Formulierung des $\S 10$ II 17 ALR abgeleitet wird. Derselbe Polizeibegriff gilt auch in Thüringen in den in mehrfacher Beziehung vorbildlichen Vorschriften der $\S 32 \mathrm{ff}$. der LVO; diese Vorschriften sind nach 1945 aufrechterhalten worden. L o ening, der damals das Thüringische Gesetzgebungsamt leitete, hat sich im Herbst 1945 in geschickter Weise - so machte man ja damals Gesetze - durch die Unterschrift seines daInaligen Landesvaters $\mathrm{Pa}$ ul die Landesverwaltungsordnung neu fassen lassen; dabei blieb aber das ganze Polizeirecht unverändert. Das Thüringische OVG hat in der Folgezeit, solange es in alter Form bestand, den Polizeibegriff auf überlieferter Grundlage weiter entwickelt, wenn auch hier wiederum auffällt, wie gering die Zahl der polizeirechtlichen Entscheidungen ist. Im Herbst 1948 wurde dann die LVO weitgehend abgeändert durch thernahme des Verwaltungsgerichtsgesetzes nach dem Entwurf der SED, wie er in den anderen Ländern der Zone schon Gesetz geworden war. Aber auch hier sind - und das ist besonders bemerkenswert - die ganzen Bestimmungen des Polizeirechts, die die LVO über den Polizeibegriff, die 
Polizeiverordnungen, die Polizeiverfügungen, die Strafverfügungen enthält, völlig unverändert bestehen geblieben.

Noch immer gelten also die alten Worte vom Schutz der Allgemeinheit oder des Einzelnen vor Gefahren, durch die die öffentliche Ruhe, Sicherheit oder Ordnung bedroht wird. Das Recht lautet in seinen Worten genau so wie bei uns, aber welchen Inhalt hat es erlangt? Dieselben Begriffe, die hier den Rechtsstaat bauen helfen, dienen dort dazu, die sogenannte fortschrittliche Entwicklung im Sinne der proletarischen Revolution zu fördern, ein Vorgang, der uns Juristen mit gespenstischem Schauer erfüllen muß, und übrigens genau so auf den anderen Rechtsgebieten im Vergleich mit dem bolschewistischen Recht überhaupt zu beobachten ist. Die juristischen Begriffe versagen, die juristische Sprache versagt bisher, wenn es sich darum handelt, die Welt von Unterschieden zu kennzeichnen, die beide Staatsauffassungen voneinander trennt. -

Ape lt-München: Ich möchte nur zwei Bemerkungen machen, eine theoretischer und eine praktischer Art.

Wir haben aus den Referaten von heute vormittag sowohl wie aus den Diskussionen etwas entnehmen können, was auch früher schon bekannt war, nämlich, daß der Polizeibegriff für die Theorie des Verwaltungsrechts herzlich wenig brauchbar ist. Zwar ist er in der Praxis unentbehrlich, aber theoretisch hat er keine besondere Bedeutung. Ich möchte in diesem $\mathrm{Zu}$ sammenhang einen Namen nennen, das ist der Name Otto Mayer. Er hat in seinem grundsätzlichen Werk einmal sehr richtig gesagt, daß für die Theorie der Polizeibegriff keine Bedeutung habe, aber er möge ruhig weiterlaufen, weil er einmal in der Praxis nicht entbehrt werden könne. Unsere Verhandlungen haben gezeigt, daß sich das auch in der Gegenwart nicht geändert hat.

In der Praxis kann man Polizeifunktion, von allgemeiner Verwaltungsfunktion kaum unterscheiden. So ist heute z. B. das Baurecht erwähnt worden. Sachsen hatte schon seit $50 \mathrm{Jah}-$ ren ein modernes Baugesetz; wenn man sich dieses Baugesetz ansieht, so enthält es sowohl Normen der aufbauenden Fürsorgeverwaltung wie auch Normen der Abwehr von Gefahren, also polizeirechtliche Normen. Wenn Herr Kollege Wolff eine Lanze dafür brach, daß man derartige Gebiete durch Sondergesetze regeln solle, so kann ich auf dieses Baugesetz verweisen, da ist das in mustergültiger Weise geschehen. Dabei zeigt sich auch, daß diese Dinge nicht voneinander zu trennen sind. Die Polizei kann nicht als selbständige Funktion neben der Verwaltung stehen; es handelt sich um eine Aufgabe der Verwaltung, um eine Seite der Verwaltung, aber nicht um eine selbständige 
Verwaltungsform. Darauf hat auch schon Otto Mayer hingewiesen.

Nun noch eine praktische Frage: Es hat mich außerordentlich interessiert, daß Herr Gönnenwein sich dafür eingesetzt hat, die Polizei in Städten in die Hand des Staates zu legen. Ich bin vollauf mit ihm einverstanden. Ich habe als sächsischer Minister des Innern diesen Standpunkt praktisch verwirklicht und in größeren Städten die Polizei verstaatlicht. Ich halte auch heute an dieser tberzeugung fest, aber leider geht die Entwicklung in Süddeutschland in ganz entgegengesetzte Richtung. In Bayern z. B. geht die Tendenz dahin, die ganze Staatsverwaltung aufzulösen und zu kommunalisieren, auch die Polizei. Das ist eine bedenkliche Entwicklung für die Erhaltung der Staatsautorität, die wir auch in einer Demokratie nicht entbehren können.

Ich bin sehr wohl in der Lage, auch hier aus praktischen Erfahrungen zu sprechen. Ich habe im Mai 1945 als kleiner Bürgermeister in Walchensee begonnen, bin auch heute noch Kreisrat im Kreise Tölz und weiß, wie es in den unteren Verwaltunge.. aussieht. Ich habe die therzeugung, da $\beta$ der jetzt eingeschlagene Weg nicht so weitergegangen werden darf. Wir haben in Weinheim im April d. J. im Institut für öffentliche Angelegenheiten die Frage der Mittelinstanzen erörtert. Ich hatte diese Frage bereits 1928 in einer größeren Denkschrift behandelt: Soll der Staat sich allein auf die Mittelinstanz, auf den Regierungspräsidenten stützen oder soll es der Landrat sein, der die staatliche untere Verwaltung trägt. Man hat über diese Fragen in Weinheim sehr interessante Diskussionen geführt mit sehr verschiedenen Meinungen. Ich möchte aber nochmals betonen, daß ich die Auffassung, die Herr Gönnenwein vertrat, durchaus teile.

Merk-Tübingen: Wie die verschiedenen Berichte zeigen, ergibt die gegenwärtige Gestaltung des Polizeirechts einen durchaus unbefriedigenden Zustand. Man könnte $\mathrm{m}$. E. eigentlich nichts Besseres tun, als möglichst bald auf diesem Gebiete zu dem "guten alten Recht" zurückzukehren, wie es vor 1933 war.

Ich vermag zunächst nicht zuzugeben, was mein verehrter Herr Vorredner gesagt hat, daß der bisherige Polizeibegriff wissenschaftlich wertlos sei. Schon daß er sich praktisch durchaus bewährt hat, widerspricht dem. Ich weiß nicht, welche $\mathrm{Be}-$ denken wissenschaftlicher Art gegen diesen Begriff der Polizei als der Abwehr von Gefahren für die Allgemeinheit oder die einzelnen, durch welche die öffentliche Sicherheit und Ordnung bedroht werden, geltend zu machen sind. Gewiß ist das mit Bezug auf das Merkmal der Ordnung ein unbestimmter Be- 
griff. Aber es hat doch wohl eben aus diesem Grunde die Bestimmung über die Aufgabe der Polizei, § $10 \mathrm{~T}$. II Tit. $17 \mathrm{Pr}$. ALR, die dann sachlich unverändert in den $\S 14 \mathrm{Pr}$. PVG von 1931 übergegangen ist und aus der der Polizeibegriff abgeleitet ist, mit dem gleichen Wortlaut sowohl in der Zeit des unbeschränkten Fürstenstaats als auch in der Zeit der verfassungsmäßig beschränkten Einherrschaft wie auch in der Zeit des Weimarer Freistaats fortbestanden und fortbestehen können. Es war hier eine Anpassungsmöglichkeit mit diesem unbestimmten Polizeibegriff gegeben, indem damit die Werte, die nach den jeweils vorhandenen allgemeinen Anschauungen in Volk und Staat vorhanden sind, in ihrem Bestande geschützt sind, da ja "Ordnung" - wie auch in der Begründung zum PVG gesagt ist - nichts anderes bedeutet als den Inbegriff der Regeln, von denen ein gedeihliches Zusammenleben in der Gemeinschaft abhängig ist.

Ich bin der Meinung, daß wir gegenüber dem derzeitigen Wirrwarr auf dem Gebiet des Polizeirechts in Deutschland allen An!q $R$ haben, in der Wissenschaft an dem alten Polizeibegriff festzuhalten. Nichts kann besser die Bestrebungen widerlegen, den Polizeibegriff auf das Gebiet der Sicherheitspolizei einzuengen und ihm gegenüberzustellen die sog. Ordnunsverwaltung, als die neuen Gesetze und Gesetzentwürfe über dasPolizeirecht, insbesondere auf dem Gebiete der Ordnungsverwaltung. $\mathrm{Da}$ ist doch gerade auch für diese die Abwehr von Gefahren für die öffentliche Sicherheit und Ordnung als Aufgabe bezeichnet. Ich kann es nicht billigen, wenn gesagt worden ist, man solle für diesen Bereich dann sprechen von „Ordnungssicherheit"; das ist zwar ein anderes Wort, der Sache nach ist das aber kein Fortschritt mit Bezug auf Klarheit gegenüber dem bisherigen Polizeibegriff.

Auf dem Gebiete der bisher sog. Verwaltungspolizei, d.h. jetzt der "Ordnungsverwaltung", besteht ein enger Zusammenhang zwischen Polizei im bisherigen Sinne und Wohlfahrts- und Kulturpflege. So z. B. bei der Straßenverwaltung, wo die Sorge für die Erhaltung der Straßen und die Sicherheit des Verkehrs zur Straßenpolizei, dagegen die Sorge für die Anlegung einer neuen Straße oder die Beseitigung einer Steigung an einer alten Straße zur Wohlfahrts- und Kulturpflege gehört. In einzelnen Zweigen der Verwaltung kann so pflegliche Tätigkeit und Polizei eng nebeneinander hergehen. Auch in Verwaltungsgesetzen kann ähnliches vorkommen; so finden sich z. B. in der württembergischen Bauordnung von 1910 neben den baupolizeilichen Vorschriften auch Bestimmungen gegen die Verunstaltung von Orts- und Landschaftsbildern sowie von Baudenkmälern, also Schönheits-, d. h. Wohlfahrts- und Kulturpflege. 
Wenn nun diese bisher sog. Verwaltungspolizei nicht mehr „Polizei“ genannt, sondern gegebenenfalls mit der zugehörigen Wohlfahrts- und Kulturpflege unter den unklaren und verschwommenen Begriff der „Ordnungsverwaltung“ oder - wie in Württemberg-Hohenzollern - des "Wesens" („Bauwesen“, "Gewerbewesen") gebracht wird, so ist dies m. E. vom wissenschaftlich-begrifflichen Standpunkt aus nur zu bedauerı. Man kann aber weiter $\mathrm{m}$. E. auch die Polizei im Sinne der Sicherheitspolizei nicht völlig herausreißen aus der sonstigen Verwaltungstätigkeit, wie z.B. nach der VO 135 der englischen Militärregierung über die deutsche Polizei. Das geht einmal wissenschaftlich-begrifflich nicht: ist doch die Polizei im sachlichen Sinne eine Hauptaufgabe der inneren Verwaltung neben der Wohlfahrts- und Kulturpflege. Aber auch in der praktischen Verwaltungstätigkeit läßt sich $\mathrm{m}$. E. eine solche Scheidung unter Zweckmäßigkeitsgesichtspunkten nicht gut durchführen. Ich bin hiernach der Auffassung, daß die polizeilichen Aufgaben im alten Sinne, möglichst zusammengefaßt, wieder den Behörden der allgemeinen inneren Verwaltung übertragen werden. Es steht selbstverständlich nichts im Wege, daß einzelne polizeiliche Gebiete unter Zurückdrängung der allgemeinen Ermächtigungen der Polizei besonders geregelt werden, wie z. B. die Baupolizei usw., und sie z. T. auch besonderen Behörden, sog. Sonderpolizeibehörden, zugewiesen werden, wie z. B. die Bergund die Wasserpolizei - wie das ja auch früher schon der Fall war.

Nun aber etwas anderes: Wie soll diese Polizei geregelt sein, soll sie schlechtweg eine staatliche Aufgabe sein oder - wenigstens zum Teil - eine Selbstverwaltungsaufgabe? Da darf ich doch zunächst geschichtlich daran erinnern, daß bis zur Steinschen Städteordnung von 1808 die Polizei nach altüberlieferter deutscher Auffassung zu der nach Gegenstand oder Bezirk in Betracht kommenden allgemeinen öffentlichen Verwaltung gehörte, daher auch für den örtlichen Bereich der betreffenden Gemeinde. Auch in Frankreich ist heute noch die Ortspolizei eine Selbstverwaltungsangelegenheit der Gemeinde, für die aber von der vorgesetzten Staatsbehörde jederzeit Weisungen erteilt werden können. Die preußische Regelung, wonach die Polizei Aufgabe des Staates ist, haben dann auch verschiedene andere deutsche Länder übernommen; aber Württemberg ist schon in der Gemeindeordnung von 1922, Baden in der Gemeindeordnung von 1921 zu der Auffassung zurückgekehrt, daß die Ortspolizei eine Selbstverwaltungsangelegenheit der Gemeinde ist. In beiden Ländern wurde aber die Ortspolizei bis 1945 so behandelt, als wäre sie eine Auftragsangelegenheit, d. h. sie unterstand nach Art einer Dienstaufsicht den Weisungen der 
übergeordneten staatlichen Verwaltungsbehörde, ähnlich wie im französischen Recht. Ich bin nun nicht der Meinung, daß die Polizei schlechtweg als eine einheitliche Staatspolizei eingerichtet sein soll. Ich sehe nicht ein, warum den Gemeinden nicht auch die Polizeiverwaltung in ihrem örtlichen Bereich übertragen werden kann. Es ist m. E. nur die Frage, ob sie als Auftragsangelegenheit, d. h. staatliche Angelegenheit, oder als Selbstverwaltungsangelegenheit bestimmt werden soll. Es mag sozusagen ein Schönheitsfehler sein, wenn sie zwar als Selbstverwaltungsangelegenheit bezeichnet, aber als eine Auftragsangelegenheit behandelt wird; doch das ist unerheblich. Wohl ist ein Bedürfnis dafür anzuerkennen, in den größeren Städten eine staatliche Polizei einzurichten; aber soll das nun für jede Gemeinde gelten? Es war doch früher so, daß der Landrat in den Landkreisen mit Weisungen in die Polizeiverwaltung der Gemeinden eingreifen konnte; im übrigen standen ihm als Kreispolizeibehörde auch Landjäger zur Verfügung. Ich sehe keine genügenden Gründe, die ganze Polizei, in allen Stufen, als staatliche Polizei zusammenzufassen und nicht in der unteren Stufe die Ortspolizei den Gemeinden zu überlassen. Man hat früher auch im Falle der Einrichtung einer staatlichen Ortspolizeiverwaltung z. T. gewisse polizeiliche Aufgaben noch der Gemeinde überlassen, wie z. B. in Württemberg die Feld- und Forstpolizei, die Friedhofspolizei, die Marktpolizei usw. - alles polizeiliche Angelegenheiten, welche die Gemeinde als solche näher berühren und jetzt zur "Ordnungsverwaltung“ bzw. zu den „Wesen" gehören. Warum soll nicht einmal dies den Gemeinden überlassen sein? Oder doch unter dem neuen Decknamen? Ich stelle mich sonach auf den Standpunkt, daß zwar in den höheren Stufen, vom Kreise $a b$, und auch in den größeren Städten die Polizei als eine staatliche eingerichtet, dagegen in der unteren Stufe die Ortspolizei für die Regel den Gemeinden überlassen werden soll, sei es nun als Auftragsangelegenheit oder auch als Selbstverwaltungsangelegenheit, die wie eine Auftragsangelegenheit behandelt wird mit der Möglichkeit, Weisungen allgemeiner Art oder im Einzelfalle im Dienstaufsichtswege zu erteilen. Es wird im übrigen auch aus finanziellen Gründen nicht angehen, in jede der vielen (z. T. über 50 ) Gemeinden eines Landkreises je einen staatlichen Polizeibeamten zu setzen, der gar nicht voll beschäftigt wäre.

S c u p i n-Münster: Ich möchte ergänzend zu dem Referat von Herrn Wolff einige Worte sprechen. Seine schöne scherzhafte Bemerkung mit den zwei halben Polizeitürken hat uns die Mängel einer überstürzten Entwicklung, die 1945 eintrat, sehr deutlich gezeigt und uns sehr einprägsam gemacht. Ich glaube 
aber, Sie haben beim Schlußteil des Vortrags schon gemerkt, $\mathrm{da} \beta$ in vielem dieser Entwicklung zugestimmt werden muß und wir mit ihr rechnen müssen, nicht deswegen, weil sie sich schlecht rückgängig machen läßt, sondern deswegen, weil irgendwo ein ernsthafter Kern steckt. Sie wissen, daß die sog. Entpolizeilichung, um dies nicht sehr schöne, aber gebräuchliche Wort einmal zu benutzen, eigentlich recht alt ist, wie die Entwicklung des Gewerbewesens, des Gesundheitswesens und anderer Gebiete zeigt.

Was ist nun eigentlich der Grund dafür? Die knappe Antwortformel ist, daß dies nichts anderes war als ein Ausdruck der allgemeinen Entwicklung, die wegführt vom Obrigkeitsstaat. Das steckt auch in dem, was wir heute sehen. Dabei wären verschiedene Wege $\mathrm{zu}$ begehen gewesen, der organisatorischinstitutionelle und der der materiellen sowie funktionalen Neuordnung. Letzteren zu beschreiten hat man gezögert, und dennoch ist er der wichtigere. Man soll, wenn schon einmal diese Entwicklung eingetreten ist, möglichst weit weggehen von der Gefahrenabwehr und hinein in die Vorsorge, wie jener Bereich der Fürsorge i. w. S. jüngst wieder von Forsthoff genannt worden ist. Wenn wir das wollen, dann kommen wir damit zugleich einen Schritt weiter in der Richtung, die zum sozialen Staat hinführt. Diese Seite des Problems muß künftig berücksichtigt werden, im Bauwesen, im Wegerecht und auf verschiedenen anderen Gebieten. Auf diese Weise, d. h. durch Intensivierung der Gesetzgebung in der Richtung der materiellen Spezialisierung des Ordnungsrechts kann dem Wirrwarr der Praxis und der Anschauungen ein Ende bereitet werden.

Aber ich möchte noch auf eines hinaus: Der soziale Staat hat eine Affinität zum Zwangsstaat, wo derjenige, dem es obliegt, Vorsorge oder gar Fürsorge zu treffen, im allgemeinen das, was er für segensreich hält, auch als das objektiv Gebotene ansieht und durchsetzt; jedenfalls wird er bestrebt sein, seinen Willen durchzusetzen.

Herr Peters brachte neulich an anderm Orte ein hübsches Beispiel für das vermeintlich segensreiche Wirken einer Ortspolizeibehörde auf einem heute dem Ordnungsrecht zugehörigen Gebiet.

Hat die vorsorgende Behörde Zwangsmittel gleich zur Hand, dann ist der Weg im einzelnen zum Zwangsstaat nicht weit. Man kann dem schon jetzt steuern. Sicher! Aber die Mittel des Rechtsstaates greifen nachträglich ein. Jedenfalls scheint es mir richtig, da $B$ auch institutionell, um dem möglichen Zwang, der vielleicht nicht ruchbar wird, vorzubeugen, eine Trennung geschaffen ist. Wir müssen das, was geworden ist, aus diesem Grunde hinnehmen und vervollkommnen, und wir müssen 
sehen, daß wir ihm Dauer geben. Es bleibt dabei, daß dem, was hier Ordnungsverwaltung etwas unvollkommen genannt wird, das Moment der Gefahrenabwehr noch anhaftet. Man muß es jedoch möglichst weit einschränken. Ich gebe zu: Man kann nicht ganz davon absehen; sogar in der Baupolizei etwa steckt eben immer noch polizeiliche Gefahrenabwehr, die überall zur Aufrechterhaltung der spezialisierten Ordnung des jeweiligen Verwaltungsgebietes notwendig ist. Es bleibt der Ordnungsverwaltung also im Unterschied zur allgemeinen Verwaltung immer dieses Moment der Gefahrenabwehr.

Der Unterschied zur Polizei ist ebenfalls nicht zu verkennen. Es wurde vom Vortragenden erwähnt, daß ich darauf hinarbeite, man möge für die sog. Ordnungsverwaltung von s pe $z$ i a l is i e r t er Gefahrenabwehr sprechen. Was Verwaltungspolizei war, war von der ursprünglich einheitlichen Polizeiorganisation sozusagen wegspezialisiert; man nannte das technische Spezialisierung. Heute spricht man auch gelegentlich schon von politischer Spezialisierung einzelner Gebiete der Ordnungsverwaltung.

Ferner tritt als Unterscheidungsmoment zur eigentlichen Polizei, wie sie sich besonders in der britischen Zone, aber auch in der amerikanischen Zone entwickelt hat, das Moment der Vorsorge hinzu, worin, wie gesagt, der neue und entscheidende Unterschied zur Polizei gegeben ist.

Ich glaube, wenn man den Vergleich mit den halben Türken wieder aufnehmen will, so muB man die Schwierigkeiten in Kauf nehmen, die durch die Spaltung der alten Polizeiorganisation in eine solche mit Schwerthand und eine solche mit Schreibhand deutlich werden und wie sie durch die bloße $\mathrm{Zu}-$ sammenarbeit von Polizei und Ordnungsverwaltung sich ergeben. Wenn man das Rad der Entwicklung nicht einfach zurückdrehen will, sondern das lebendige Wirken des Schicksals in ihr erfassen will, so müssen wir die Ordnungsverwaltung institutionell und formell so unpolizeilich wie möglich gestalten und werden damit am ehesten der allgemeinen Grundlinie unserer Rechtsvorstellungen und der sozialen Vorstellungen auf diesem Gebiete gerecht werden.

S ch a ck-Hamburg: Der Ausdruck Ordnungsverwaltung, Ordnungsbehörde und Ordnungsaufgabe ist meiner Ansicht nach zu bemängeln. Er ist in einem der Länder der britischen Zone hochgekommen und hat sich schnell auf die ganze britische Zone erweitert. Aber ich finde das äußerst unglücklich. Es entspricht einer festgefügten Begriffsbestimmung des Polizeirechts, da B „Ordnung “ im Gegensatz zur "Sicherheit" alles umfaßt, was durch die Begriffe „Anstand", „Moral", „Sittlichkeit" 
gekennzeichnet wird. In dieser Beziehung unterscheiden auch dementsprechend das PVG von 1931 und ebenso die neuen Polizeigesetze des britischen Gebiets deutlich Sicherheit ,oder" Ordnung. Durch Einfügung des Wortes "oder" an Stelle von "und" wollte man diese zwei verschiedenen Kreise deutlich voneinander scheiden.

Nun aber die Verwaltungspolizei, die also hier als Ordnungsbehörde tituliert ist. Was hat diese überhaupt mit dem Begriff der Ordnung im überkommenen Sinne an sich zu tun? Eigentlich gar nichts. Neben ihrer pflegerischen Aufgabe haben die Verwaltungspolizei, Baupolizei, Gewerbepolizei usw. im wesentlichen die Aufgabe der öffentlichen Sicherheit zu erfüllen. Daher ist also die Bezeichnung Ordnungsbehörde nur geeignet, Verwirrung zu schaffen. Es wäre Aufgabe unserer Theoretiker, darauf hinzuweisen, daß eine bessere Bezeichnung gewählt werden müßte. Die Situation ist, wie aus dem Schaubild hervorgeht, die, daß sich keiner mehr zurechtfindet. Die Beziehungen zwischen Ordnungsbehörden und Polizeibehörden sind strittig untereinander geworden, das weiß man aus dem Schrifttum, und man hat in zunehmendem Maße die Polizei funktionsunfähig gemacht.

Ich will noch kurz berühren, was Herr Wolff gesagt hat bezüglich der Ubertragung der Freiheitsentscheidung auf die Vormundschaftsgerichte in Hamburg. Herr Wolft hat das bemängelt. (Zuruf: Nie!) Was hat Hamburg getan? Es hat das Grundgesetz ausgeführt und hat also die Freiheitsentscheidung von der richterlichen Entscheidung abhängig gemacht. Das war sehr rechtsstaatlich. Hamburg ist schon immer sehr justizstaatlich gewesen. Aber auch der ordentliche Richter kann fehl gehen. Ich habe in der Monatszeitschrift für deutsches Recht Anfang dieses Jahres einen Fall besprochen, da hat der Hamburger Vormundschaftsrichter einfach auf Grund der Tatsache, daß die Sozialbehörde als frühere Verwaltungspolizeibehörde auf einen telephonischen Anruf der Ehefrau eines betrunkenen Mannes hin diesen zwecks Einweisung in eine Trinkerheilanstalt dem Vormundschaftsrichter vorführte, diese Unterbringung ausgesprochen.

Aber Hamburg ist nicht ein Rechtsstaat zweiter Ordnung; als Beschwerdeinstanz konnte das Landgericht angerufen werden, und dieses hob diese Entscheidung auf.

\section{W olff-Münster verzichtet auf das Schlußwort.}

G ö n n e n w e in - Heidelberg: Ich möchte gleichfalls verzichten. Herrn Merk möchte ich nur noch sagen: Es gibt keine naturrechtliche Begründung der Forderung nach Staatspolizei. 
Angelegenheiten der nachbarschaftlichen Sicherheitsbewahrung auf den Dörfern, z. B. Feldpolizei usw., die sollen Selbstverwaltungsangelegenheiten der Gemeinde sein.

Ich habe humoristische Beispiele für die Notwendigkeit der staatlichen Polizei angeführt; hinter dem Humor steckt aber der bittere Frnst, und ich wollte gebeten haben, ihn nicht zu überhören. Ich glaube, so weit auseinander sind unsere Auffassungen gar nicht. Die Staatsaufgaben sind qualitativ und quantitativ gewachsen seit 1808 , und auch eine veränderte Staatsauffassung steht hinter der Forderung nach einer staatlichen Polizei.

Ende der Tagung. 